\title{
Unraveling cryptic diversity among shallow-water tonguefishes (Pleuronectiformes: Cynoglossidae: Symphurus) from the Indo-West Pacific region, with descriptions of five new species
}

\author{
MAO-YING LEE ${ }^{1,2 *} \&$ THOMAS A. MUNROE 3 \\ ${ }^{1}$ Marine Fisheries Division, Fisheries Research Institute, Council of Agriculture, Executive Yuen, 199 Hou-Ih Road, Keelung 20246, \\ Taiwan. \\ ${ }^{2}$ Institute of Oceanography, National Taiwan University, No.1 Sec. 4 Roosevelt 295 Road, Taipei 10617, Taiwan \\ ${ }^{3}$ National Marine Fisheries Service National Systematics Laboratory, NOAA, Smithsonian Institution, P.O. Box 37012, National Museum \\ of Natural History, WC-57, MRC-153, Washington, DC 20013-7012. "munroet@si.edu; @ https://orcid.org/0000-0002-6317-0985 \\ ${ }^{*}$ Corresponding author. " coleopetera@gmail.com; 내ttps://orcid.org/0000-0002-4643-3173
}

\section{Table of contents}

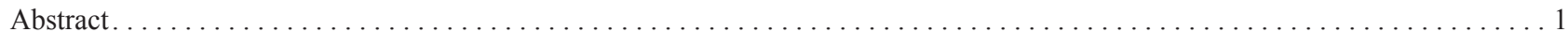

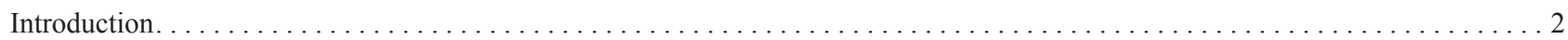

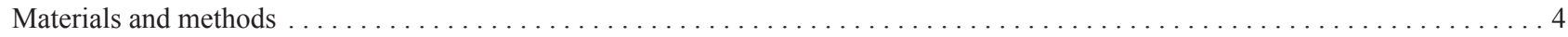

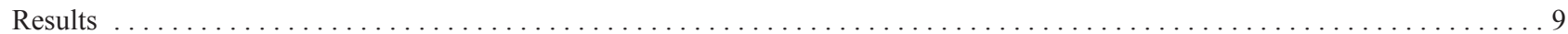

Species accounts for members of the $\boldsymbol{S}$. microrhynchus species complex with low scale counts. . . . . . . . . . . . . 9

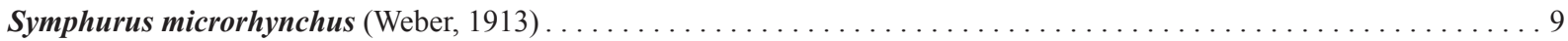

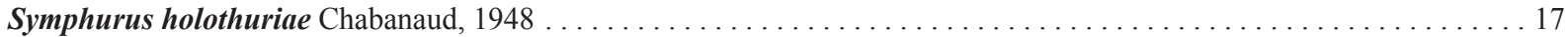

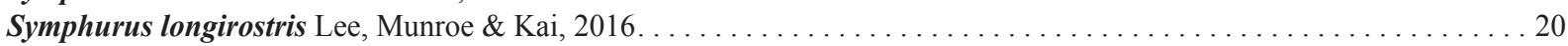

Species accounts for members of the $\boldsymbol{S}$. microrhynchus species complex with high scale counts . . . . . . . . . . . 23

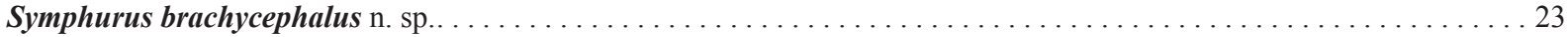

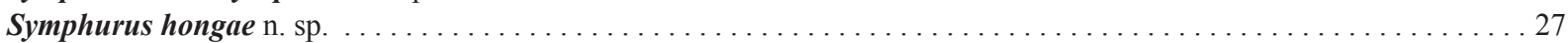

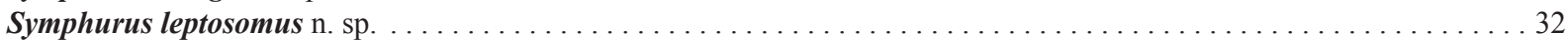

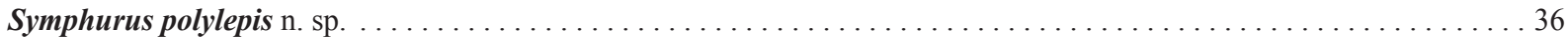

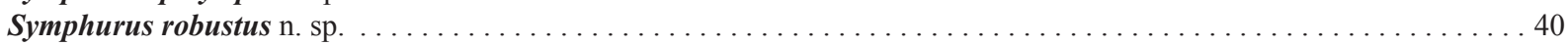

Species accounts for shallow-water species not members of Symphurus microrhynchus species complex . . . . . . . . . . 44

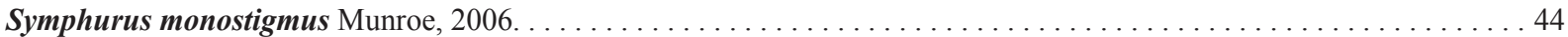

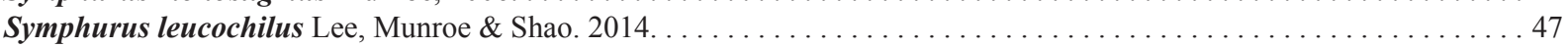

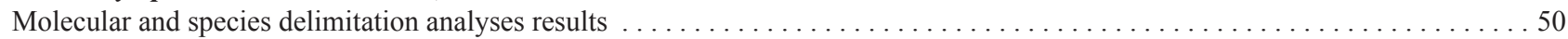

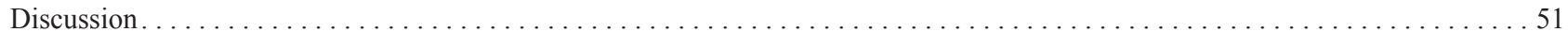

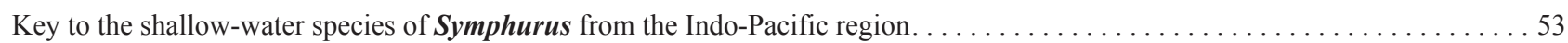

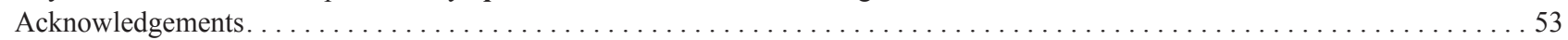

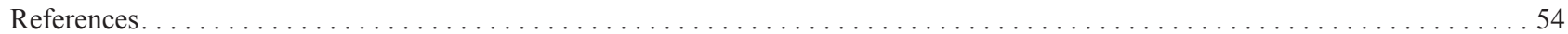

\begin{abstract}
Species of Symphurus (Pleuronectiformes: Cynoglossidae) are relatively small-sized tonguefishes occurring worldwide in tropical, subtropical, and warm-temperate seas. In the Indo-West Pacific Ocean, species of Symphurus inhabiting waters shallower than $200 \mathrm{~m}$ are rarely reported; only five have been described, S. microrhynchus (Weber, 1913), S. holothuriae Chabanaud, 1948, S. monostigmus Munroe, 2006, S. leucochilus Lee et al. 2014, and S. longirostris Lee et al. 2016. Examination of museum and recently collected specimens yielded over 100+ Symphurus captured in relatively shallow waters off Japan, Papua New Guinea, the Philippines, Taiwan, and Vietnam. All of these specimens, except $S$. monostigmus (with 14 caudal-fin rays), were originally tentatively identified as $S$. microrhynchus because of shared similarities (small size, low meristic values, 12 caudal-fin rays, shared pigmentation traits). Detailed comparisons revealed that, although similar, specimens from allopatric locations have small differences in meristic, morphometric and pigmentation features. In previous literature, these small differences were thought to represent intraspecific variation among populations of a widespread species, S. microrhynchus. However, further study, including molecular data, has revealed that such minor differences among specimens from allopatric locations actually represent interspecific, and not population-level,
\end{abstract}


variations. Where available, molecular differences among these allopatric populations, in contrast to the morphological features, were significantly different (9.0 to 26.3\%), providing additional strong support for the hypothesis that more than one species is represented among fishes examined. Combined data from morphological and molecular characters, and species delimitation analysis, reveal that five, undescribed, cryptic species should be recognized: S. brachycephalus n. sp. from Vietnam, S. hongae n. sp. from Taiwan, S. leptosomus n. sp. from the Philippines, S. polylepis n. sp. from Papua New Guinea, and $S$. robustus n. sp. from Japan. Also, based on new information, the previous decision to place $S$. holothuriae Chabanaud in the synonymy of $S$. microrhynchus was determined to be premature. This species should be recognized as valid until additional specimens are captured and the taxonomic status of this nominal species re-evaluated. At least 10 species of Indo-West Pacific shallow-water Symphurus are now known. Eight are members of the Symphurus microrhynchus species complex with hypothesized closer relationship to each other than to the other two species of shallow-water tonguefishes. Included in this study are redescriptions of S. microrhynchus and S. holothuriae based on their holotypes, including an expanded number of morphological characters not previously used to diagnose these species; redescriptions are also provided for comparative purposes of three other shallow-water species; five new cryptic species are described; and lastly, detailed comparisons and an identification key to all 10 species of shallow-water Symphurus occurring in the Indo-West Pacific Ocean are provided. Two additional populations are also identified that likely represent other undescribed taxa belonging to the S. microrhynchus species complex. Adequate specimens are not available at this time to formally describe these nominal species. This study contributes further understanding about species diversity within Symphurus inhabiting shallow waters of the Indo-West Pacific Ocean. Several other nominal species of small-sized cynoglossid and soleid flatfishes are currently considered to have widespread distributions in the Indo-West Pacific. Many of these species also have junior synonyms available based on nominal species described from allopatric sites within their geographic ranges. How many of these presumed populations of widespread species will be resurrected from synonymy once additional specimens and their genetic information becomes available remains an interesting question for future study.

Key words: Symphurus microrhynchus, Symphurus holothuriae, flatfishes, taxonomic revision, integrated approach, symphurine tonguefishes, shallow-water cryptic species, pigmentation characters, dwarf species

\section{Introduction}

Species of Symphurus are small-sized, left-sided flatfishes belonging to the pleuronectiform family Cynoglossidae. Approximately 31 nominal species of Symphurus are distributed in the Indo-Pacific region, most of which are deepwater species (Alcock 1891; Norman 1939; Chabanaud 1955a; Munroe 1992; Krabbenhoft \& Munroe 2003; Munroe \& Hashimoto 2008; Lee et al. 2009a; 2009b; Munroe et al. 2011; Lee et al. 2013; 2014). Among species of Symphurus reported from the Indo-Pacific region, only five have been recorded from depths shallower than 200 $\mathrm{m}$. This assemblage of shallow-water species of Symphurus comprises four characterized by having 12 caudal-fin rays: S. microrhynchus (Weber, 1913), the first described species of shallow-water tonguefish reported from the Indo-West Pacific region (Weber 1913; Chabanaud 1955b; Munroe \& Marsh 1997; Lee et al. 2013; 2014; 2017); S. holothuriae Chabanaud, 1948, a species collected off western Australia and known only from the holotype, and considered a possible junior synonym of $S$. microrhynchus (Weber, 1913) by Chabanaud (1955b) and regarded as a junior synonym of S. microrhynchus by Munroe \& Marsh (1997); S. leucochilus Lee et al. 2014, a species formerly frequently misidentified as $S$. orientalis (Bleeker, 1879) and one with meristic features that overlap those of S. microrhynchus and related species (Lee et al. 2014; 2017); and S. longirostris Lee et al. 2017, a species recently described from Japanese waters whose meristic features are similar to, or overlap those of, S. microrhynchus and related species. Among Indo-Pacific Symphurus, 14 nominal species, including five nominal species described in this study, have 12 caudal-fin rays (Alcock 1891; Chabanaud 1948; 1955b; 1957; Munroe \& Marsh 1997; Munroe 2001; Lee et al. 2013; 2014). Of the Indo-West Pacific shallow-water tonguefishes, S. monostigmus Munroe, 2006 collected in the Western Indian Ocean off South Africa (Munroe 2006), is distinctly different from the others in that it is the only shallow-water species featuring 14 caudal-fin rays.

Lee et al. (2013) in their work redescribing S. orientalis discovered that morphological data used in earlier studies to diagnose this species from congeners actually included meristic data from specimens previously identified as S. orientalis, but having lower meristic values as the same as those of S. microrhynchus (sensu Munroe \& Marsh 1997). Lee et al. (2014) described these specimens as S. leucochilus, a shallow-water species from the western North Pacific. From their examination of specimens featuring low counts of meristic features, including holotypes of S. microrhynchus and S. holothuriae, Lee et al. (2014) also discovered that the species concept of S. microrhyn- 
chus sensu Munroe \& Marsh (1997) was incorrect because a complex of at least six nominal species, most of which whose status was unresolved, was included in their material.

With inclusion of S. longirostris, recently described by Lee et al. (2017) from Japanese waters, eight nominal species of shallow-water Symphurus have been discovered (Lee et al. 2014; 2017; this study) that share similar morphological and pigmentation characteristics, including similar and sometimes overlapping numbers of dorsal-fin rays (81-88), anal-fin rays (68-74), total vertebrae (45-48), transverse scale rows (26-37), and longitudinal scale rows (72-94). These eight species are referred to herein as the $S$. microrhynchus species complex. Within the $S$. microrhynchus species complex, two species groups are recognized (Lee et al. 2014; 2017): those with low meristic features (S. microrhynchus, S. holothuriae, and S. longirostris), and another group of five species described herein that have higher meristic features, especially scale counts. These five species were hypothesized to belong to the same species group within the $S$. microrhynchus complex in the earlier studies of Lee et al. $(2014 ; 2017)$.

One interesting finding of Lee et al. (2014) is that morphological differences among these eight species of the $S$. microrhynchus species complex are subtle, in contrast to the available molecular data (16S rRNA and COI sequence), which indicates distinct genetic differences among nominal species, even between those collected from close geographic proximity, such as the tonguefishes collected in Vietnam and Taiwan, for example. The available molecular data indicate these species are genetically distinct from each other, but they are more closely related to each other than either are to S. leucochilus (Lee et al. 2014; 2017). Although some meristic values of S. leucochilus overlap those of several of these undescribed species, molecular data (Lee et al. 2014) indicates that S. leucochilus is more closely related to $S$. orientalis than it is to members of the $S$. microrhynchus species complex.

Among the eight members of the $S$. microrhynchus species complex, S. microrhynchus, based on a single specimen collected in the Java Sea, Indonesia (Weber 1913; Weber \& de Beaufort 1929), was the first to be described. Munroe \& Marsh (1997) redescribed S. microrhynchus based on comprehensive examination of morphological and pigmentation features of 11 specimens collected from several different geographical locations in the IWP, including the holotype of $S$. holothuriae, which they identified as this species. Based on morphological similarities among these specimens, Munroe \& Marsh (1997) hypothesized that S. microrhynchus had widespread occurrence throughout the Indo-West Pacific region, especially in waters of the Indo-Australian Archipelago.

Later, Lee et al. (2017), based on both morphological and molecular evidence, described another shallow-water tonguefish, S. longirostris, from Japanese waters. In that work, they also suggested that $S$. holothuriae, which Munroe \& Marsh (1997) considered to be a junior subjective synonym of S. microrhynchus (sensu Munroe \& Marsh, 1997), should be recognized as a valid species. However, diagnostic differences between S. holothuriae and S. microrhynchus that would justify recognition of the former species were not discussed further in that study.

In the paper describing S. longirostris, Lee et al. (2017) also pointed out that several individuals identified as S. microrhynchus by Munroe \& Marsh (1997) should actually be classified into two different species groups distinguished by several meristic features. One group, comprising five undescribed species, includes two nominal species, S. cf. microrhynchus TW and S. cf. microrhynchus VN (Lee et al. 2014; 2017) for which molecular data are available, and three other nominal species known only from preserved specimens. Members of this species group are characterized by having higher counts of longitudinal scales, and also in having head widths much larger than their head lengths. Some nominal species in this group also have pepper-dot-sized melanophores (and smaller melanophores) in the dermis on the blind side in the region overlying pterygiophores of the dorsal- and anal-fin rays.

The second group includes three nominal species: S. microrhynchus and S. holothuriae, two poorly known species, known from two and one specimen, respectively, and S. longirostris (Lee et al. 2017), which is distributed only in Japanese waters. These three species are characterized by having lower scale counts, head lengths greater than their head widths, and with a uniformly pigmented blind side without pepper-dot melanophores.

Based on the limited molecular data available, Lee et al. (2017) pointed out that two monophyletic lineages (high and low scale count groups) within the S. microrhynchus species complex are sister taxa, and furthermore, that the two nominal species with higher scale counts for which tissue samples were available are hypothesized to be sister to each other.

Objectives of this study are to use the integrated approach in taxonomy (Pullandre et al. 2012; Zhang et al. 2013) to revise the shallow-water species of symphurine tonguefishes from the Indo-West Pacific region. Symphurus microrhynchus is redefined and redescribed based on the holotype; S. holothuriae is resurrected from synonymy and redescribed based on the holotype; five new, cryptic species of shallow-water Symphurus are formally described; each of the 10 known species of shallow-water tonguefishes are diagnosed; and lastly, an identification key to the 10 species of Symphurus described from shallow-waters of the Indo-West Pacific region is provided. 


\section{Materials and methods}

A total of 133 specimens, including those preserved in fish collections, as well as freshly collected specimens (Table 1), constitute the basis for data collected in this study. Institutional abbreviations follow those listed in Fricke and Eschmeyer (2021). Additional information for comparative materials of all other Indo-Pacific species of Symphurus included in this study are listed in Munroe (1992), Shen et al. (1993), Munroe \& Marsh (1997), Munroe \& Amaoka (1998), Krabbenhoft \& Munroe (2003), Munroe (2006), Munroe \& Hashimoto (2008), Lee et al. (2009a; 2009b; 2013; 2014; 2017), and Munroe et al. (2011).

Methods for counting meristic characters, measuring morphometric features, general terminology, and morphological features distinguishing species follow those of Munroe (1998), except for body thickness (TH), which is defined herein as the body thickness measured at the dorsal margin of the operculum and expressed as $\%$ of $\mathrm{BD}$. Other morphological features differing between species not included in previous studies are: presence/absence of a fleshy, membranous connection between the ocular-side anterior nostril and the eyes; and presence/absence of a fleshy membrane of skin covering both eyes.

All specimens examined were radiographed. Meristic values are reported in Tables $2-5$. Terminology and formulae for interdigitation patterns of proximal dorsal pterygiophores and vertebral neural spines (ID pattern) follow those of Munroe (1992). Morphometric characters were measured to the nearest $0.1 \mathrm{~mm}$ using either dial calipers or dissecting microscope fitted with an ocular micrometer. Morphometric features are expressed either as proportions of percent standard length (SL), percent head length (HL), or percent body depth (BD). Morphometric information appears in Tables 6-12.

Description of pigmentation features are based primarily on freshly collected specimens, with supplemental information provided from specimens preserved in formalin and transferred to $75 \%$ ethanol. Pigmentation features that differed significantly between species are illustrated in Figure 1. These included presence (Fig. 1a)/absence (Fig. 1b) of pepper-dots (irregularly shaped, sometimes numerous, smaller-sized melanophores) located on the blind side of the body, especially on body regions overlying pterygiophores of the dorsal- and anal-fin rays; presence (Fig. 1a)/absence (Fig. 1b) of dermal melanophores (irregularly shaped, larger-sized melanophores usually occurring singly in a series at bases of the anteriormost dorsal- and anal-fin rays); presence (Fig. 1c)/absence (Fig. 1b) of melanophores occurring serially along the vertebral axis (best viewed from blind side); and, pigmentation of the peritoneum.

Maturity was estimated by macroscopic examination of extent of posterior elongation of the ovaries and presence of developing ova in the ovaries (both observed using light transmitted through the body). In species of Symphurus, no obvious differences are apparent in testis size between mature and immature males (Munroe 1998); therefore, macroscopic estimates of maturity are based entirely on females.

Including the outgroup, a total of 42 COI sequences from previous studies (Table 1), previously deposited in GenBank, were incorporated into phylogenetic and species delimitation analysis. Compiled sequences were initially aligned by using MUSCLE (Edgar, 2004) available on the online server at https://www.ebi.ac.uk/Tools/msa/muscle/. These sequences were then manually adjusted for alignment. All sequences had $615+$ bps for COI after alignments. Phylogenetic analysis was performed in RAxML v. 8.0.4 (Stamatakis, 2014), a partition maximum likelihood (ML) method was conducted with the nucleotide substitution model GTR $+\mathrm{G}$. Nodal support was assessed by bootstrapping (Felsenstein, 1985) through the ML criterion, based on 1,000 pseudoreplicates in each run. The result of ML analysis was transferred to tree topology by FigTree v14.3. Genetic distances between species were calculated using the Kimura two-parameter substitution model (K2P) under MEGA 7.0 (Kumar et al. 2016).

The COI dataset was also analyzed with two methods of species delimitation: Automatic Barcode Gap Discovery (ABGD) (Puillandre et al. 2012) and Bayesian Poisson Tree Process (PTP) model (Zhang et al. 2013). The ABGD analysis was examined through the ABGD online version (https://bioinfo.mnhn.fr/abi/public/abgd/) with the K2P pairwise distance model and default setting. The PTP analysis was conducted on PTP webserver (http://species. h-its.org/ptp/) with $500000 \mathrm{MCMC}$ generations and the default setting.

In final decisions of species delimitation, we followed the methods of Kekkonen \& Hebert (2014), Lo et al. (2017), and Hung et al. (2017). Results of the incongruence species delimitation analysis (ABGD, bPTP, Morphological examination) in allopatric sister OTUs were considered as one OTU. 


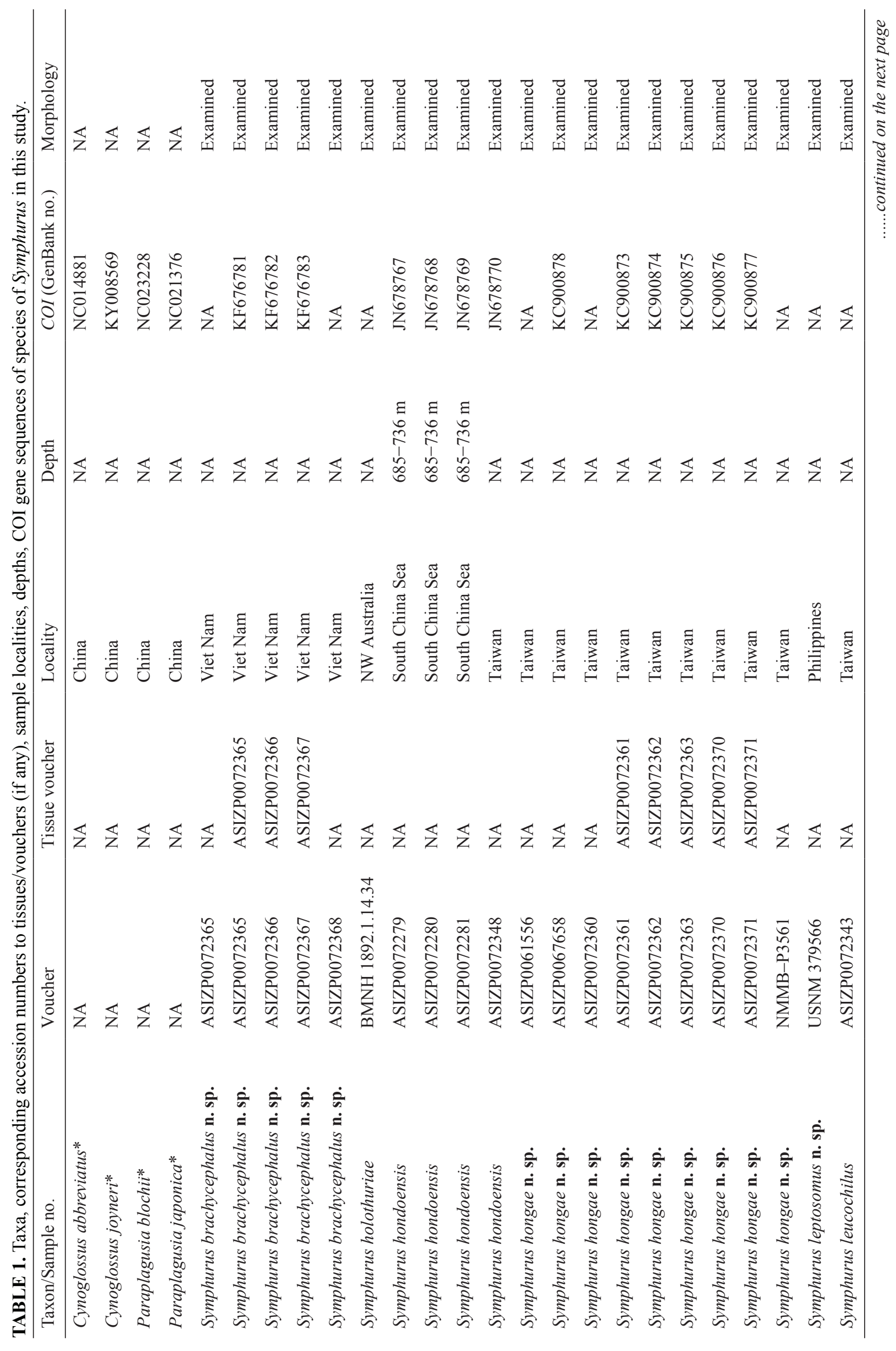




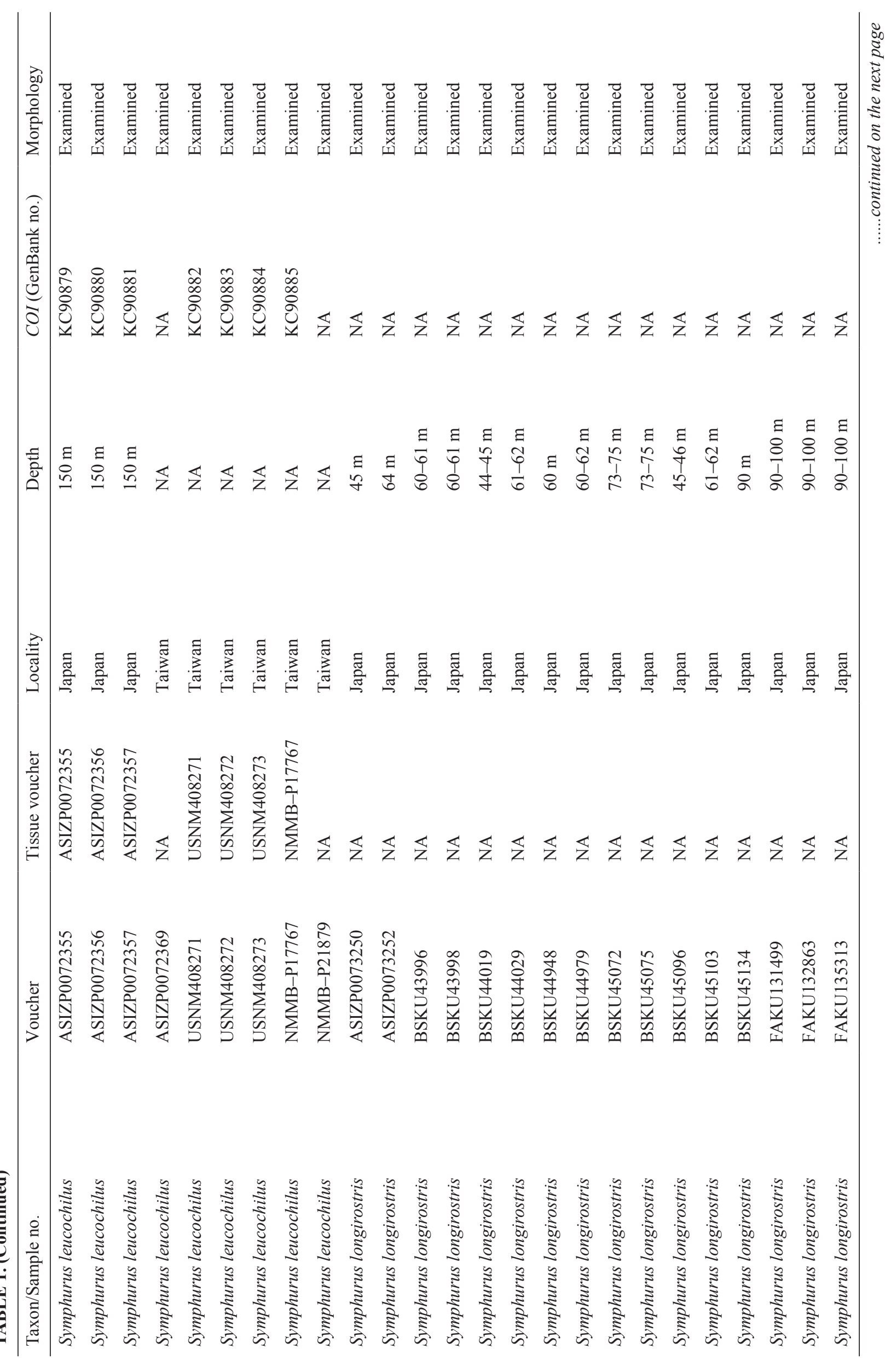




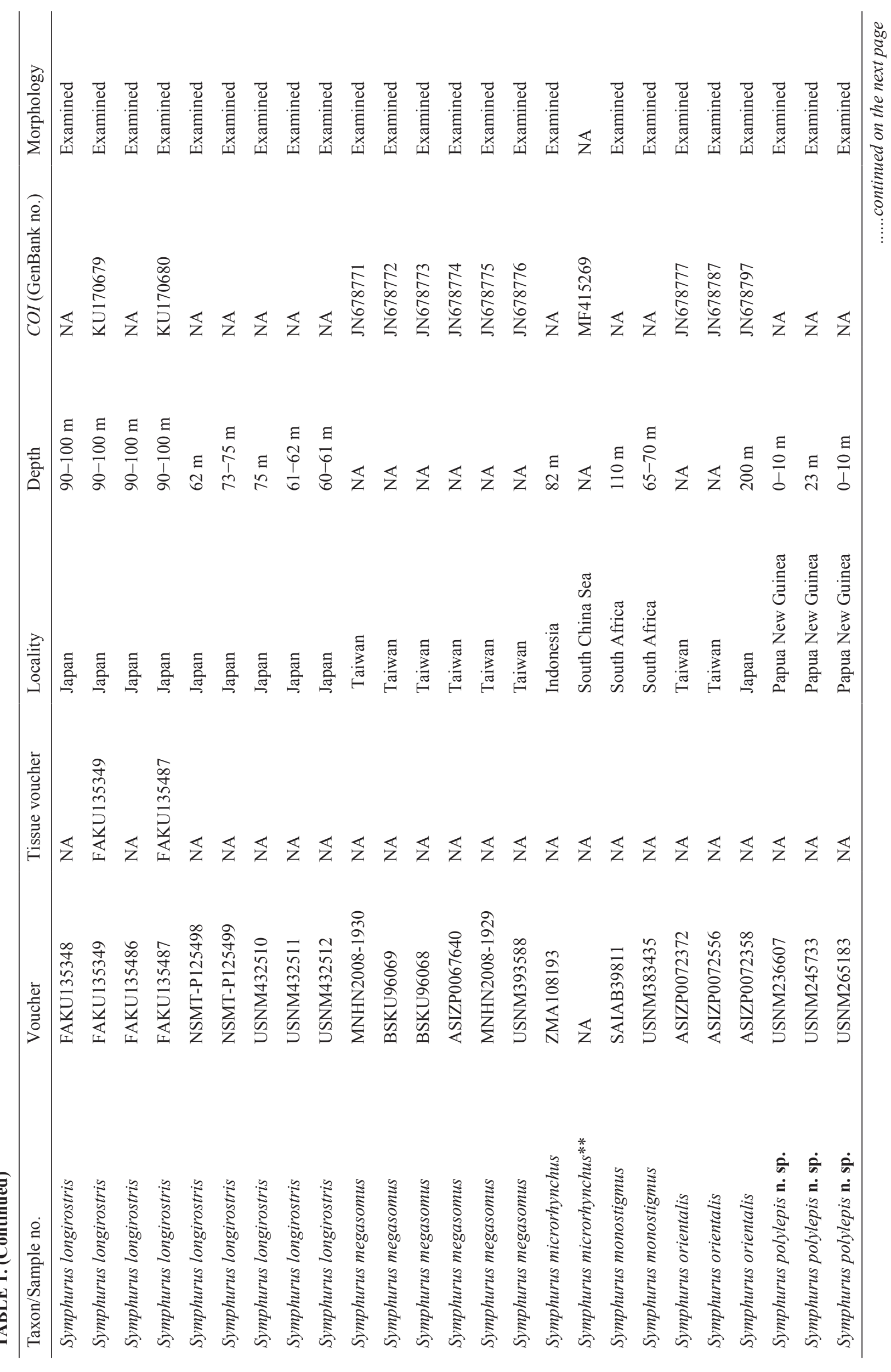




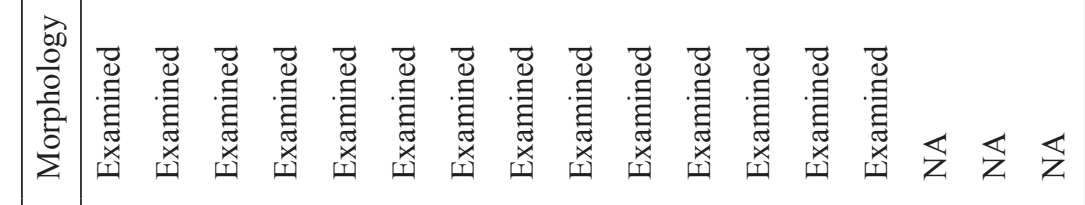

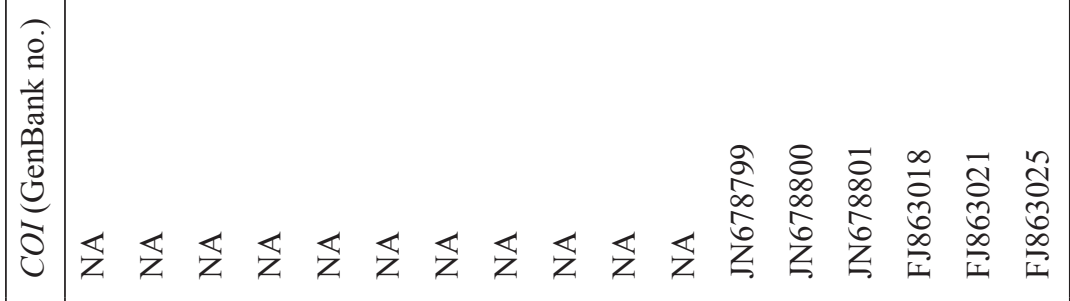

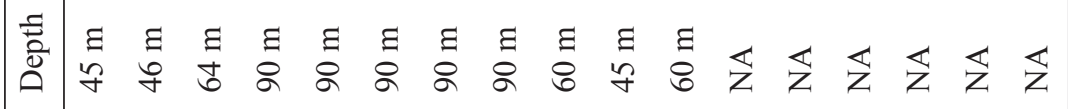

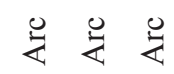

苾

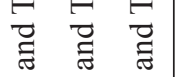

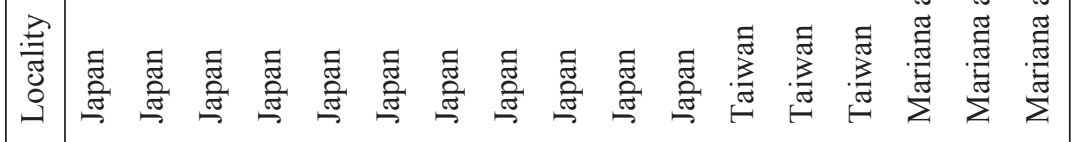

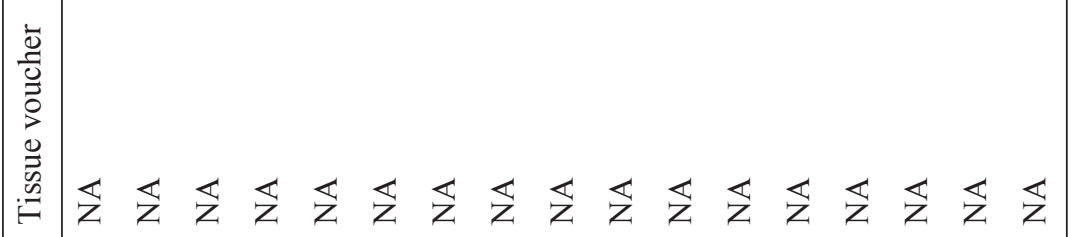

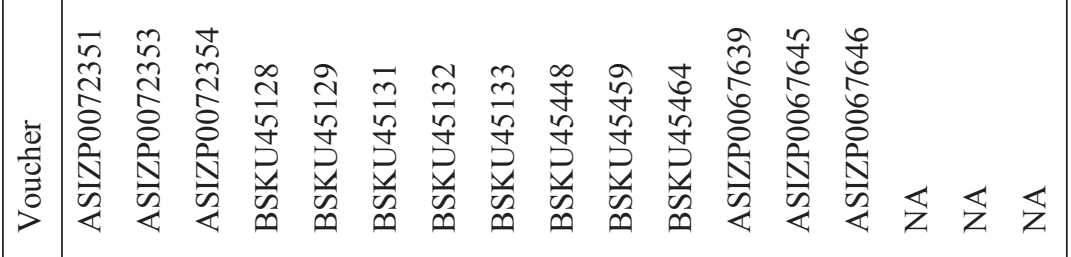

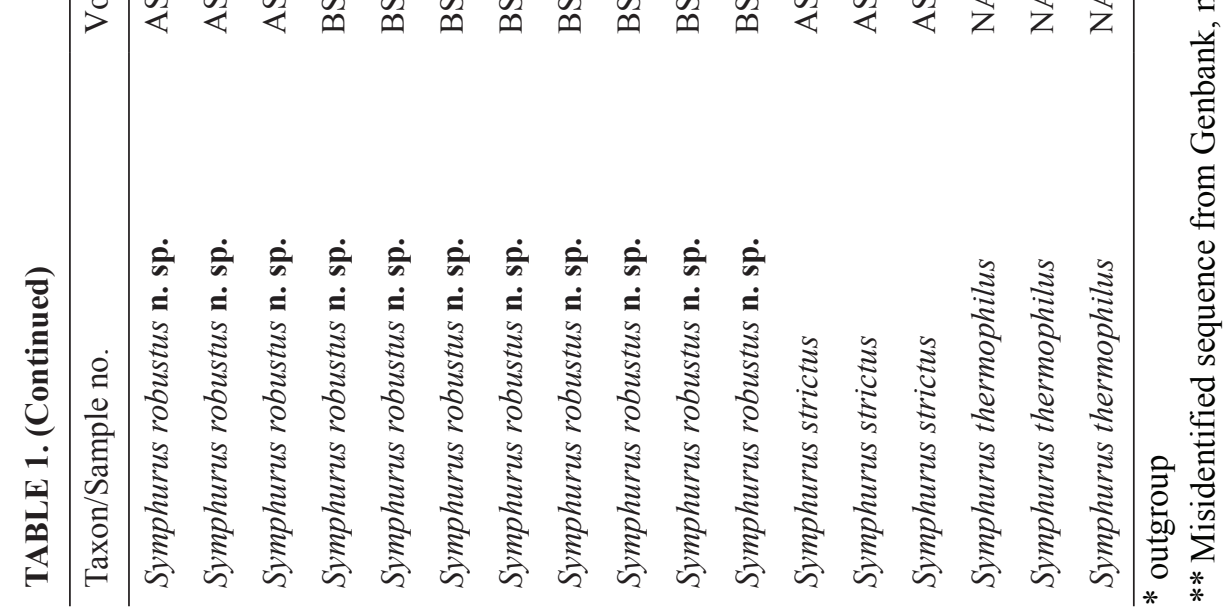




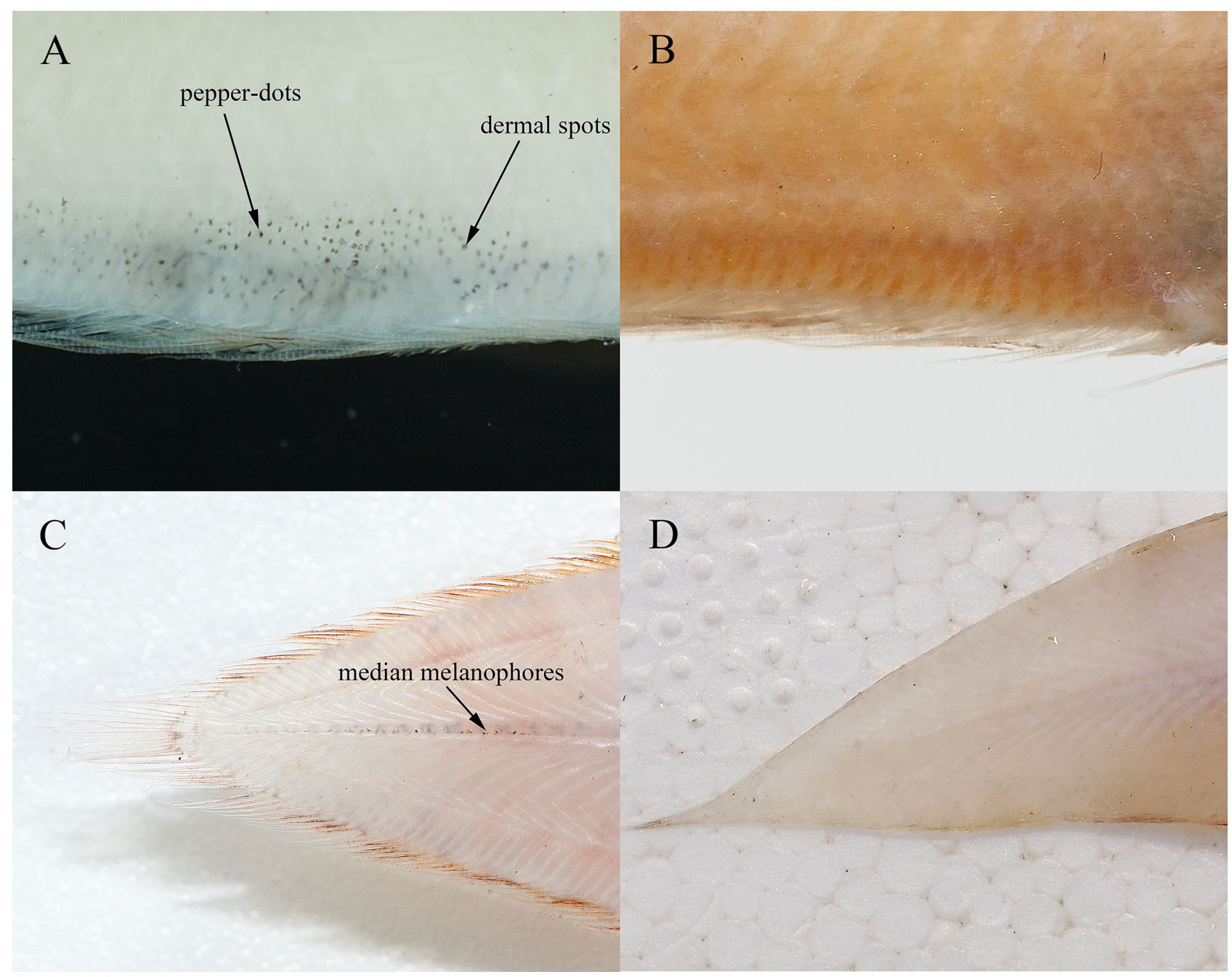

FIGURE 1. Diagnostic pigmentation features on blind sides of Indo-West Pacific shallow-water species of Symphurus. (A) Example of pepper-dots and dermal spots represented by S. hongae, ASIZP0072360, male, 48.0 mm SL, Dong-Gang, SW Taiwan, 04 Jul 2007. (B) Example of an unpigmented blind side represented by S. longirostris, ASIZP0072352, female (mature), $57.3 \mathrm{~mm}$ SL, off Kochi, Japan, 04 Apr 1994. (C) Example of median melanophores along vertebral axis as represented by $S$. leucochilus, holotype, USNM 408271, mature female, $58.7 \mathrm{~mm} \mathrm{SL}$, Da-Shi fish market, northeastern Taiwan, 24 Aug 2011. (D) Example of species without median series of melanophores on vertebral axis represented by S. brachycephalus, ASIZP0072364, female (mature), 49.4 mm SL, off Nan Trang, Vietnam, 19 Apr 2009.

\section{Results}

Species accounts for members of the $S$. microrhynchus species complex with low scale counts

\section{Symphurus microrhynchus (Weber, 1913)}

(Figs. 2-3; Tables 1-6)

Aphoristia microrhynchus Weber, 1913: 444, Fig. 85 (Java Sea, 6¹6.5’S, 114³7’E, Siboga station 319, depth 82 m, Holotype: ZMA 108193).

Symphurus microrhynchus. Weber and de Beaufort, 1929: 209, 211 (redescription; transfer to Symphurus; in identification key with S. regani and S. gilesii). Chabanaud 1939: 27 (listed). Koumans 1953: 214 (one specimen from Indonesia, without descriptive information). Chabanaud 1955b: 45 (redescription; comparisons with S. holothuriae and S. trifasciatus; S. holothuriae a possible synonym). Munroe 1992: 361 (provided informative counts and compared with congeners). (?) Dufour et al. 1996: 415 (several specimens metamorphosing to juvenile stage; mentioned in Munroe \& Marsh 1997 as possibly this species). Munroe \& Marsh, 1997: 191 (in part) (redescription based on specimens of several different species; compared 
with S. holothuriae and S. trifasciatus). Lee et al. 2014: 564 (in part) (S. microrhynchus sensu Munroe \& Marsh 1997 composite mix of several different species; comparisons of S. microrhynchus sensu Munroe \& Marsh 1997 with S. leucochilus). Lee et al. 2017: 72 (in part) (S. microrhynchus sensu Munroe \& Marsh 1997 composite mix of several different species; comparisons of S. microrhynchus sensu Munroe \& Marsh 1997 with S. longirostris).

Symphurus microrhynchus (not Weber). Voronina et al. 2016: 401 (21 specimens, Vietnam; meristics, color pattern; diagnostic features; possibility of a cryptic species; distribution).

Holotype: ZMA 108193, 42.2 mm SL, immature female, Indonesia: Java Sea, 6²16.5'S, 114³7'E, Siboga station 319, depth 82 m, 22 Feb 1900.

Diagnosis. Symphurus microrhynchus is distinguished from all congeners by the combination of: a 1-2-2-2-2 ID pattern; 12 caudal-fin rays; $9(3+6)$ abdominal vertebrae; 48 total vertebrae; 4 hypurals; 87 dorsal-fin rays; 73 anal-fin rays; 64 longitudinal scale rows; 25 transverse scale rows; and 15 scale rows on the head posterior to the lower orbit; body elongate $(\mathrm{BD}=24.9 \%$ of $\mathrm{SL})$; preanal length long $(\mathrm{PAL}=28.1 \%$ of $\mathrm{SL})$; upper head lobe much smaller than lower head lobe; head long $(\mathrm{HL}=24.2 \%$ of $\mathrm{SL})$, longer than head width $(\mathrm{HW} / \mathrm{HL}=0.97)$; postorbital length long $(\mathrm{POL}=76.5 \%$ of $\mathrm{HL})$; snout short $(\mathrm{SNL}=10.4 \%$ of $\mathrm{HL}, \mathrm{SNL} / \mathrm{ED}=1.25)$, slightly rounded anteriorly; dorsal-fin origin located at vertical posterior to upper eye; predorsal length short ( $\mathrm{PDL}=18.1 \%$ of $\mathrm{HL}$ ); eye relatively small $(\mathrm{ED}=8.4 \%$ of $\mathrm{HL})$; eyes unequal in position with anterior margin of upper eye greatly in advance of anterior margin of lower eye; fleshy ridge well developed on posterior part of ocular-side lower jaw; with membrane covering upper and lower eyes; with continuous, fleshy membrane connecting anterior nostril with lower part of eye; ocular-side pigmentation uniformly yellowish-brown; blind-side pigmentation uniformly yellow; both sides with obvious dermal spots on bases of anteriormost dorsal and anal fins.

Description. Symphurus microrhynchus is likely a dwarf species. This species is known from two specimens. The only specimen available to this study was the holotype, an immature female measuring $42.2 \mathrm{~mm}$ SL (Fig. 2). Meristic characters are summarized in Tables 2-5. ID pattern 1-2-2-2-2. Caudal-fin rays 12. Dorsal-fin rays 87. Anal-fin rays 73. Pelvic-fin rays 4. Total vertebrae 48; abdominal vertebrae $9(3+6)$. Hypurals 4. Longitudinal scale rows 64 . Scale rows on head posterior to lower orbit 15 . Transverse scale rows 25 .

Proportions of morphometric features presented in Table 6. Body elongate; maximum depth in middle of body, approximately at point of insertion of first anal-fin ray, body with gradual taper posterior to midpoint. Preanal length much longer than body depth. Head moderately long and narrow; head width shorter than head length (HW/HL= 0.97). Upper head lobe much smaller than lower head lobe $(U H L / L H L=0.78)$, and much shorter than postorbital length. Lower lobe of ocular-side opercle wider than upper opercular lobe; posterior margin of lower lobe projecting slightly beyond posterior margin of upper opercular lobe. Snout short, slightly rounded anteriorly, its length slightly greater than eye diameter $(\mathrm{SNL} / \mathrm{ED}=1.25)$. Dermal papillae present and well developed on blind side of snout and chin. Ocular-side anterior nostril tubular and short, when depressed posteriorly usually not reaching anterior margin of lower eye. Ocular-side posterior nostril a small, rounded tube located on snout just anterior to interorbital space. Blind-side anterior nostril tubular and relatively short, easily distinguishable from dermal papillae; blind-side posterior nostril a shorter and wider, posteriorly directed tube situated posterior to vertical at posterior margin of jaws. Jaws long and slightly arched; upper jaw length slightly longer than snout length; posterior margin of upper jaw extending to vertical through posterior margin of lower eye. Ocular-side lower jaw with well-developed fleshy ridge on posterior portion. Cheek depth relatively wide, slightly longer than snout length. Eyes small, oval, unequal in position, upper eye greatly in advance of lower eye. Pupillary operculum absent. Dorsal-fin origin located at vertical posterior to upper eye; predorsal length relatively short. Anteriormost dorsal-fin rays obviously shorter than more posterior fin rays. Scales absent on both sides of dorsal- and anal-fin rays. Pelvic fin long; longest pelvic-fin ray, when extended posteriorly, usually reaching base of sixth anal-fin ray. Posteriormost pelvic-fin ray connected to anal fin by delicate membrane. Caudal fin broken, unsure if base of fin with rows of ctenoid scales present or not. Scales on both sides of body numerous, strongly ctenoid.

Teeth present and recurved slightly inwards on all jaws, but better developed on blind-side jaws. Ocular-side premaxilla and dentary with single row of sharply pointed, well-developed teeth. Blind-side premaxilla with two rows of sharp, recurved teeth. Blind-side lower jaw with three rows of well-developed teeth.

Pigmentation. Pigmentation of live or freshly collected S. microrhynchus unknown. From preserved holotype (Fig. 2), ocular-side background pigmentation generally yellowish-brown, without pepper-dot melanophores in dermis overlying pterygiophores. External surface of abdominal area dark brown. Background pigmentation of ocular side of head generally similar to that on body. Ocular side of snout light yellow. Dermal spots present at bases of 
anteriormost dorsal-fin rays and also on isthmus. Outer surface of ocular-side opercle yellowish-brown, margin of opercle yellowish-brown, with same background pigmentation as that on body and head. Inner surface of ocularside opercle and isthmus with small light-brown dots, ocular-side lips and chin region uniformly yellow. Ocularside anterior nostril light yellow. Upper aspects of eyes and eye sockets bluish-black; pupils bluish-black, lighter than pigmentation of eye sockets. Blind side uniformly yellow. No median longitudinal row of darkly pigmented melanophores evident along vertebral axis. Outer surface of blind-side opercle light yellow similar to background pigmentation. Inner surface of blind-side opercle unpigmented. Fin rays of dorsal, anal, and pelvic fins uniformly yellowish-brown; basal regions of fin rays and membranes covering fin rays light yellow.

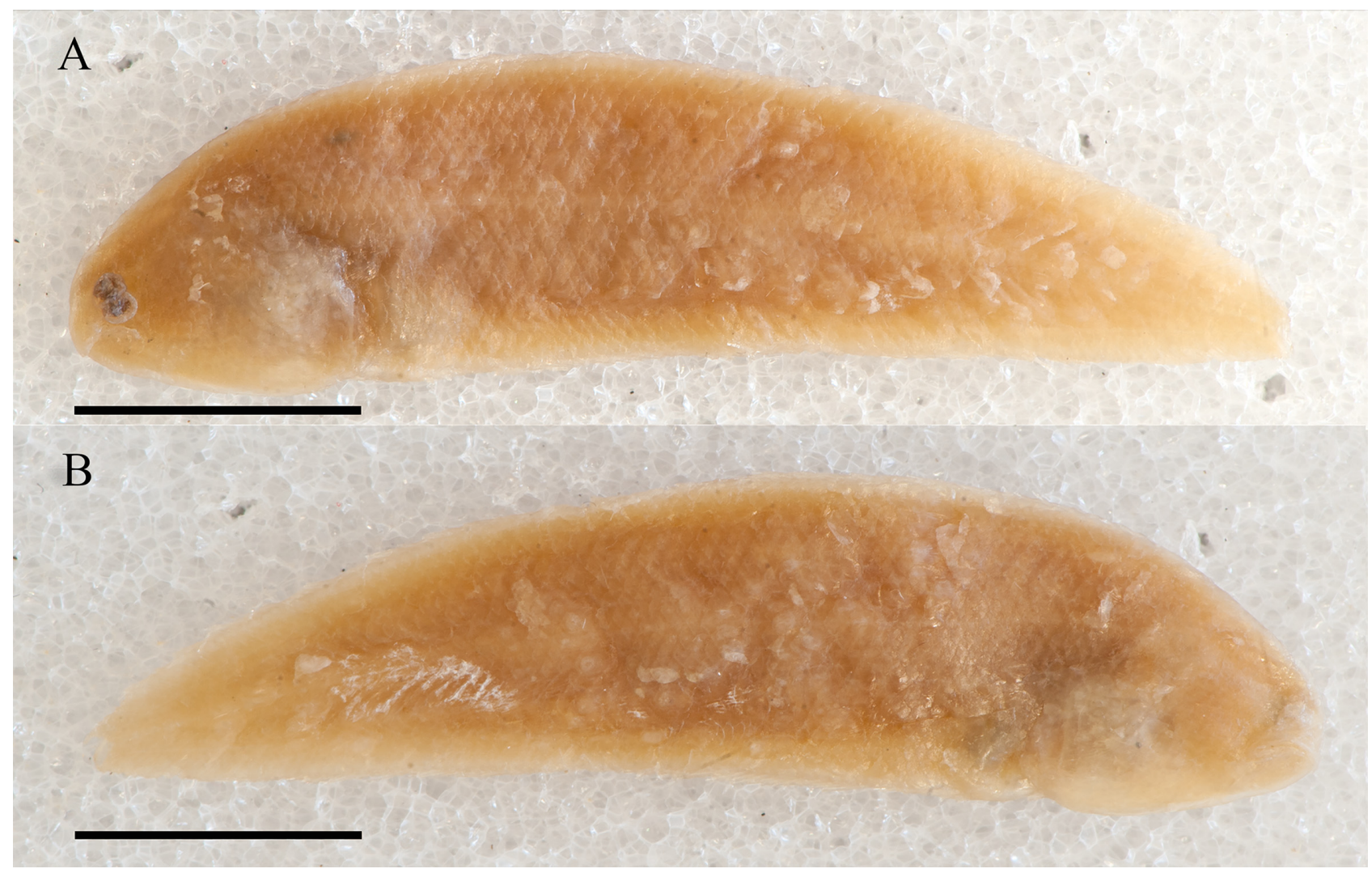

FIGURE 2. Symphurus microrhynchus, holotype, ZMA 108193, immature female, $42.2 \mathrm{~mm}$ SL, Java Sea. A. Ocular-side pigmentation of preserved specimen. B. Blind-side pigmentation of same specimen. Scale equals $10 \mathrm{~mm}$.

Distribution. The holotype of S. microrhynchus was collected at a depth of $82 \mathrm{~m}$ in the Java Sea, off Indonesia (Fig. 3). Koumans (1953) reported a second specimen (RMNH 20305, $27.0 \mathrm{~mm} \mathrm{SL}$ ) identified as this species, from the Savu Sea near Koepang, Indonesia. Munroe \& Marsh (1997) examined this specimen and agreed with Kouman's identification. Reports of S. microrhynchus from locations other than Indonesia that appear in Munroe \& Marsh (1997), including Zanzibar, Tanzania; Papua New Guinea (see also Kailola 1971); French Polynesia; northwest Australia; and the Arafuru Sea, as well as specimens from Vietnam (Voronina et al. 2016) are not S. microrhynchus, but are based on other species (see species accounts below).

Remarks. Symphurus microrhynchus was described from a single specimen collected in 1900 off Indonesia (Weber 1913). Weber compared and distinguished his new species from two deepwater western Indian Ocean species, Aphoristia trifasciatus Alcock and A. septemstriatus Alcock (both species now placed in Symphurus), noting especially the fewer numbers of longitudinal scales in his new species (approximately 68) compared with the much higher values in these others. Weber also mentioned some pigmentation features of the preserved holotype of his new species including the statement that the specimen was apparently faded, but that the ocular side was darker than the blind side and had darker, round, scattered spots along bases of the dorsal and anal fins. Chabanaud (1955b), in his redescription of this species, also noted the specimen was devoid of pigment except for these melanophores. Weber commented that the holotype also had weak indication of about five transverse bands. Evidence of these interrupted bands and also some large blotches appear in the figure accompanying the original description of this species. Weber described the blind side of the holotype as light brown, but did not mention any pepper-dot mela- 
nophores overlying pterygiophore regions of blind sides of the dorsal and anal fins, nor did he describe any large melanophores along the vertebral axis on the blind side.

Munroe \& Marsh (1997) redescribed S. microrhynchus based on a composite series of specimens collected from geographic locations including Zanzibar, Tanzania, Vietnam, New Guinea, Indonesia, French Polynesia, and Australia. They considered S. microrhynchus to be a widespread species, but new data (see below) reveals that at least five other species were included in their account for S. microrhynchus. Lee et al. $(2014 ; 2017)$ also confirmed that more than a single species was present among material identified as S. microrhynchus in Munroe \& Marsh (1997). In fact, among specimens examined by Munroe \& Marsh (1997), approximately six nominal species (including $S$. holothuriae) were included.

Re-examination of the holotypes of S. microrhynchus and S. holothuriae, led Lee et al. $(2014 ; 2017)$ to discover useful characters to distinguish these two nominal species, and these authors suggested that these two nominal species should both be recognized as valid species based on differences in several characters, including those in ID pattern and counts for total vertebrae. These and other differences between S. microrhynchus and S. holothuriae are provided in the Comparisons section below.

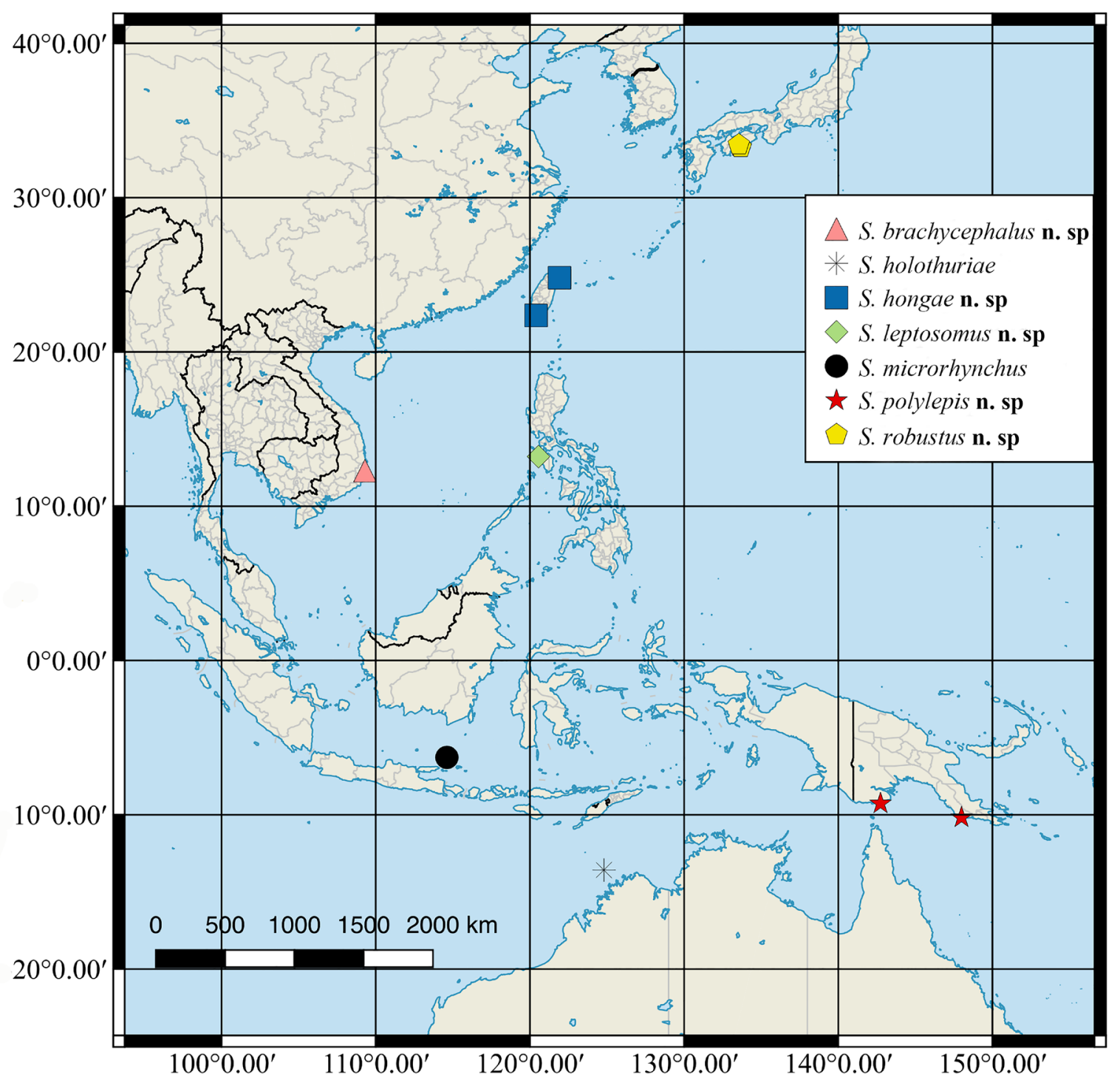

FIGURE 3. Geographic distribution of Symphurus microrhynchus, S. holothuriae, and five new species of Indo-West Pacific shallow-water tonguefishes based on specimens examined in this study. Symbols may represent more than one locality and/or more than a single collection from each locality. 
TABLE 2. Frequency distributions of numbers of dorsal-, anal-, and caudal-fin rays for Symphurus from shallow-waters of Indo-Pacific.

\begin{tabular}{|c|c|c|c|c|c|c|c|c|c|c|c|c|c|}
\hline \multirow[b]{2}{*}{ Species } & \multicolumn{13}{|c|}{ Number of dorsal-fin rays } \\
\hline & 81 & 82 & 83 & 84 & 85 & 8 & \multicolumn{2}{|r|}{87} & 88 & 89 & 90 & 91 & 92 \\
\hline S. microrhynchus & - & - & - & - & - & - & \multicolumn{2}{|c|}{1} & - & - & - & - & - \\
\hline S. holothuriae & - & - & - & 1 & - & - & \multicolumn{2}{|r|}{-} & - & - & - & - & - \\
\hline S. monostigmus & - & - & - & - & - & 2 & \multicolumn{2}{|c|}{-} & \multirow[t]{2}{*}{-} & - & - & - & - \\
\hline S. leucochilus & - & - & - & - & - & - & \multicolumn{2}{|c|}{-} & & 1 & 4 & 3 & 2 \\
\hline S. longirostris & 1 & 2 & 5 & 14 & 7 & 6 & & 1 & 1 & - & - & - & - \\
\hline S. brachycephalus $\mathbf{n}$. sp. & 1 & 1 & 3 & 6 & 5 & 2 & & 1 & - & - & - & - & - \\
\hline S. hongae n. sp. & - & - & - & - & 1 & 4 & & 7 & 6 & 4 & 1 & - & - \\
\hline S. leptosomus n. sp. & - & - & - & - & - & - & & - & 1 & - & - & - & - \\
\hline S. polylepis n. sp. & - & - & - & 1 & 2 & 1 & & 1 & - & - & - & - & - \\
\hline S. robustus n. sp. & - & - & - & - & 2 & 7 & & 10 & 3 & - & - & - & - \\
\hline & \multicolumn{13}{|c|}{ Number of anal-fin rays } \\
\hline Species & 68 & 69 & 70 & 71 & 72 & 73 & 74 & 75 & 76 & 77 & 78 & 79 & 80 \\
\hline S. microrhynchus & - & - & - & - & - & 1 & - & - & - & - & - & - & - \\
\hline S. holothuriae & - & - & 1 & - & - & - & - & - & - & - & - & - & - \\
\hline S. monostigmus & - & - & - & - & - & 1 & 1 & - & - & - & - & - & - \\
\hline S. leucochilus & - & - & - & - & - & - & - & - & 1 & 1 & 4 & 2 & 1 \\
\hline S. longirostris & 1 & 4 & 7 & 12 & 6 & 3 & 4 & - & - & - & - & - & - \\
\hline S. brachycephalus n. sp. & - & 3 & 3 & 3 & 5 & 4 & 1 & - & - & - & - & - & - \\
\hline S. hongae n. sp. & - & - & - & 1 & 1 & 6 & 8 & 2 & 2 & 2 & 1 & - & - \\
\hline S. leptosomus $\mathbf{n} . \mathbf{s p .}$ & - & - & - & - & 1 & - & - & - & - & - & - & - & - \\
\hline S. polylepis n. sp. & 1 & 1 & - & - & 2 & - & 1 & - & - & - & - & - & - \\
\hline \multirow[t]{2}{*}{ S. robustus $\mathbf{n} . \mathbf{s p .}$} & - & - & - & - & 3 & 9 & 5 & 3 & 2 & - & - & - & - \\
\hline & \multicolumn{13}{|c|}{ Number of caudal-fin rays } \\
\hline Species & \multicolumn{4}{|l|}{12} & \multicolumn{5}{|l|}{13} & \multicolumn{4}{|l|}{14} \\
\hline S. microrhynchus & \multicolumn{4}{|l|}{1} & - & & & & & - & & & \\
\hline S. holothuriae & 1 & & & & - & & & & & - & & & \\
\hline S. monostigmus & - & & & & - & & & & & 2 & & & \\
\hline S. leucochilus & 10 & & & & - & & & & & - & & & \\
\hline S. longirostris & 36 & & & & - & & & & & - & & & \\
\hline S. brachycephalus $\mathbf{n}$. sp. & 19 & & & & - & & & & & - & & & \\
\hline S. hongae n. sp. & 23 & & & & - & & & & & - & & & \\
\hline S. leptosomus n. sp. & 1 & & & & - & & & & & - & & & \\
\hline S. polylepis n. sp. & 5 & & & & - & & & & & - & & & \\
\hline S. robustus n. sp. & 22 & & & & - & & & & & - & & & \\
\hline
\end{tabular}

Another finding provided by Lee et al. $(2014 ; 2017)$ is discovery that $S$. microrhynchus and S. holothuriae have much lower scale counts than those of other specimens identified as S. microrhynchus by Munroe \& Marsh (1997). This finding identified two groups of species within the $S$. microrhynchus species complex: a high scale count group and a low scale count group.

Re-examination of the type specimens of $S$. microrhynchus and S. holothuriae by M.Y. Lee for the present study also revealed some incongruous information concerning morphometric values between Lee's unpublished data and that of Munroe \& Marsh (1997). In their study, Munroe \& Marsh (1997) recorded the UHL as being equal to the LHL in S. microrhynchus, in contrast, the LHL was reported to be larger than the UHL in S. holothuriae. Re-examination of the type specimens by Lee during his work conducted at the USNM actually revealed that these data 
are reversed. This fact was verified during several re-examinations of the types and also from data available from photographs. The incongruity between measurements made in the re-examination and that reported in Munroe \& Marsh (1997) only happened for the UHL \& LHL measurements, and it appears that these differences resulted from interchanging data reported for these two species. We suggest the revised data of M.Y. Lee are more accurate than that reported in Munroe \& Marsh (1997), and thus these data are utilized in the redescriptions of S. microrhynchus above and for that of $S$. holothuriae, which follows below.

Symphurus microrhynchus is only known from the preserved holotype and one other preserved specimen (Koumans 1951). Additional specimens are needed to gain robust data, including both morphological and molecular data, for distinguishing this species. Not only would newly collected specimens provide additional information for understanding intraspecific variation in morphological features, but these specimens would also provide the source for genetic information, so necessary for integrating morphological and molecular approaches for resolving taxonomic issues and discovering systematic relationships of S. microrhynchus and morphologically similar species. Additional specimens will also provide better understanding of the ecology, abundance, demographics, and life history of this species.

TABLE 3. Frequency distributions of numbers of abdominal vertebrae, total vertebrae, and ID patterns for Symphurus from shallow-waters of Indo-Pacific.

\begin{tabular}{|c|c|c|c|c|c|c|c|c|c|}
\hline \multirow[b]{2}{*}{ Species } & \multicolumn{7}{|c|}{ Number of vertebrae } & \multicolumn{2}{|c|}{ Number of abdominal vertebrae } \\
\hline & 45 & 46 & 47 & 48 & 49 & 50 & 51 & & $3+6$ \\
\hline S. microrhynchus & - & - & - & 1 & - & - & - & & 1 \\
\hline S. holothuriae & - & 1 & - & - & - & - & - & & 1 \\
\hline S. monostigmus & - & - & - & 2 & - & - & - & & 2 \\
\hline S. leucochilus & - & - & - & - & 4 & 3 & 3 & & 10 \\
\hline S. longirostris & 4 & 16 & 15 & 2 & - & - & - & & 37 \\
\hline S. brachycephalus $\mathbf{n} . \mathbf{s p .}$ & 1 & 10 & 7 & 1 & - & - & - & & 19 \\
\hline S. hongae n. sp. & - & 2 & 9 & 10 & 2 & - & - & & 23 \\
\hline S. leptosomus n. sp. & - & - & 1 & - & - & - & - & & 1 \\
\hline S. polylepis n. sp. & - & 2 & 2 & 1 & - & - & - & & 5 \\
\hline \multirow[t]{2}{*}{ S. robustus n. sp. } & - & - & 15 & 5 & 2 & - & - & & 22 \\
\hline & \multicolumn{9}{|c|}{ ID Pattern } \\
\hline Species & \multicolumn{2}{|c|}{$1-2-2-2-2$} & \multicolumn{3}{|c|}{$1-2-2-2-1$} & \multicolumn{2}{|c|}{$1-2-2-1-2$} & $1-2-1-2-2$ & $1-2-3-2-2$ \\
\hline S. microrhynchus & \multicolumn{2}{|l|}{1} & \multicolumn{2}{|c|}{-} & \multicolumn{3}{|c|}{-} & - & - \\
\hline S. holothuriae & \multicolumn{2}{|l|}{-} & \multicolumn{2}{|c|}{-} & \multicolumn{3}{|c|}{-} & - & 1 \\
\hline S. monostigmus & \multicolumn{2}{|l|}{2} & \multicolumn{2}{|c|}{-} & \multicolumn{3}{|c|}{-} & - & - \\
\hline S. leucochilus & \multicolumn{2}{|l|}{10} & \multicolumn{2}{|c|}{-} & \multicolumn{3}{|c|}{-} & - & - \\
\hline S. longirostris & \multicolumn{2}{|l|}{31} & \multicolumn{2}{|c|}{-} & \multicolumn{3}{|c|}{2} & 4 & - \\
\hline S. brachycephalus $\mathbf{n}$. sp. & \multicolumn{2}{|l|}{17} & \multicolumn{2}{|c|}{ - } & \multicolumn{3}{|c|}{-} & - & 2 \\
\hline S. hongae n. sp. & \multicolumn{2}{|l|}{21} & \multicolumn{2}{|c|}{-} & \multicolumn{3}{|c|}{-} & - & 2 \\
\hline S. leptosomus n. sp. & \multicolumn{2}{|l|}{1} & \multicolumn{2}{|c|}{-} & \multicolumn{3}{|c|}{-} & - & - \\
\hline S. polylepis n. sp. & 5 & & - & & & - & & - & - \\
\hline S. robustus n. sp. & 20 & & 1 & & & - & & - & 1 \\
\hline
\end{tabular}

Comparisons. Symphurus microrhynchus is one of three species in the S. microrhynchus species complex featuring lower scale counts. Other members included in this species group are S. holothuriae and S. longirostris. Comparisons of $S$. microrhynchus and $S$. holothuriae are limited because each of these nominal species is known only from their holotypes.

Symphurus microrhynchus differs from S. holothuriae in having a 1-2-2-2-2 ID pattern (vs. 1-2-3-2-2 pattern in $S$. holothuriae). Whether this difference in ID pattern is a real distinction between these two nominal species, or merely represents intraspecific variation within $S$. holothuriae (see comments below), will require additional speci- 
mens of both species to determine their predominant ID patterns. The holotype of S. microrhynchus has 48 total vertebrae compared with 46 in the holotype of $S$. holothuriae. Values for this character may also be a species level diagnostic feature between these two species, but again more specimens of each species are needed to determine intraspecific variation of vertebral numbers in these species and whether values for this character are useful in diagnosing these two species.

TABLE 4. Frequency distributions of the number of head, and transverse scale rows for Symphurus from shallow-waters of Indo-Pacific.

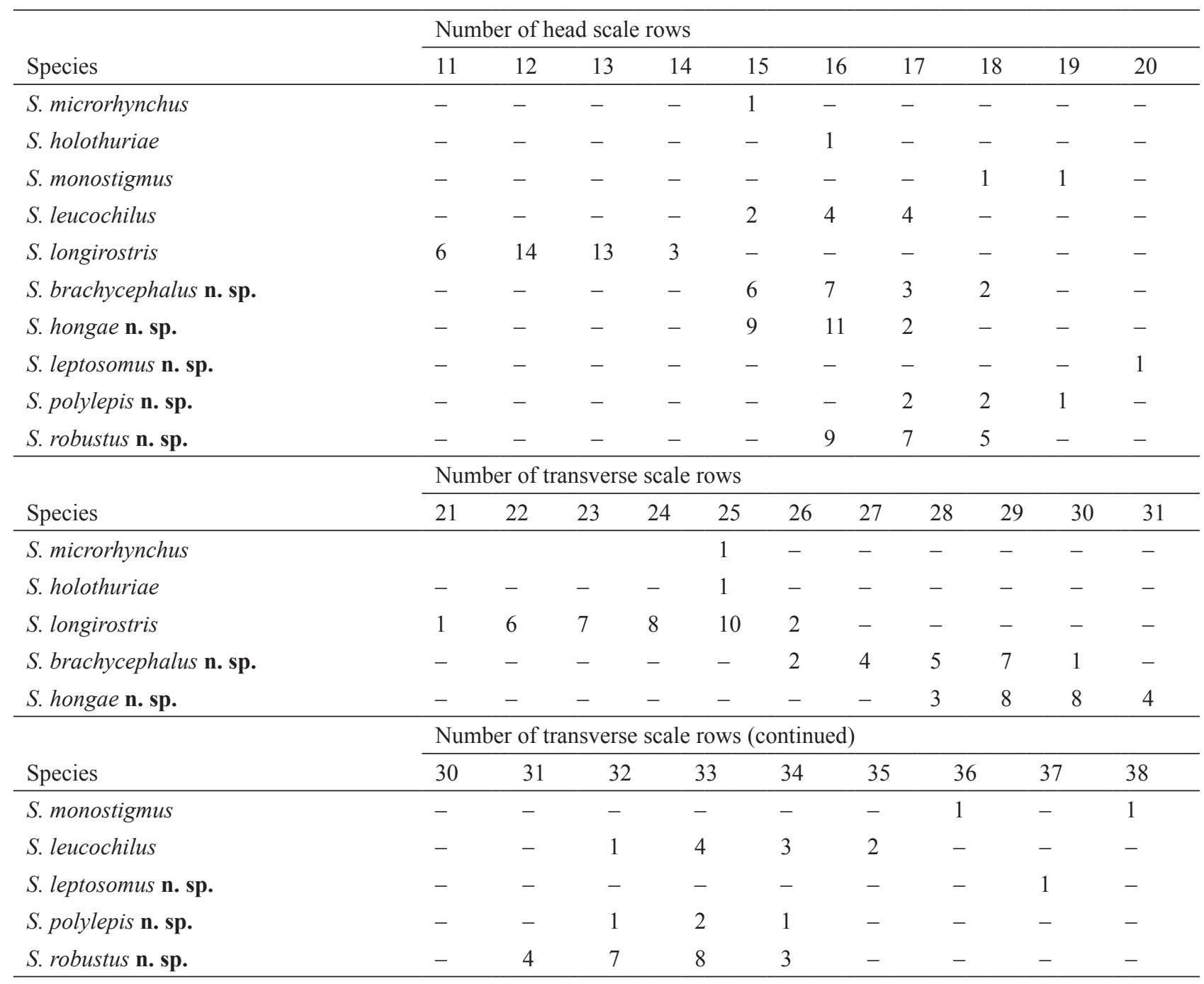

Among morphometric features, $S$. microrhynchus differs from $S$. holothuriae with respect to the width of the lower and upper head lobes. In S. microrhynchus, the lower head lobe is slightly wider (LHL=13.1\% of SL) compared with that of $S$. holothuriae (LHL $=11.6 \%$ of SL). In contrast, the upper head lobe of S. microrhynchus is slightly narrower $(\mathrm{UHL}=10.3 \%$ of SL) compared with that of $S$. holothuriae (UHL $=11.7 \%$ of SL). These differences are reflected in the ratios of UHL/LHL in the two species ( 0.78 in S. microrhynchus vs. 1.01 in S. holothuriae). In other species of Symphurus observed in previous studies (Lee et al. 2009b; 2013; 2014; 2017), intraspecific variation in the ratio between the UHL and LHL is usually stable and thus this feature is usually useful to separate species into two groups: those with UHL/LHL $\leq 1$ versus those with UHL/LUL $>1$. In S. holothuriae, the UHL=11.7\% SL is slightly larger than the LHL (11.6\% of SL).

Symphurus microrhynchus is similar to $S$. longirostris, the third member of the low scale count group of the $S$. microrhynchus species complex, in general body shape, and counts of dorsal-, anal- and caudal-fin rays, total vertebrae, longitudinal scales, and transverse scales (Table 6). Symphurus microrhynchus differs from this species in having more rows of scales on the head posterior to the lower eye (15 vs. 11-14 in S. longirostris). These species differ with respect to several morphometric features (Table 6), including that S. microrhynchus has a longer and wider 
head (vs. shorter and narrower in S. longirostris); a shorter SNL (vs. longer); smaller ratio of SNL/ED (larger ratio in S. longirostris); shorter lower jaw (vs. longer); relatively longer POL; more anterior insertion of the $1^{\text {st }}$ dorsal-fin ray in S. microrhynchus, which results in a shorter PDL (18.1\% of HL) in this species compared with that of S. longirostris ( $\mathrm{PDL}=23.8-32.7 \%$ of $\mathrm{HL}$ ); and the lower head lobe of S. microrhynchus is larger than the upper head lobe $(\mathrm{UHL} / \mathrm{LHL}=0.78)$, whereas in $S$. longirostris the lower head lobe is smaller than the upper head lobe $(\mathrm{UHL} / \mathrm{LHL}=$ 1.01-1.20). Other differences between S. microrhynchus [sensu this study] and S. longirostris were discussed in Lee et al. (2017).

TABLE 5. Frequency distributions of the numbers of longitudinal scale rows for Symphurus from shallow-waters of Indo-western Pacific.

\begin{tabular}{|c|c|c|c|c|c|c|c|c|c|c|c|c|c|}
\hline \multirow[b]{2}{*}{ Species } & \multicolumn{13}{|c|}{ Number of longitudinal scale rows } \\
\hline & 56 & 57 & 58 & 59 & 60 & 61 & 62 & 63 & 64 & 65 & 66 & 67 & 68 \\
\hline S. microrhynchus & - & - & - & - & - & - & - & - & 1 & - & - & - & - \\
\hline S. holothuriae & - & - & - & - & 1 & - & - & - & - & - & - & - & - \\
\hline \multirow[t]{2}{*}{ S. longirostris } & 1 & 1 & 4 & 2 & 5 & 4 & 5 & 3 & 4 & 3 & 1 & - & - \\
\hline & \multicolumn{13}{|c|}{ Number of longitudinal scale rows (continued) } \\
\hline Species & 69 & 70 & 71 & 72 & 73 & 74 & 75 & 76 & 77 & 78 & 79 & 80 & 81 \\
\hline S. leucochilus & - & - & - & - & - & - & 1 & 1 & 2 & 1 & 1 & 2 & - \\
\hline S. brachycephalus n. $\mathbf{~ s p . ~}$ & - & - & - & 1 & 1 & 2 & 1 & 3 & 2 & 4 & 2 & 1 & - \\
\hline S. hongae $\mathbf{n}$. sp. & - & - & - & 2 & 4 & 3 & 4 & 2 & 2 & 2 & 2 & 1 & 1 \\
\hline S. leptosomus $\mathbf{n}$. sp. & - & - & - & - & - & - & - & 1 & - & - & - & - & - \\
\hline \multirow{2}{*}{ S. robustus $\mathbf{n}$. sp. } & - & - & - & - & - & - & - & - & - & 1 & 1 & - & - \\
\hline & \multicolumn{13}{|c|}{ Number of longitudinal scale rows (continued) } \\
\hline Species & 82 & 83 & 84 & 85 & 86 & 87 & 88 & 89 & 90 & 91 & 92 & 93 & 94 \\
\hline S. monostigmus & - & - & - & - & - & - & - & - & - & - & 1 & - & - \\
\hline S. leucochilus & 1 & 1 & - & - & - & - & - & - & - & - & - & - & - \\
\hline S. brachycephalus $\mathbf{n} . \mathbf{s p .}$ & 1 & - & - & - & - & - & - & - & - & - & - & - & - \\
\hline S. polylepis n. sp. & - & - & - & - & - & - & 1 & 1 & 1 & 1 & - & - & 1 \\
\hline S. robustus n. sp. & 3 & 3 & 4 & 3 & 3 & 1 & 1 & - & - & - & - & - & - \\
\hline
\end{tabular}

Symphurus microrhynchus differs from the five species of the S. microrhynchus species group featuring high scale counts (S. brachycephalus n. sp., S. hongae n. sp., S. leptosomus n. sp., S. polylepis n. sp., and S. robustus $\mathbf{n}$. sp.) by its fewer number of rows of longitudinal (64 vs. 72-94) and transverse scales (25 vs. 26-37 in these others). And, in S. microrhynchus, head width is shorter than head length $(\mathrm{HW} / \mathrm{HL}=0.97)$, whereas, in the five species with high scale counts, their heads are wider than long with HW/HL ratios ranging from 1.02-1.20 for these species.

Symphurus microrhynchus has the same ID pattern (1-2-2-2-2) and overlapping counts for dorsal-fin rays (87 vs. $86-92$ ), anal-fin rays ( 73 vs. 73-80), and total vertebrae (48 vs. 48-51) as those found in S. monostigmus and S. leucochilus. However, S. microrhynchus is readily differentiated from both S. monostigmus and S. leucochilus in having a membranous connection between the ocular-side anterior nostril and the lower eye, and this species also has a fleshy ridge on the ocular-side lower jaw; both features are absent in S. monostigmus and S. leucochilus. In $S$. microrhynchus, head length is nearly equal to its width $(\mathrm{HW} / \mathrm{HL}=0.97)$ versus head width greater than head length $(\mathrm{HW} / \mathrm{HL}=1.07-1.42)$ in these other two species. Additionally, S. microrhynchus has fewer rows of longitudinal (64 vs. 75-93) and transverse scales (25 vs. 32-38) than is found in these others. Symphurus microrhynchus differs further from S. monostigmus in having 12 (vs. 14) caudal-fin rays and 4 (vs. 5) hypurals, and in lacking the pigment spot on the abdomen that features so prominently in S. monostigmus. 
TABLE 6. Morphometrics for the three nominal species, S. holothuriae (BMNH 1892.1.14.34), S. microrhynchus (ZMA 108193 ), and S. longirostris (holotype in the parentheses). SL in mm; characters $2-15$ in \% of SL; $16-23$ in \% of HL; 24 in $\%$ of BD.

\begin{tabular}{|c|c|c|c|}
\hline Character & S. holothuriae & S. microrhynchus & S. longirostris \\
\hline 1. SL(mm) & 32.2 & 42.2 & $26.6-65.5(37.9)$ \\
\hline 2. BD & 25.7 & 24.9 & $22.1-26.3(26.3)$ \\
\hline 3. TKL & 81.3 & 78.9 & $78.6-82.5(82.5)$ \\
\hline 4. PDL & 4.8 & 4.4 & $5.2-6.9(6.8)$ \\
\hline 5. PAL & 27.6 & 28.1 & $24.6-27.3(26.4)$ \\
\hline 6. DBL & 95.2 & 95.6 & $93.1-94.8(93.2)$ \\
\hline 7. $\mathrm{ABL}$ & 72.1 & 71.9 & $72.7-75.4(73.7)$ \\
\hline 8. PL & 8.3 & NA & $7.6-12.1(8.8)$ \\
\hline 9. PA & 2.7 & 4.7 & $2.5-5.8(5.2)$ \\
\hline 10. CFL & NA & NA & $10.7-14.4(14.4)$ \\
\hline 11. HL & 24.0 & 24.2 & $20.5-22.6(22.6)$ \\
\hline 12. HW & 23.3 & 23.5 & $19.3-22.0(21.8)$ \\
\hline 13. POL & 18.2 & 18.5 & $13.0-14.9(14.9)$ \\
\hline 14. UHL & 11.7 & 10.3 & $10.1-12.2(11.2)$ \\
\hline 15. LHL & 11.6 & 13.1 & $9.3-11.5(10.7)$ \\
\hline 16. PDL & 19.7 & 18.1 & $23.8-32.7(29.8)$ \\
\hline 17. POL & 75.9 & 76.5 & $62.8-67.5(65.7)$ \\
\hline 18. SNL & 14.32 & 10.4 & $18.7-24.4(21.9)$ \\
\hline 19. UJL & 18.92 & 19.0 & $21.0-25.9(25.1)$ \\
\hline 20. ED & 9.8 & 8.35 & $9.3-12.1(11.0)$ \\
\hline 21. CD & 15.0 & 13.5 & $13.6-21.3(18.8)$ \\
\hline 22. OPLL & 30.2 & 37.5 & $23.2-31.8(24.2)$ \\
\hline 23. OPUL & 20.0 & 16.7 & $14.9-24.8(23.1)$ \\
\hline 24. TH & 17.2 & 18.3 & $20.1-27.4(21.2)$ \\
\hline 25. HW/HL & 0.97 & 0.97 & $0.92-0.99(0.96)$ \\
\hline 26. Pupil/ED & 0.38 & 0.44 & $0.33-0.47(0.44)$ \\
\hline
\end{tabular}

\section{Symphurus holothuriae Chabanaud, 1948}

(Figs. 3-4; Tables 1-6)

Symphurus holothuriae Chabanaud, 1948: 510 (Holothuria Bank, northwestern Australia. Holotype: BMNH 1892.1.14.34; compared with S. trifasciatus). Chabanaud 1955b: 45 (comparisons with S. microrhynchus; pigmentation features; probably synonym of S. microrhynchus). Munroe 1992: 376 (ID pattern; discussion about taxonomic status; comment on melanophores at bases of dorsal and anal fins; similar to S. microrhynchus). Lee et al. 2017: 71 (compared with S. longirostris).

Symphurus holothuriae (not Chabanaud). Nielsen 1961: 226 (2 specimens of S. schultzi misidentified as S. holothuriae). Munroe 1992: 372 (re-identified 2 specimens of S. schultzi that were misidentified as S. holothuriae). Munroe \& Marsh 1997: 195 (discussed 2 specimens of $S$. schultzi misidentified as $S$. holothuriae).

Symphurus microrhynchus (not Weber). Munroe \& Marsh 1997: 191 (synonym of S. microrhynchus).

Holotype: BMNH 1892.1.14.34, 32.3 mm SL, male, off Holothuria Bank, northwestern Australia, 14 Jan 1892.

Diagnosis. Symphurus holothuriae is distinguished from all congeners by the combination of: a 1-2-3-2-2 ID pattern; 12 caudal-fin rays; $9(3+6)$ abdominal vertebrae; 46 total vertebrae; 4 hypurals; 84 dorsal-fin rays; 70 anal-fin rays; 60 longitudinal scale rows; 25 transverse scale rows; 16 scale rows on head posterior to lower orbit; body elongate (BD 25.7\% of SL); preanal length long (PAL 27.6\% of SL); upper head lobe equal in length to lower head lobe; head long (HL 24.0\% of SL), head length longer than head width (HW/HL=0.97); postorbital length 
long (POL of $75.9 \% \mathrm{HL}$ ); snout short (SNL $14.3 \%$ of HL, SNL/ED= 1.45) and slightly blunt anteriorly; dorsal-fin origin at vertical through posterior margin of upper eye; predorsal length short ( $\mathrm{PDL}=19.7 \%$ of $\mathrm{HL}$ ); eyes unequal in position with anterior margin of upper eye noticeably in advance of anterior margin of lower eye; well-developed fleshy ridge on posterior part of ocular-side lower jaw; body pigmentation yellowish-green on both sides.

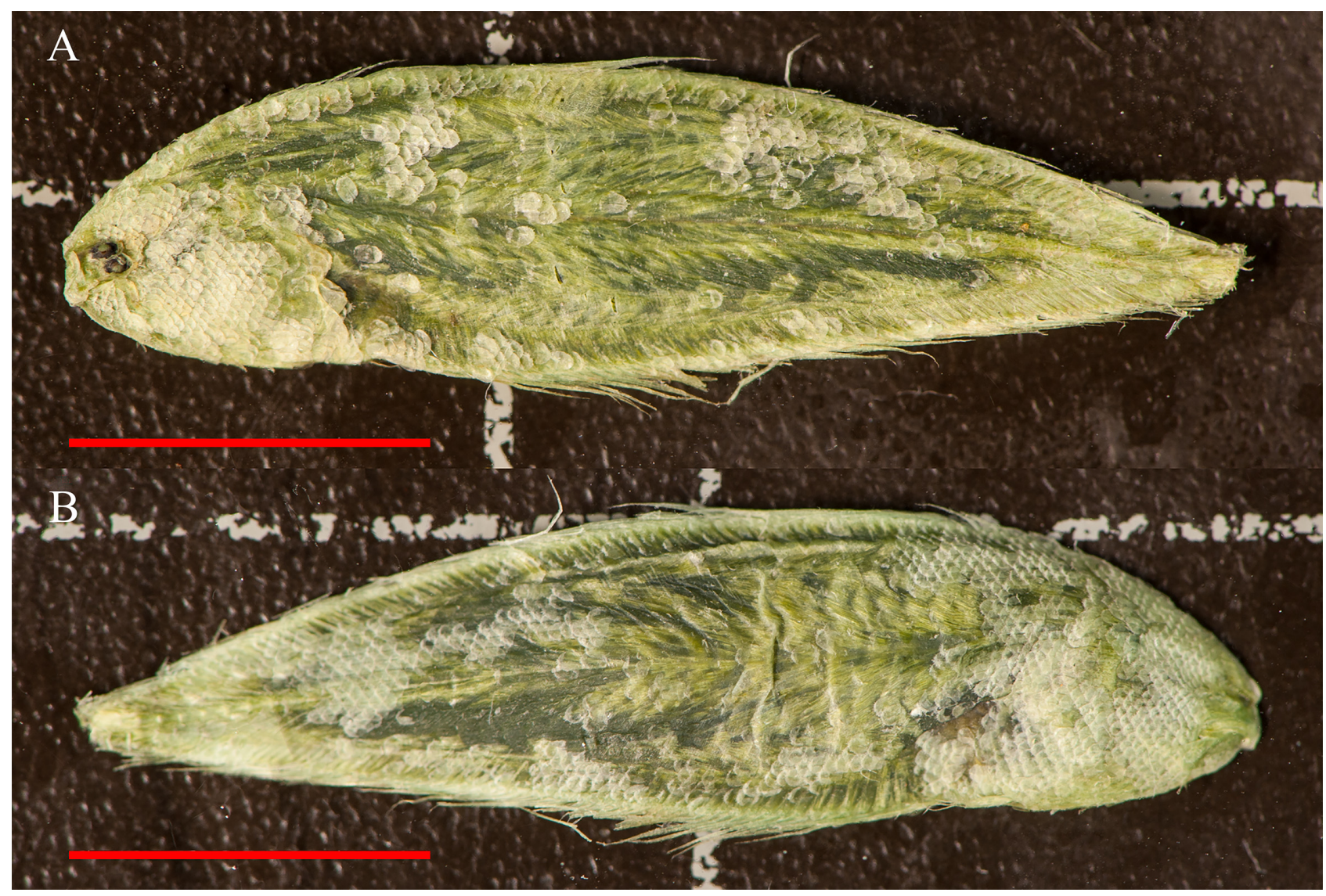

FIGURE 4. Symphurus holothuriae, holotype, BMNH 1892.1.14.34, male, 32.2 mm SL, off Holothuria Bank, northwestern Australia. A. Ocular-side pigmentation of preserved specimen. B. Blind-side pigmentation of same specimen. Scale equals 10 $\mathrm{mm}$.

Description. Symphurus holothuriae (Fig. 4) is likely a dwarf species and is known only from a single, male specimen of $32.3 \mathrm{~mm}$ SL. Meristic characters are summarized in Tables 2-5. ID pattern 1-2-3-2-2. Caudal-fin rays 12 . Dorsal-fin rays 84 . Anal-fin rays 70 . Pelvic-fin rays 4 . Total vertebrae 46 ; abdominal vertebrae $9(3+6)$. Hypurals 4. Longitudinal scale rows 60 . Scale rows on head posterior to lower orbit 16. Transverse scale rows 25.

Proportions of morphometric features are presented in Table 6. Body elongate; maximum depth in middle of body, at point about equal to vertical at $10^{\text {th }}$ anal-fin ray; body with gradual taper posterior to midpoint. Preanal length longer than body depth. Head moderately long and narrow; head width shorter than head length $(\mathrm{HW} / \mathrm{HL}=$ 0.97). Upper head lobe equal to width of lower head lobe $(\mathrm{UHL} / \mathrm{LHL}=1.00)$, and much shorter than postorbital length. Lower lobe of ocular-side opercle wider than upper lobe; posterior margin of lower lobe projecting slightly beyond posterior margin of upper opercular lobe. Snout short, slightly blunt anteriorly, its length slightly greater than eye diameter $(\mathrm{SNL} / \mathrm{ED}=1.45)$. Dermal papillae present and well developed on blind side of snout and chin. Ocular-side anterior nostril tubular and short, not reaching anterior margin of lower eye when depressed posteriorly. Ocular-side posterior nostril a small, rounded tube located on snout just anterior to interorbital space. Blind-side anterior nostril tubular and relatively short, easily distinguishable from dermal papillae; blind-side posterior nostril a shorter and wider, posteriorly directed tube situated posterior to vertical at posterior margin of jaws. Jaws long and slightly arched; upper jaw length slightly longer than snout length; posterior margin of upper jaw extending to vertical through posterior margin of lower eye. Ocular-side lower jaw with well-developed fleshy ridge on its posterior portion. Cheek depth relatively wide, slightly greater than snout length. Eyes small, oval, unequal in position with anterior margin of upper eye greatly in advance of anterior margin of lower eye. Pupillary operculum absent. 
Dorsal-fin origin located at vertical through posterior margin of upper eye; predorsal length relatively short. Anteriormost dorsal-fin rays obviously shorter than more posterior dorsal-fin rays. Scales absent on both sides of dorsaland anal-fin rays. Pelvic fin long; longest pelvic-fin ray, when extended posteriorly, usually reaching base of sixth anal-fin ray. Posteriormost pelvic-fin ray connected to anal fin by delicate membrane. Caudal fin broken; uncertain if ctenoid scale rows present on base of fin or not. Scales on both sides of body numerous, strongly ctenoid.

Teeth present and recurved slightly inwards on all jaws, but better developed on blind-side jaws. Ocular-side premaxilla and dentary with single row of sharply pointed, well-developed teeth. Blind-side premaxilla with two rows of sharp, recurved teeth. Blind-side lower jaw with four rows of well-developed teeth.

Pigmentation. Pigmentation of live or freshly collected S. holothuriae unknown. Background pigmentation of both sides of preserved holotype (Fig. 4) a faded, uniform yellowish-green. Upper aspects of eyes and eye sockets bluish-black; pupils yellowish-green.

In the original description, Chabanaud (1948) described the preserved holotype as having a uniformly light reddish-yellow ocular side with paler fins. Later, Chabanaud (1955b) noted that the holotype of S. holothuriae lacked any evidence of transverse banding and it also lacked darkly pigmented melanophores along bases of the dorsal- and anal-fin rays. Munroe \& Marsh (1997) reported that when they examined the holotype, the specimen was mostly faded, but, in contrast to the statement of Chabanaud (1955b), a few dermal melanophores were evident on the bases of some anterior dorsal-fin rays.

Distribution. Symphurus holothuriae is known only from a single specimen collected on Holothuria Bank, northwestern Australia (Fig. 3).

Remarks. In the original description, Chabanaud (1948) did not compare S. holothuriae with S. microrhynchus, only with S. trifasciatus, an Indian Ocean deepwater species featuring similar meristic features. Later (Chabanaud 1955b), did compare $S$. holothuriae with $S$. microrhynchus noting that $S$. holothuriae lacked the transverse bands that were present on $S$. microrhynchus and that it also lacked the series of darkly pigmented melanophores along bases of the dorsal- and anal-fin rays, which are present in S. microrhynchus. Chabanaud (1955b) did not consider these differences significant because he stated that $S$. holothuriae was very similar to, and probably a synonym of, S. microrhynchus.

The next paper dealing with S. holothuriae was that of Munroe (1992) in his survey of ID patterns among species of Symphurus. Munroe noted that $S$. holothuriae was only one of three species (S. undatus and $S$. hondoensis representing the others) featuring a 1-2-3-2-2 ID pattern. Sometimes, species characterized by the 1-2-2-2-2 ID pattern have variant specimens that have a $1-2-3-2-2$ ID pattern. Since $S$. holothuriae is known only from the holotype, it cannot be determined whether the predominant ID pattern for this species is $1-2-3-2-2$, or if the pattern present in the holotype represents a variant pattern for this species. More specimens of $S$. holothuriae are needed to determine the predominant ID pattern for this species.

Munroe (1992) also noted that $S$. holothuriae was otherwise morphologically similar to three other poorly known Indo-Pacific species (S. microrhynchus, S. trifasciatus, and S. luzonensis). Except for differences in ID patterns (1-2-3-2-2 in S. holothuriae vs. 1-2-2-2-2 in these others), S. holothuriae has comparable caudal-, dorsal-, and anal-fin ray counts and vertebral counts, to those found in these others.

In their redescription of S. microrhynchus, Munroe \& Marsh (1997) considered S. holothuriae to be a junior subjective synonym of $S$. microrhynchus. They noted that the holotype of $S$. holothuriae has meristic and morphometric features that generally agree with those of the holotype of $S$. microrhynchus, their opercle shapes are similar, and S. holothuriae has a few dermal melanophores present at the bases of the anteriormost dorsal-fin rays, which are also present in S. microrhynchus. Munroe \& Marsh (1997) also noted some differences between the holotypes of these two species including those in ID pattern and the lower vertebral count of $S$. holothuriae compared with that of S. microrhynchus, but did not think these differences were sufficient to distinguish these as different species.

More recent evidence, based on morphology (Lee et al. 2014; 2017), indicates that $S$. holothuriae is a shallowwater species belonging to the low scale count group within the $S$. microrhynchus species complex. In addition to $S$. holothuriae, this species group also includes S. longirostris and S. microrhynchus. Further examination of additional specimens is needed to gain better understanding of intraspecific variation, ecology, abundance, and life history attributes for this species.

Comparisons. Among shallow-water species of Symphurus, S. holothuriae is most similar to S. microrhynchus and $S$. longirostris, the other members of the low scale count group of species in the S. microrhynchus species complex. These species share similar general body shapes, and have overlapping counts of dorsal-, anal-, and caudal-fin 
rays, longitudinal scales, and transverse scales (Tables 4-5). Differences between S. holothuriae and S. microrhynchus were highlighted above in the Remarks and Comparisons sections for S. microrhynchus.

Symphurus holothuriae differs from S. longirostris in having more scale rows on the head posterior to the lower eye (16 vs. 11-14 in S. longirostris) and in several morphometric features (Table 6). Symphurus holothuriae has a longer and wider head (vs. head shorter and narrower in S. longirostris), a shorter SNL (vs. longer), smaller ratio of SNL/ED (larger ratio in S. longirostris), shorter lower jaw (vs. longer), and relatively longer POL. Symphurus holothuriae has a more anterior insertion of the $1^{\text {st }}$ dorsal-fin ray than does $S$. longirostris, which results in this species having a shorter PDL (18.1\% of HL) compared with that of $S$. longirostris (PDL $>23.8 \%$ of HL). The lower head lobe is also larger than the upper head lobe $(\mathrm{UHL} / \mathrm{LHL}=0.78)$, whereas in $S$. longirostris the lower head lobe is smaller than the upper head lobe (UHL/LHL=1.01-1.20). Other differences between S. holothuriae and S. longirostris were discussed in Lee et al. (2017).

Symphurus holothuriae differs from the group of five species in the S. microrhynchus species complex featuring high scale counts (S. brachycephalus n. sp., S. hongae n. sp., S. leptosomus $\mathbf{n}$. sp., S. polylepis n. sp., and $S$. robustus n. sp.) by its fewer longitudinal (64 vs. $72-94$ ) and transverse scales ( 25 vs. $26-37$ in these others). And, in S. holothuriae, head width is narrower than the corresponding head length, whereas, in the five species with high scale counts, their heads are wider than long (HW/HL $=0.97$ in $S$. holothuriae vs. HW/HL ranging from 1.02-1.20 for these other species).

Symphurus holothuriae has overlapping, or nearly overlapping, counts for dorsal-fin rays (87 vs. 86-92), and anal-fin rays (70 vs. 73-80) as those found in S. monostigmus and S. leucochilus. However, S. holothuriae is readily differentiated from both $S$. monostigmus and $S$. leucochilus in having a different ID pattern (1-2-3-2-2 vs. 1-2-22-2 in these others) and fewer total vertebrae (46 vs. 48-51). Symphurus holothuriae has a membranous connection between the ocular-side anterior nostril and the lower eye, and this species also has a fleshy ridge present on the ocular-side lower jaw; both features are absent in these other species. Additionally, S. holothuriae has fewer longitudinal (60 vs. $75-92$ ) and transverse scales ( 25 vs. $32-38$ ) than is found in these other species. In S. holothuriae, the head length is nearly equal to its width $(\mathrm{HW} / \mathrm{HL}=0.97)$ versus head width greater than head length $(\mathrm{HW} / \mathrm{HL}=$ 1.07-1.42) in these other two species. Symphurus holothuriae differs further from S. monostigmus in having 12 (vs. 14) caudal-fin rays and 4 (vs. 5) hypurals, and $S$. holothuriae lacks the pigment spot on the abdomen that features so prominently in S. monostigmus.

\section{Symphurus longirostris Lee, Munroe \& Kai, 2016}

(Figs. 1, 5, 14; Tables 1-6, 13)

Symphurus longirostris Lee, Munroe \& Kai, 2017 (2016 online): 71, Figs. 1-2 (off Japan, 45-100 m. Holotype: FAKU 135349).

Specimens examined. 37, including the holotype \& 36 paratypes, 26.6-65.5 mm SL. Holotype: FAKU 135349,

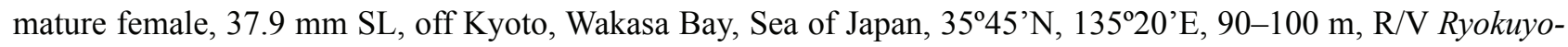
maru, 18 Mar 2013. Detailed information on the other material examined for this species can be found in Lee et al. (2017).

Diagnosis. Symphurus longirostris is distinguished from all congeners by the combination of: a 1-2-2-2-2 ID pattern; 12 caudal-fin rays; $9(3+6)$ abdominal vertebrae; $45-48$ total vertebrae; 4 hypurals; $81-88$ dorsal-fin rays; 68-74 anal-fin rays; 56-66 longitudinal scale rows; and 11-14 scale rows on head posterior to lower orbit; a slender body $(\mathrm{BD}=22.1-26.3 \%$ of $\mathrm{HL})$; relatively long preanal length $(\mathrm{PAL}=24.6-27.3 \%$ of $\mathrm{SL})$; upper head lobe slightly larger than lower head lobe; head moderately long $(\mathrm{HL}=20.5-22.6 \%$ of $\mathrm{SL})$, longer than head width $(\mathrm{HW} / \mathrm{HL}=$ 0.92-0.99); short postorbital length $(\mathrm{POL}=62.5-67.5 \%$ of $\mathrm{HL})$; long snout $(\mathrm{SNL}=18.7-24.4 \%$ of $\mathrm{HL}, \mathrm{SNL} / \mathrm{ED}=$ 1.66-2.24), round to obliquely blunt anteriorly; dorsal-fin origin at vertical through posterior margin of upper eye, or at point posterior to eye; long predorsal length $(\mathrm{PDL}=23.8-32.7 \%$ of $\mathrm{HL}$ ); well-developed fleshy ridge on posterior part of ocular-side lower jaw; membrane covering both eyes; also with fleshy membrane continuous between ocular-side anterior nostril and lower part of eye; ocular-side pigmentation yellow to light-brown; blind-side pigmentation uniformly white without pepper-dots; both sides with obvious dermal spots on bases of anteriormost dorsal- and anal-fins; and peritoneum bluish-black on its dorsalmost aspect.

Description. Symphurus longirostris (Fig. 5) is a dwarf species known from 37 specimens, the largest of which 
is $65.5 \mathrm{~mm} \mathrm{SL}$. Meristic characters are summarized in Tables 2- 5. Predominant ID pattern 1-2-2-2-2 (31/37 specimens, including holotype). Caudal-fin rays 12 . Dorsal-fin rays $81-88$. Anal-fin rays $68-74$. Pelvic-fin rays 4 . Total vertebrae 45-48; abdominal vertebrae $9(3+6)$. Hypurals 4. Longitudinal scale rows 56-66. Scale rows on head posterior to lower orbit 11-14. Transverse scales 21-26.

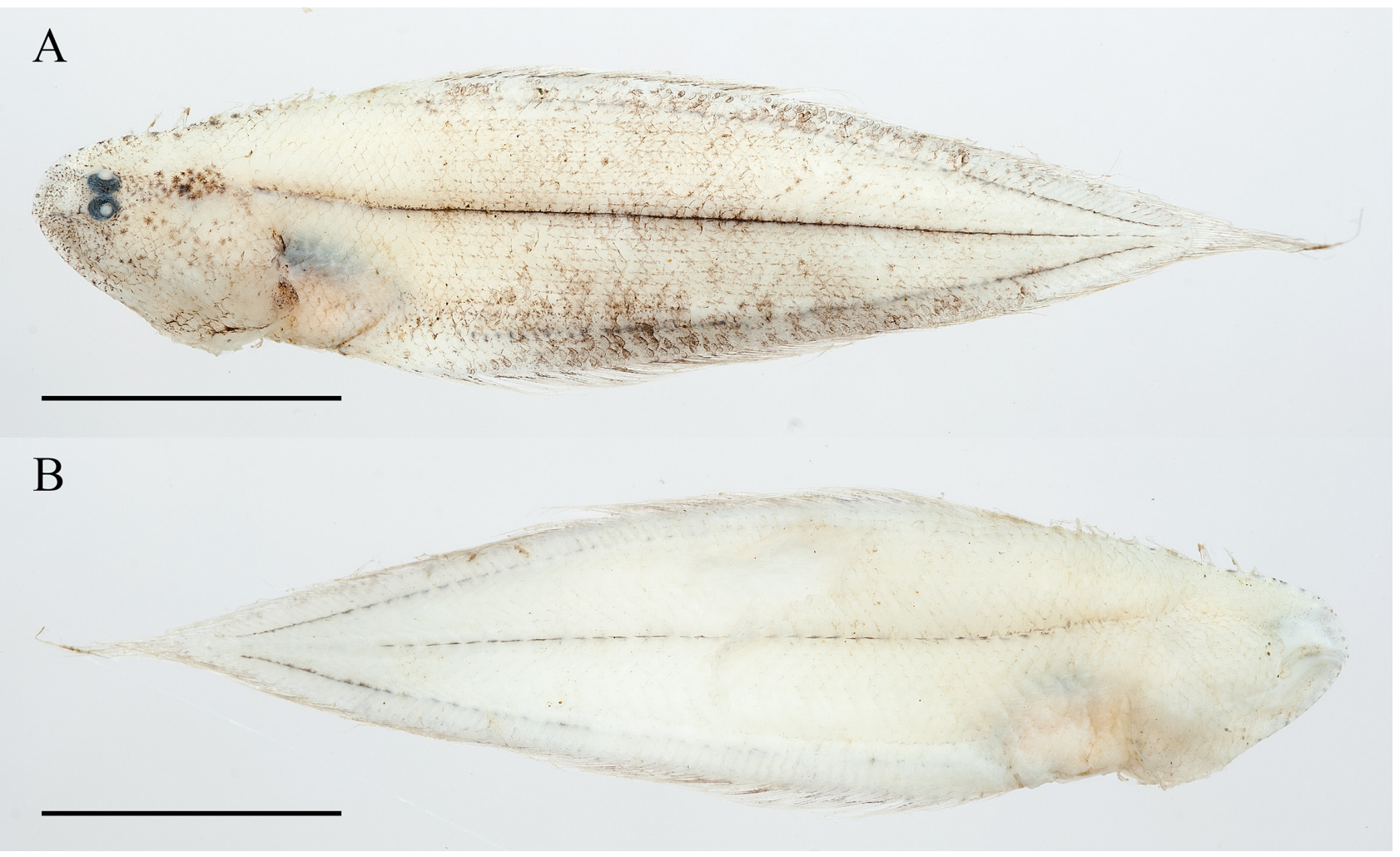

FIGURE 5. Symphurus longirostris, holotype, FAKU 135349, mature female, 37.9 mm SL, off Wakasa Bay, off Kyoto, Sea of Japan, Japan. A. Ocular-side pigmentation of preserved specimen. B. Blind-side pigmentation of same specimen. Scale equals $10 \mathrm{~mm}$.

Proportions of morphometric features are presented in Table 6. Body relatively elongate, moderately deep; maximum depth in anterior one-third of body, usually at point between anus and fifth anal-fin ray; body with gradual taper posterior to midpoint. Preanal length larger than body depth. Head moderately long and narrow; head width slightly shorter than head length $(\mathrm{HW} / \mathrm{HL}=0.92-0.99$, Mean $=0.96)$. Upper head lobe wider than lower head lobe $(\mathrm{UHL} / \mathrm{LHL}=1.01-1.20$, Mean=1.08); shorter than postorbital length. Snout relatively long; slightly round to obliquely blunt anteriorly; its length usually much greater than eye diameter $(\mathrm{SNL} / \mathrm{ED}=1.66-2.24, \mathrm{Mean}=1.95)$. Dermal papillae present, well developed, on blind side of snout and chin. Ocular-side anterior nostril tubular and short, usually not reaching anterior margin of lower eye when depressed posteriorly. Ocular-side posterior nostril, a small, rounded tube located on snout just anterior to interorbital space. Blind-side anterior nostril, tubular, moderately long, easily distinguishable from dermal papillae; blind-side posterior nostril, a shorter and wider posteriorly directed tube situated posterior to vertical at posterior margin of jaws. Eyes moderately large $(E D=9.3-12.1 \%$ of HL), oval, and contiguous; with membrane covering both eyes; anteroventral eye membrane connected with anterior nostril by fleshy membrane. Eyes usually equal in position, or with anterior margin of upper eye slightly in advance of that of lower eye. Pupillary operculum absent. Jaws short and slightly arched; upper jaw length slightly longer than snout length; posterior margin of upper jaw usually extending to point between verticals through anterior margin of pupil and posterior margin of lower eye. Ocular-side lower jaw with well-developed fleshy ridge on its posterior half. Cheek depth narrow, slightly shorter than snout length. Lower lobe of ocular-side opercle wider than upper opercular lobe; posterior margin of lower lobe projecting slightly beyond posterior margin of upper opercular lobe. Dorsal-fin origin located at vertical through posterior margin of upper eye, or at point slightly posterior to this vertical; predorsal length relatively long. Anteriormost dorsal-fin rays obviously shorter than more posterior fin rays. Scales absent on both sides of dorsal- and anal-fin rays. Pelvic fin moderately long; longest pelvic-fin ray, when extended posteriorly, usually reaching base of third to fourth anal-fin ray. Posteriormost pelvic-fin ray con- 
nected to anal fin by delicate membrane. Caudal fin relatively long, with several (usually less than four) rows of ctenoid scales on base of fin. Scales on both sides of body numerous, strongly ctenoid.

Teeth present and recurved slightly inward on all jaws, but better developed on blind-side jaws. Ocular-side premaxilla and dentary with single row of sharply pointed, well-developed teeth. Blind-side premaxilla with two to three rows of sharp, recurved teeth. Blind-side lower jaw with three to six rows of well-developed teeth.

More detailed information, including additional morphological and molecular data, were previously provided in Lee et al. (2017).

Pigmentation. Pattern of body pigmentation generally similar for both sexes at all sizes (Fig. 5). Background body coloration of ocular side generally light yellow to light brown; ocular surface darker along regions overlying pterygiophores of dorsal and anal fins; median longitudinal row of darkly pigmented melanophores present along vertebral axis on blind side of specimens usually smaller than $45 \mathrm{~mm}$ SL. Melanophores in dermis also present in darker regions overlying pterygiophores of dorsal and anal fins. External surface of abdominal area usually reddish to light brown with bluish-black pigmentation covering dorsalmost part. Background coloration of ocular side of head generally similar to that on body, except for one dark region behind eyes formed by dense cluster of dermal melanophores, and with obvious dermal spots at bases of anterior dorsal-fin rays. Ocular side of snout light yellow. Ocular-side anterior nostril light yellow to brown. Upper aspects of eyes and eye sockets light blue with light-bluish spots; pupils bluish-black. Ocular-side lips and chin region uniformly yellow to brown; margins of lips with small melanophores. Nearly entire outer surface of ocular-side opercle yellow to brown, similar to background coloration on body and head. Margin of opercle darker brown, especially at opercular opening. Inner surface of ocular-side opercle and isthmus with small dark brownish or blackish dot-sized melanophores. Isthmus also with pepper-dots on its surface. Blind side generally white to light-yellow, with bluish-black pigment on dorsalmost part of peritoneum showing through abdominal wall. Some specimens, usually those smaller than $45 \mathrm{~mm}$ SL, with median longitudinal row of darkly pigmented melanophores along vertebral axis. A single, longitudinal row of well-developed dermal melanophores present along bases of anteriormost dorsal- and anal-fin rays. Outer surface of blind-side opercle white to light yellow, generally corresponding to background coloration. Inner surface of blind-side opercle unpigmented. Fin rays of dorsal, anal, and pelvic fins uniformly yellow to brown; basal regions of fin rays and membranes covering fin rays light yellow, with diffuse scattering of yellow to brown chromatophores over entire fin membranes on both sides of fins. Dorsal and anal fins with alternating series of darkly streaked and lightly pigmented fin rays throughout entire lengths of fins. Basal margins of fin rays and associated fin membranes on blind side light yellow to light brown.

Pigmentation of recently preserved specimens (Fig. 5). Similar to that of freshly caught fishes; pigmentation of older specimens preserved decades ago usually faded, but dermal spots at bases of anterior dorsal-fin rays and on isthmus, as well as bluish-black coloration on dorsalmost part of peritoneum, still clearly visible in these specimens.

Remarks. Compared with most other species of shallow-water Symphurus, S. longirostris appears to be a common species collected in shallow waters around Japan (including Pacific side and Japanese Sea).

Comparisons. Symphurus longirostris is one of three species in the S. microrhynchus species complex that features lower scale counts. Other members with lower scale counts include $S$. microrhynchus and S. holothuriae. These three species share a similar general body shape, and have overlapping counts of dorsal-, anal-, and caudal-fin rays, longitudinal scales, and transverse scales (Table 6). Characters distinguishing S. longirostris from S. microrhynchus and $S$. holothuriae were highlighted in the Comparisons sections above for these two species, respectively.

Symphurus longirostris differs from the group of five species of the S. microrhynchus species complex (S. brachycephalus n. sp., S. hongae n. sp., S. leptosomus n. sp., S. polylepis n. sp., and S. robustus n. sp.) featuring high scale counts by its lower numbers of longitudinal (56-66 vs. 72-94) and transverse scales (21-26 vs. 26-37 in these others). Symphurus longirostris has the head width shorter than the head length (HW/HL=0.92-0.99), whereas, in the five species with high scale counts, their heads are wider than long with HW/HL ratios ranging from $1.02-1.20$ for these species.

Despite having the same ID pattern (1-2-2-2-2) and overlapping counts for dorsal-fin rays (81-88 vs. 86-92) and anal-fin rays (68-74 vs. 73-80) as those found in S. monostigmus and S. leucochilus, S. longirostris is readily distinguished from these species by several features. For example, S. longirostris has a membranous connection between the ocular-side anterior nostril and the lower eye, and it also has a fleshy ridge present on the ocular-side lower jaw; both features being absent in these other species. Symphurus longirostris has fewer total vertebrae 
(45-48 vs. 48-51) than do these other species, and its head length is nearly equal to its width (HW/HL=0.92-0.99) versus head width greater than head length $(\mathrm{HW} / \mathrm{HL}=1.07-1.42)$ in these other species. Additionally, S. longirostris has fewer longitudinal scales (56-66 vs. 75-83), fewer rows of head scales (11-14 vs. 15-19) and transverse scales (21-26 vs. 32-38), than is found in these other species. Symphurus longirostris differs further from S. monostigmus in having 12 (vs. 14) caudal-fin rays and 4 (vs. 5) hypurals, and S. longirostris also lacks the pigment spot on the abdomen that features so prominently in S. monostigmus.

\section{Species accounts for members of the $S$. microrhynchus species complex with high scale counts}

\section{Symphurus brachycephalus n. sp.}

(English name: Short-headed tonguefish)

(Figs. 1, 3, 6, 14; Tables 1-5, 7, 13)

Symphurus microrhynchus (not Weber). Munroe \& Marsh 1997: 194 (misidentified as S. microrhynchus; Vietnam). Voronina et al. 2016: 401 (21 specimens, Vietnam; meristic features, color photograph, diagnostic characters, distribution after Munroe \& Marsh 1997; recognized possibility of a cryptic species).

Symphurus cf. microrhynchus (VN). Lee et al. 2014: 576 (tentatively identified; genetic information used for resolving other taxonomic issues). Lee et al. 2017: 72 (tentatively identified; genetic information used for resolving other taxonomic issues).

Holotype: ASIZP0072365, male, 45.2 mm SL, Off Nha Trang, southeastern Vietnam, collected by H.-C. Ho \& M.Y. Lee, 19 April 2009.

Paratypes: 18 specimens (42.3-60.4 mm SL) collected off Nha Trang, southeastern Vietnam, by H.-C. Ho \& M.-Y. Lee. ASIZP0072364, 6 specimens, 43.1-50.4 mm SL, 19 April 2009. ASIZP0072366, male, 44.4 mm SL, 19 April 2009. ASIZP0072367, male, 49.2 mm SL, 19 April 2009. ASIZP0072368, 10 specimens, 42.3-60.4 mm SL, 23 April 2009.

Diagnosis. Symphurus brachycephalus is distinguished from all congeners by the combination of: a 1-2-2-2-2 ID pattern; 12 caudal-fin rays; $9(3+6)$ abdominal vertebrae; 45-48 total vertebrae; 4 hypurals; 81-87 dorsal-fin rays, 69-74 anal-fin rays, 72-82 longitudinal scale rows, 26-30 transverse scale rows, 15-18 scale rows on head posterior to lower orbit; moderately wide body $(\mathrm{BD}=24.9-27.5 \%$ of $\mathrm{SL})$; short preanal length (PAL $=21.4-25.9 \%$ of SL); relatively short head $(\mathrm{HL}=17.3-20.8 \%$ of $\mathrm{SL})$ with its length usually shorter than its width $(\mathrm{HW} / \mathrm{HL}=$ 1.04-1.19); relatively long postorbital length $(\mathrm{POL}=69.6-74.9 \%$ of $\mathrm{HL})$; upper head lobe usually wider than lower head lobe; dorsal-fin origin at, or slightly posterior to, vertical through posterior margin of upper eye; long predorsal length ( $\mathrm{PDL}=22.4-28.9 \%$ of $\mathrm{HL})$; snout relatively short $(\mathrm{SNL}=13.4-19.4 \%$ of $\mathrm{HL}, \mathrm{SNL} / \mathrm{ED}=1.21-1.71$ ), rounded to obliquely blunt anteriorly; eyes moderate $(\mathrm{ED}=9.5-12.7 \%$ of $\mathrm{HL}$ ); equal in position (anterior margin of upper eye equal to anterior margin of lower eye, or slightly subequal with anterior margin of upper slightly in advance of anterior margin of lower eye); membrane covering both eyes; fleshy ridge well-developed on posterior part of ocular-side lower jaw; also with continuous fleshy membrane connecting anterior nostril to ventral part of lower eye; ocular-side pigmentation uniformly yellow to light brown; blind-side pigmentation uniformly white; both sides of body with obvious dermal spots on bases of anteriormost dorsal- and anal-fin rays; peritoneum reddish, with bluishblack pigmentation on dorsalmost surface.

Description. Symphurus brachycephalus (Fig. 6) is a dwarf species known from 19 specimens, the largest of which measures $60.2 \mathrm{~mm}$ SL. Meristic characters summarized in Tables 2-5. Predominant ID pattern 1-2-2-2-2 (17/19 specimens). Caudal-fin rays 12. Dorsal-fin rays 81-87. Anal-fin rays 69-74. Pelvic-fin rays 4. Total vertebrae 45-48; abdominal vertebrae $9(3+6)$. Hypurals 4 . Longitudinal scale rows $72-82$. Scale rows on head posterior to lower orbit 11-14. Transverse scales 21-26.

Proportions of morphometric features presented in Table 7. Body moderately deep, maximum depth in anterior one-third of body usually at point between anus and fourth anal-fin ray, and with gradual taper posterior to midpoint. Preanal length slightly shorter than body depth. Head moderately short and wide; head width greater than head length $(\mathrm{HW} / \mathrm{HL}=1.04-1.14$, Mean=1.08). Upper head lobe wider than lower head lobe $(\mathrm{UHL} / \mathrm{LHL}=1.05-1.48$, Mean=1.23); much shorter than postorbital length. Lower lobe of ocular-side opercle wider than upper opercular lobe; posterior margin of lower lobe projecting slightly beyond posterior margin of upper opercular lobe. Snout rela- 
tively short, slightly rounded to obliquely blunt anteriorly, its length slightly greater than eye diameter (SNL/ED= 1.21-1.71, Mean=1.44). Dermal papillae present, well developed, on blind-side snout and chin. Ocular-side anterior nostril tubular and short, usually not reaching anterior margin of lower eye when depressed posteriorly. Ocular-side posterior nostril a small, rounded tube located on snout just anterior to interorbital space. Blind-side anterior nostril tubular and moderately long, easily distinguishable from dermal papillae; blind-side posterior nostril a shorter and wider posteriorly directed tube situated posterior to vertical at posterior margin of jaws. Jaws short and slightly arched; upper jaw length much longer than snout length; posterior margin of upper jaw usually extending to point between verticals through anterior margin of lower eye and midpoint of lower eye. Ocular-side lower jaw with welldeveloped fleshy ridge on its posterior half. Cheek depth narrow, slightly shorter than snout length. Eyes moderate ( $\mathrm{ED}=9.5-12.7 \%$ of $\mathrm{HL}$ ), oval, and contiguous; fleshy membrane covering both eyes; eye membrane connected to anterior nostril by fleshy membrane. Eyes unequal with anterior margin of upper eye usually in advance of anterior margin of lower eye. Pupillary operculum absent. Dorsal-fin origin located between verticals through posterior margin of pupil of upper eye and posterior margin of upper eye; predorsal length relatively long. Anteriormost dorsal-fin rays obviously shorter than more posterior fin rays. Scales absent on both sides of dorsal- and anal-fin rays. Pelvic fin moderately long; longest pelvic-fin ray, when extended posteriorly, usually reaching base of fourth to sixth analfin ray. Posteriormost pelvic-fin ray connected to anal fin by delicate membrane. Caudal fin relatively long, base of fin with several (usually less than four) rows of ctenoid scales. Scales on both sides of body numerous, strongly ctenoid.

TABLE 7. Morphometrics for the holotype (ASIZP0072365) and examined specimens of Symphurus brachycephalus. SL in $\mathrm{mm}$; characters $2-15$ in \% of SL; $16-23$ in \% of HL; 24 in \% of BD

\begin{tabular}{|c|c|c|c|c|}
\hline \multirow[t]{2}{*}{ Character } & \multirow[t]{2}{*}{ Holotype } & \multicolumn{3}{|c|}{ Examined Specimens } \\
\hline & & $\mathrm{n}$ & Range & Mean \pm SD \\
\hline 1. SL & 45.7 & 19 & $42.5-60.2$ & $47.54 \pm 3.78$ \\
\hline 2. BD & 26.3 & 19 & $24.9-27.5$ & $25.81 \pm 0.81$ \\
\hline 3. TKL & 81.4 & 19 & $79.4-85.3$ & $82.05 \pm 1.66$ \\
\hline 4. PDL & 4.4 & 19 & $4.4-5.7$ & $4.92 \pm 0.42$ \\
\hline 5. PAL & 22.9 & 19 & $21.4-25.9$ & $23.51 \pm 1.20$ \\
\hline 6. DBL & 95.6 & 19 & $94.3-95.6$ & $95.09 \pm 0.43$ \\
\hline 7. $\mathrm{ABL}$ & 77.1 & 19 & $74.0-78.6$ & $76.58 \pm 1.31$ \\
\hline 8. PL & 8.4 & 16 & $6.9-10.1$ & $8.20 \pm 1.04$ \\
\hline 9. PA & 2.3 & 19 & $2.0-5.5$ & $2.99 \pm 0.80$ \\
\hline 10. CFL & 11.2 & 17 & $10.8-13.3$ & $11.63 \pm 0.54$ \\
\hline 11. HL & 19.3 & 19 & $17.3-20.8$ & $19.60 \pm 0.93$ \\
\hline 12. HW & 23.0 & 19 & $19.5-23.5$ & $21.24 \pm 1.10$ \\
\hline 13. POL & 13.9 & 19 & $12.6-15.5$ & $14.01 \pm 0.73$ \\
\hline 14. UHL & 13.1 & 19 & $10.6-13.1$ & $11.71 \pm 0.76$ \\
\hline 15. LHL & 9.9 & 19 & $8.0-10.9$ & $9.59 \pm 0.80$ \\
\hline 16. PDL & 22.8 & 19 & $22.4-28.9$ & $25.10 \pm 1.87$ \\
\hline 17. POL & 72.1 & 19 & $69.6-74.9$ & $71.56 \pm 1.41$ \\
\hline 18. SNL & 14.7 & 19 & $13.4-19.4$ & $15.54 \pm 1.42$ \\
\hline 19. UJL & 16.7 & 19 & $16.7-21.2$ & $18.68 \pm 1.26$ \\
\hline 20. ED & 12 & 19 & $9.5-12.7$ & $10.85 \pm 0.80$ \\
\hline 21. $\mathrm{CD}$ & 15.4 & 19 & $13.0-18.7$ & $15.15 \pm 1.91$ \\
\hline 22. OPLL & 32.1 & 19 & $23.7-32.1$ & $26.98 \pm 2.57$ \\
\hline 23. OPUL & 19.5 & 19 & $19.5-25.5$ & $22.10 \pm 2.19$ \\
\hline 24. TH & 19.7 & 19 & $15.2-19.7$ & $17.41 \pm 1.27$ \\
\hline 25. HW/HL & 1.19 & 19 & $1.04-1.19$ & $1.08 \pm 0.04$ \\
\hline 26. Pupil/ED & 0.41 & 19 & $0.38-0.61$ & $0.47 \pm 0.07$ \\
\hline
\end{tabular}


Teeth present and recurved slightly inwards on all jaws, but better developed on blind-side jaws. Ocular-side premaxilla and dentary with single row of sharply pointed, well-developed teeth. Blind-side premaxilla with three to four rows of sharp, recurved teeth. Blind-side lower jaw with four to six rows of well-developed teeth.

Pigmentation. Pattern of body pigmentation generally similar for both sexes at all sizes. Ocular-side background pigmentation of body generally light-yellow to light-brown (Fig. 6); body pigmentation above pterygiophore regions of dorsal and anal fins usually the same as background pigmentation on other parts of body; no dark melanophores along vertebral axis in any specimens. Melanophores absent in dermis overlying pterygiophores. External surface of abdominal area usually reddish to light brown. Background pigmentation of ocular side of head generally similar to that on body, except for one dark region formed by cluster of dermal melanophores posterior to eyes. Ocular of side of snout light yellow; obvious dermal spots at bases of anterior dorsal-fin rays and also on isthmus. Outer surface of ocular-side opercle yellow to light-brown, usually with light-red to dark-red pigmentation on opercle, margin of opercle yellow to light-brown, with same background pigmentation as that on body and head. Inner surfaces of ocular-side opercle and isthmus with small, dark brown or blackish dots; ocular-side lips and chin region uniformly yellow to brown, margins of lips pigmented with small black melanophores. Ocular-side anterior nostril light-yellow to brown. Dorsal aspects of eyes and eye sockets light blue with darker spots; pupils bluishblack. Blind side generally white to light yellow; peritoneum reddish, with bluish-black pigmentation only on dorsalmost part. No median longitudinal row of darkly pigmented melanophores along vertebral axis of specimens at all sizes. Outer surface of blind-side opercle white to light yellow similar to that of background pigmentation. Inner surface of blind-side opercle unpigmented. Fin rays of dorsal, anal, and pelvic fins uniformly yellow to brown; basal regions of fin rays and membranes covering fin rays light yellow, with diffuse scattering of yellow to brown chromatophores covering entire fin membrane on both sides of fins. Entire dorsal and anal fins with regularly scattered streaks separating fins into darker and lighter areas. Basal margins of fin rays and associated fin membranes on blind side light yellow to light brown.

Pigmentation of recently preserved specimens (Fig. 6). Similar to that of freshly caught fishes, except reddish pigmentation of ocular-side opercle and peritoneum faded after fixation. Dermal spots at bases of anterior dorsal-fin rays and on isthmus, as well as bluish-black pigmentation at dorsalmost part of peritoneum, similar to that of fresh specimens.

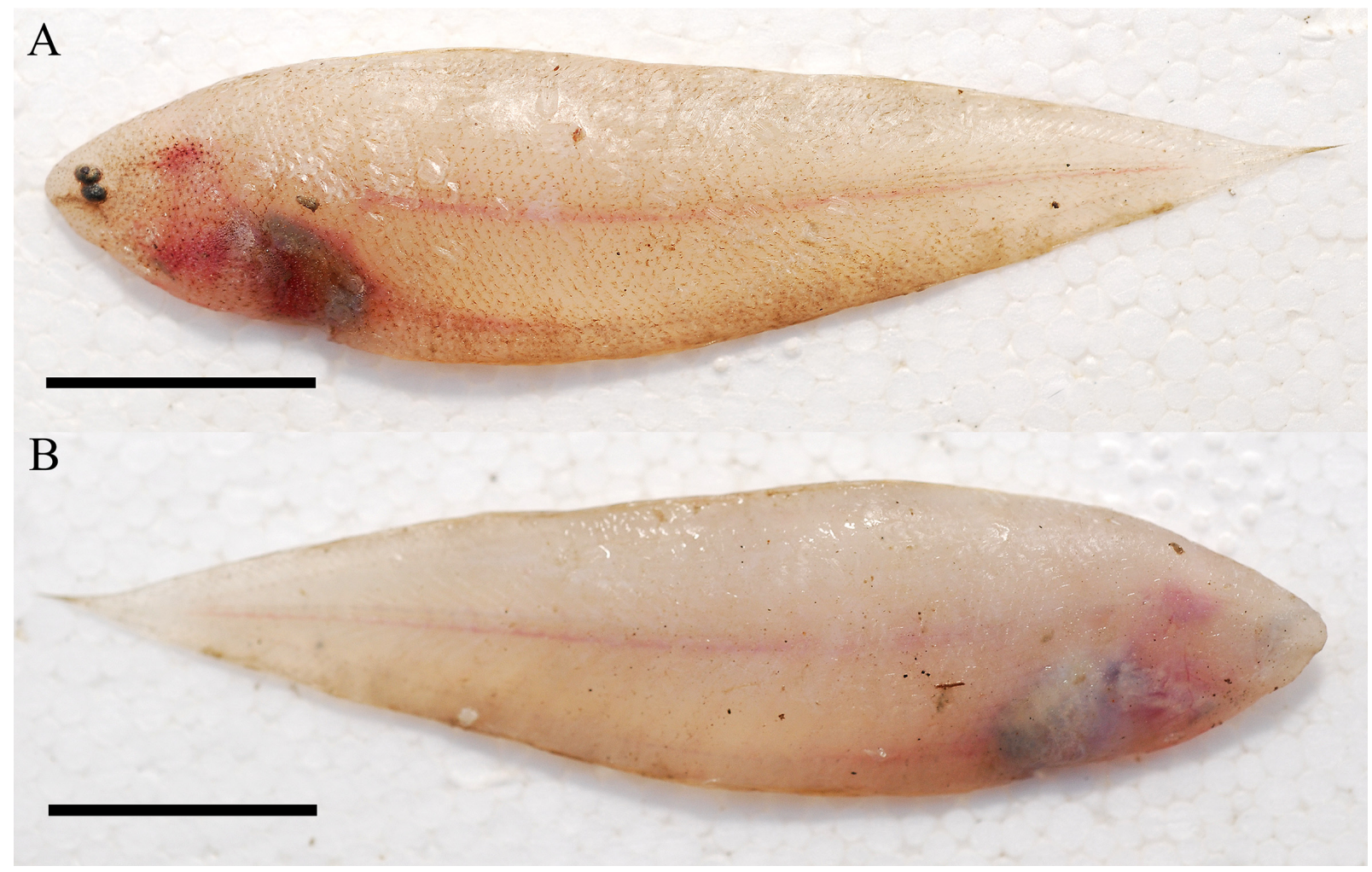

FIGURE 6. Symphurus brachycephalus n. sp., holotype, ASIZP0072365, male, 45.2 mm SL, Off Nha Trang, Southeastern Vietnam. A. Ocular-side pigmentation of freshly caught specimen. B. Blind-side pigmentation of same specimen. Scale equals $10 \mathrm{~mm}$. 
Size and Sexual Maturity. A total of 19 specimens ranging in size from 42.5-60.2 mm SL were available to this study. Males $(n=10,44.4-53.1 \mathrm{~mm} \mathrm{SL})$ attain similar sizes to those of mature females $(n=5,42.5-60.2 \mathrm{~mm}$ $\mathrm{SL})$. Four of the nine females (47.3-49.3 mm SL) are immature with little elongation of the ovaries. Five females (42.5-60.2 mm SL) are mature with elongate ovaries, but none are gravid, and all ovaries are without obvious ova. Voronina et al. (2016) examined 21 specimens (sex not reported) from Vietnam that ranged in size from 47.0 to 60.0 mm SL.

Distribution. Symphurus brachycephalus is known from specimens taken from fish landings at Nha Trang, Vietnam (Fig. 3). In addition to specimens examined in the present study, Munroe \& Marsh (1997) misidentified two specimens as S. microrhynchus that were also collected in Nha Trang Bay that likely are S. brachycephalus. Voronina et al. (2016) examined 21 specimens, likely S. brachycephalus, collected from Nha Trang and Vân Phong Bay, Vietnam.

Based on information provided by the collector (Hans Ho, person. comm.) for specimens examined in the present study, S. brachycephalus were recovered from landings that also contained an assemblage of fish species which generally live at, or about at, depths shallower than $100 \mathrm{~m}$. Based on this observation, we hypothesize that S. brachycephalus is a shallow-water species of tonguefish (i.e., inhabiting depths of approximately $100 \mathrm{~m}$ or so). Further investigation providing more specific details about capture localities, bathymetric distribution, and substrata inhabited by this species are needed.

Etymology. The name brachycephalus, derived from the Greek, brachy meaning short, and cephalus, meaning head, in reference to the relatively shorter head of this species compared with those of similar shallow-water tonguefishes.

Comparisons. Among the high scale count group of species within the S. microrhynchus species complex, $S$. brachycephalus is most similar to S. polylepis $\mathbf{n}$. sp. These two species are the only ones among the high scale count species lacking pepper-dots and dermal melanophores associated with bases of the anterior dorsal- and anal-fin rays. In comparing meristic values between these two species, $S$. brachycephalus has relatively fewer rows of head scales (15-18 vs. $17-19$ in S. polylepis n. sp.), fewer transverse scales (26-30 vs. 32-34 in S. polylepis n. sp.), and much lower counts of longitudinal scales (72-82 vs. 88-94) compared with those of S. polylepis $\mathbf{n}$. sp. In its morphometric features, S. brachycephalus differs from S. polylepis n. sp. in its head shape, which is relatively shorter $(\mathrm{HL}=17.3-20.8 \%$ of SL vs. $21.9-23.8 \%$ of SL in S. polylepis n. sp.) and narrower (HW=19.5-23.5\% of SL vs. $23.1-25.8 \%$ of SL in S. polylepis n. sp.), with a shorter postorbital length ( $\mathrm{POL}=12.6-15.2 \%$ of SL vs. $15.7-16.6 \%$ of SL in S. polylepis n. sp.). Also, the lower head lobe (LHL $=8.0-10.9 \%$ of SL vs. $10.7-12.2 \%$ of SL in S. polylepis n. sp.) is smaller, and the predorsal length is shorter ( $\mathrm{PDL}=4.4-5.7 \%$ of SL vs. $5.7-6.7 \%$ of SL in S. polylepis $\mathbf{n}$. sp.). Symphurus brachycephalus usually has a mostly reddish peritoneum, with bluish-black pigmentation present only on the dorsalmost part (vs. peritoneum entirely bluish-black in S. polylepis n. sp.), and its ocular-side pigmentation is uniformly light brown without crossbands (vs. ocular side usually with several incomplete or complete crossbands in S. polylepis n. sp.).

Meristic and morphometric characters of $S$. brachycephalus partially or totally overlap those of S. robustus $\mathbf{n}$. sp., S. leptosomus n. sp., and $S$. hongae n. sp., the other species in the $S$. microrhynchus species group possessing high scale counts. However, $S$. brachycephalus is easily distinguished from these others by differences in pigmentation. Symphurus brachycephalus lacks pepper-dots and dermal melanophores at both sides of the bases of dorsaland anal-fin rays (vs. well-developed pepper-dots and dermal melanophores at bases of dorsal- and anal-fin rays on both sides or only on the blind side of these fin rays in these other three species). And, S. brachycephalus has a reddish peritoneum (vs. bluish-black peritoneum in these three other species).

Although sharing some similarities with the group of three species (S. microrhynchus, S. holothuriae and $S$. longirostris) featuring low scale counts, S. brachycephalus differs from these three species in a number of features. Overall, S. brachycephalus has relatively higher counts of head scales (15-18 vs. 15 in S. microrhynchus, 16 in $S$. holothuriae, and 11-14 in S. longirostris), relatively more transverse scales (26-30 vs. 25 in S. microrhynchus, 25 in S. holothuriae, and 21-26 in S. longirostris), and more longitudinal scales (72-82 vs. 64 in S. microrhynchus, 60 in S. holothuriae, and 56-66 in S. longirostris). In morphometric features, head width is larger than head length in $S$. brachycephalus compared with that for $S$. microrhynchus, S. holothuriae and $S$. longirostris $(\mathrm{HW} / \mathrm{HL}=1.04-1.19$ in S. brachycephalus vs. HW/HL $=0.94$ in $S$. microrhynchus, $\mathrm{HW} / \mathrm{HL}=0.97$ in $S$. holothuriae, and $\mathrm{HW} / \mathrm{HL}=0.92-0.99$ in S. longirostris). Other differences between S. brachycephalus and these species were highlighted in the Comparisons sections in the species accounts above for S. microrhynchus, S. holothuriae and S. longirostris, respectively. 
Symphurus brachycephalus has the same ID pattern (1-2-2-2-2) and similar counts for dorsal-fin rays (87 vs. $86-92)$ and anal-fin rays (73 vs. $73-80$ ) as those found in $S$. monostigmus and S. leucochilus. However, $S$. brachycephalus is readily differentiated from both $S$. monostigmus and S. leucochilus in having a fleshy ridge on the posterior half of the ocular-side lower jaw (vs. no fleshy ridge on ocular-side lower jaw in these others), and it has a membranous connection between the ocular-side anterior nostril and lower eye (vs. no fleshy membranous connection between anterior nostril and eye in these other species). Symphurus brachycephalus has fewer transverse scales (26-30 vs. 32-38) than is found in either of these other species.

Symphurus brachycephalus differs from S. leucochilus in that the dorsal-fin origin is usually located at, or posterior to, the vertical line through the posterior margin of the upper eye (vs. dorsal-fin origin at vertical located at anterior margin of upper eye in S. leucochilus). The eyes of S. brachycephalus are contiguous and covered by a fleshy membrane (vs. upper and lower eye usually separated by narrow interorbital space, and both eyes not covered by fleshy membrane in S. leucochilus).

Symphurus brachycephalus has comparatively fewer fin rays (dorsal-fin rays 81-87 vs. 89-92 in S. leucochilus; anal-fin rays 69-74 vs. 76-80), and fewer total vertebrae (45-48 vs. 49-51) than that found in S. leucochilus.

Symphurus brachycephalus has fewer longitudinal (72-82) scales than is found in (92) in S. monostigmus. Symphurus brachycephalus also differs further from S. monostigmus in having 12 (vs. 14) caudal-fin rays and 4 hypurals (vs. 5 hypurals), and in lacking the pigment spot on the abdomen that features so prominently in S. monostigmus. Symphurus brachycephalus also has a narrower head $(\mathrm{HW} / \mathrm{HL}=1.04-1.19)$ versus that of $S$. monostigmus $(\mathrm{HW} / \mathrm{HL}=1.38-1.42)$.

\section{Symphurus hongae n. sp.}

(English name: Hong's tonguefish)

(Figs. 1, 3, 7-8, 14; Tables 1-5, 8, 13)

Symphurus cf. microrhynchus (TW). Lee et al. 2014: 576 (tentatively identified; genetic information used to resolve another taxonomic issue). Lee et al. 2017: 72 (tentatively identified; genetic information used to resolve another taxonomic issue).

Holotype: ASIZP0067658, male, 53.3 mm SL, Off Nangfang-Ao, Northeastern Taiwan, M.-Y. Lee, 8 Mar 2007.

Paratypes: 35 (22 examined in detail) specimens (39.6-57.0 mm SL): ASIZP0061556, mature female, 56.8 mm SL, off Da-Shi, Northeastern Taiwan, T.-H. Wu, 7 Dec 2000. ASIZP0072360, 28 (15 exam.), males, 39.6$49.5 \mathrm{~mm}$ SL, off Dong-Gang, Southwestern Taiwan, M.-Y. Lee \& T. A. Munroe, 4 Jul 2007. ASIZP0072361, immature female, 42.9 mm SL, Off Dong-Gang, Southwestern Taiwan, M.-Y. Lee \& T. A. Munroe, 4 Jul 2007. ASIZP0072362, mature female, $45.1 \mathrm{~mm}$ SL, off Dong-Gang, Southwestern Taiwan, M.-Y. Lee \& T. A. Munroe, 4 Jul 2007. ASIZP0072363, male, 44.6 mm SL, off Dong-Gang, Southwestern Taiwan, M.-Y. Lee \& T. A. Munroe, 4 Jul 2007. ASIZP0072370, male, 57.0 mm SL, off Da-Shi, Northeastern Taiwan, M.-Y. Lee, 30 Dec 2009. ASIZP0072371, mature female, 50.6 mm SL, off Da-Shi, Northeastern Taiwan, M.-Y. Lee, 30 Dec 2009. NMMB-P 3561, mature female, 51.8 mm SL, off Kao-Hsiung, Southwestern Taiwan, 100 m, J.-H. Lee, 2 Aug 2001.

Diagnosis. Symphurus hongae n. sp. is distinguished from all congeners by the combination of: a 1-2-2-2-2 ID pattern; 12 caudal-fin rays; $9(3+6)$ abdominal vertebrae; 46-49 total vertebrae; 4 hypurals; 85-90 dorsal-fin rays; 71-78 anal-fin rays; 72-81 longitudinal scale rows; $28-31$ transverse scale rows; $15-17$ scale rows on head posterior to lower orbit; relatively wide body $(\mathrm{BD}=27.2-30.2 \%$ of $\mathrm{SL})$; PAL slightly long (22.5-27.6\% of SL); short head $(\mathrm{HL}=20.4-22.7 \%$ of SL), with its length usually shorter than its width $(\mathrm{HW} / \mathrm{HL}=1.07-1.16)$; relatively long postorbital length $(\mathrm{POL}=71.0-74.8 \%$ of $\mathrm{HL})$; upper head lobe usually larger than lower head lobe; dorsal-fin origin at vertical through posterior margin of pupil of upper eye; short predorsal length ( $\mathrm{PDL}=16.1-21.7 \%$ of $\mathrm{HL}$ ); snout short ( $\mathrm{SNL}=11.7-15.5 \%$ of $\mathrm{HL}$; $\mathrm{SNL} / \mathrm{ED}=0.87-1.39$ ), rounded to obliquely blunt anteriorly; anterior margin of upper eye usually in advance of anterior margin of lower eye; fleshy ridge well developed on posterior part of ocular-side lower jaw; with membrane covering both eyes; with continuous fleshy flap between ocular-side anterior nostril and lower part of eye; ocular-side pigmentation uniformly yellow to light brown, with dermal melanophores present at bases of anteriormost dorsal-fin rays ; blind-side pigmentation uniformly white, usually with pepper-dots and dermal melanophores at bases of dorsal- and anal-fin rays; both sides of bases of anteriormost dorsal- and analfin rays with obvious dermal spots; peritoneum bluish-black.

Description. Symphurus hongae (Fig. 7) is a dwarf species known from 36 specimens, the largest of which is 
$57.0 \mathrm{~mm}$ SL. Meristic characters summarized in Tables 2-5. Predominant ID pattern 1-2-2-2-2 (21/23 specimens). Caudal-fin rays 12 . Dorsal-fin rays 85-90. Anal-fin rays 71-78. Pelvic-fin rays 4. Total vertebrae 46-49; abdominal vertebrae $9(3+6)$. Hypurals 4. Longitudinal scale rows $72-81$. Scale rows on head posterior to lower orbit 15-17. Transverse scale rows $28-31$.

Proportions of morphometric features presented in Table 8. Body moderately deep; maximum depth in anterior one-third of body usually at point equal with vertical between anus and seventh anal-fin ray; body with gradual taper posterior to midpoint. Preanal length shorter than body depth. Head moderately short and wide; head width longer than head length $(\mathrm{HW} / \mathrm{HL}=1.07-1.16$, Mean=1.12). Upper head lobe wider than lower head lobe $(\mathrm{UHL} / \mathrm{LHL}=$ 1.04-1.48, Mean=1.22); slightly shorter than postorbital length. Lower lobe of ocular-side opercle wider than upper opercular lobe; posterior margin of lower lobe projecting slightly beyond posterior margin of upper opercular lobe. Snout relatively short, slightly rounded to obliquely blunt anteriorly; snout length usually equal to, or slightly greater than, eye diameter $(\mathrm{SNL} / \mathrm{ED}=0.87-1.39$, Mean=1.15). Well developed dermal papillae present on blind side of snout and chin. Ocular-side anterior nostril tubular and short, usually not reaching anterior margin of lower eye when depressed posteriorly. Ocular-side posterior nostril a small, rounded tube located on snout just anterior to interorbital space. Blind-side anterior nostril tubular and relatively long, easily distinguishable from dermal papillae; blind-side posterior nostril a shorter, wider, posteriorly directed tube situated posterior to vertical at posterior margin of jaws. Jaws short and slightly arched; upper jaw length slightly longer than snout length; posterior margin of upper jaw usually extending to point between verticals through anterior margin of lower eye and anterior margin of pupil of lower eye. Ocular-side lower jaw with well-developed fleshy ridge on its posterior portion. Cheek depth relatively wide; usually equal to, or slightly longer than, snout length. Eyes moderately large (ED $=10.9-14.0 \%$ of HL), oval, contiguous; membrane covering both eyes; eye membrane connected with anterior nostril by fleshy flap of skin. Eyes usually unequal in position, with anterior margin of upper eye greatly in advance of anterior margin of lower eye. Pupillary operculum absent. Dorsal-fin origin located at point between verticals through posterior margin of upper eye and vertical slightly posterior to eye; predorsal length relatively short. Anteriormost dorsal-fin rays obviously shorter than more posterior fin rays. Scales absent on both sides of dorsal- and anal-fin rays. Pelvic fin moderately long; longest pelvic-fin ray, when extended posteriorly, usually reaching base of third to fifth analfin ray. Posteriormost pelvic-fin ray connected to anal fin by delicate membrane. Caudal fin relatively long, with several rows of ctenoid scales on its base. Scales on both sides of body numerous, strongly ctenoid.

Teeth present and recurved slightly inwards on all jaws, but better developed on blind-side jaws. Ocular-side premaxilla and dentary with single row of sharply pointed, well-developed teeth. Blind-side premaxilla with two to three rows of sharp, recurved teeth. Blind-side lower jaw with three to six rows of well-developed teeth.

Pigmentation of freshly collected specimens. Pattern of body pigmentation generally similar for both sexes at all sizes (Fig. 7). Background body pigmentation of ocular side generally light-yellow to light-brown, sometimes also with several complete or incomplete crossbands; ocular surface darker along regions overlying pterygiophores of dorsal and anal fins. Melanophores in dermis also present in darker region of pterygiophores. External surface of abdominal area usually bluish-black. Background pigmentation of ocular side of head generally similar to that on body; one dark region behind eyes formed by concentration of dermal melanophores. Ocular side of snout light yellow, obvious dermal spots at bases of anterior dorsal-fin rays and on the isthmus. Outer surface of ocular-side opercle yellow to brown, with same background pigmentation as that on body and head; margin of opercle darker brown and easily distinguishable from bluish regions of opercle. Inner surface of ocular-side opercle and isthmus with small dark brown or blackish dots; ocular-side lips and chin region uniformly yellow to brown; margins of lips pigmented with small black melanophores. Ocular-side anterior nostril light-yellow to brown. Upper aspects of eyes and eye sockets light blue with darker spots; pupils bluish-black. Blind side generally white to light-yellow with bluish-black peritoneum showing through abdominal wall; pepper-dots overlying pterygiophore regions of dorsal and anal fins; some specimens with median longitudinal row of darkly pigmented melanophores along vertebral axis. Well-developed dermal melanophores also forming single longitudinal row along bases of dorsal and anal fins. Outer surface of blind-side opercle white to light-yellow, similar to that of background pigmentation. Inner surface of blind-side opercle unpigmented. Fin rays of dorsal, anal, and pelvic fins uniformly yellow to brown; basal regions of fin rays and membranes between fin rays light-yellow, with diffuse scattering of yellow to brown chromatophores covering entire fin membranes on both sides of fins. Entire dorsal and anal fins with regular pattern of streaks separating fins into darker and lighter areas. Basal margins of fin rays and associated fin membranes on blind side light-yellow to light-brown. 

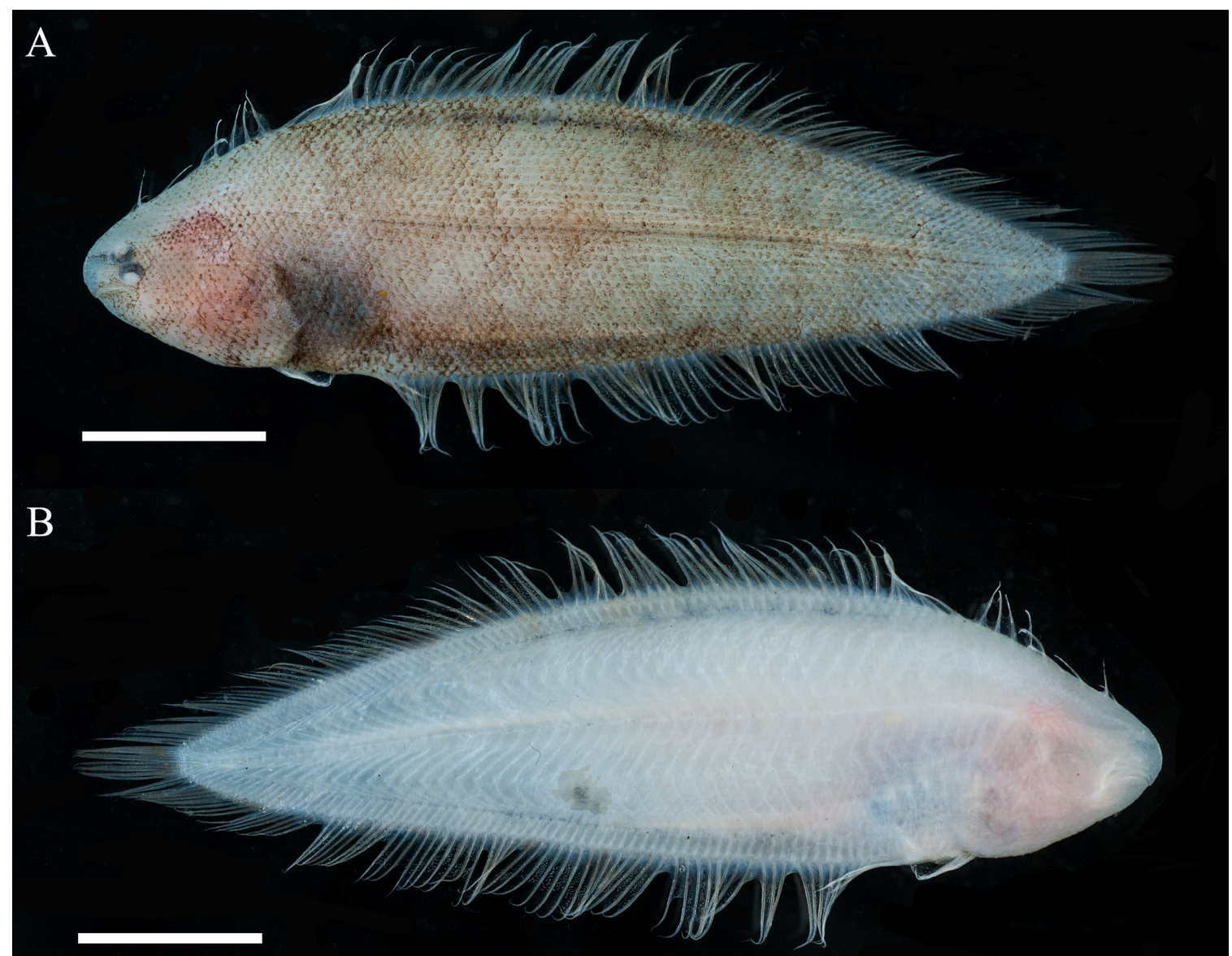

C

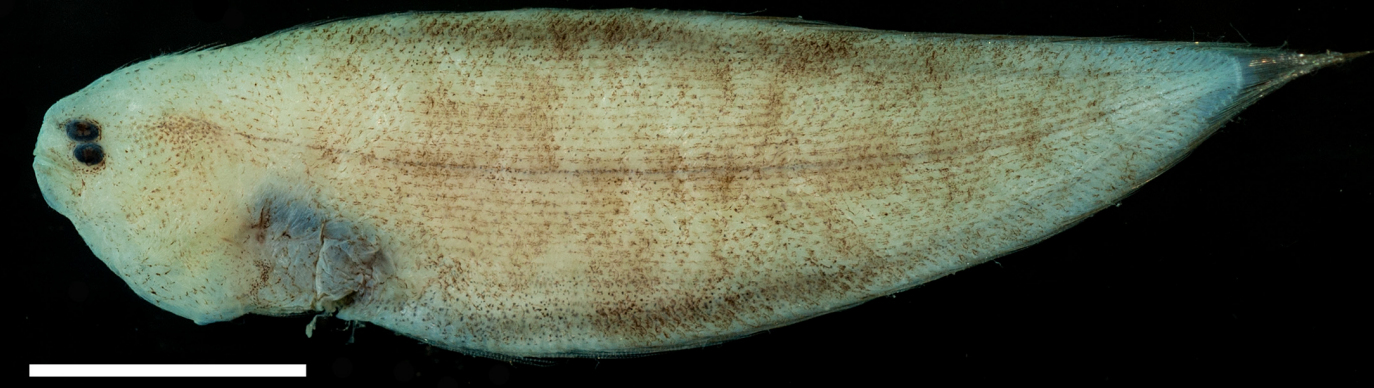

$\mathrm{D}$

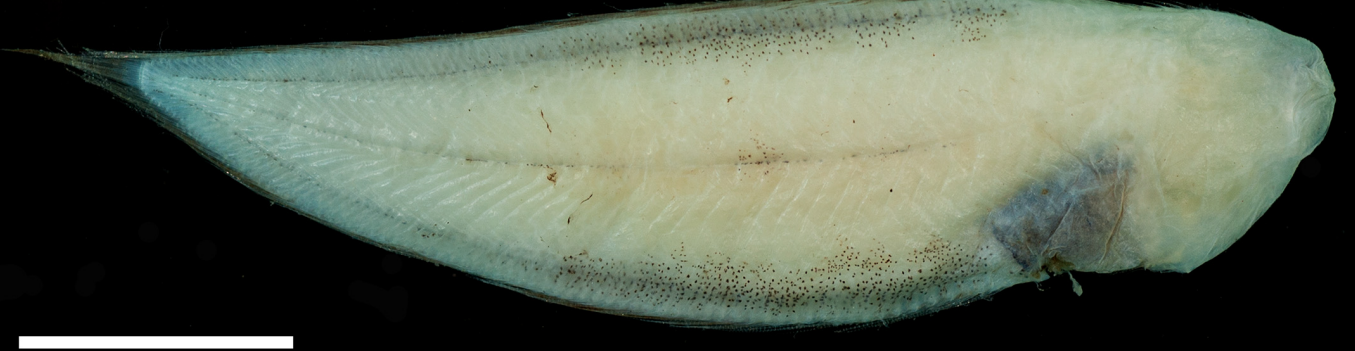

FIGURE 7. Symphurus hongae n. sp., holotype, ASIZP0067658, male, $53.3 \mathrm{~mm}$ SL, Off Nangfang-Ao, North eastern Taiwan. A. Ocular-side pigmentation of holotype. B. Blind-side pigmentation of holotype. C. Symphurus hongae n. sp., paratype, ASIZP0072360, male, $43.1 \mathrm{~mm}$ SL, Off Nangfang-Ao, Northeastern Taiwan. D. Blind-side pigmentation of paratype. Scale equals $10 \mathrm{~mm}$. 
TABLE 8. Morphometrics for the holotype (ASIZP0067658) and examined specimens of Symphurus hongae. SL in mm; characters $2-15$ in $\%$ of SL; $16-23$ in $\%$ of HL; 24 in $\%$ of BD.

\begin{tabular}{|c|c|c|c|c|}
\hline \multirow[t]{2}{*}{ Character } & \multirow[t]{2}{*}{ Holotype } & \multicolumn{3}{|c|}{ Examined Specimens } \\
\hline & & $\mathrm{n}$ & Range & Mean \pm SD \\
\hline 1. SL & 53.3 & 23 & $39.6-57.0$ & $45.30 \pm 5.42$ \\
\hline 2. BD & 29.3 & 23 & $27.2-30.2$ & $28.30 \pm 0.88$ \\
\hline 3. TKL & 80.2 & 23 & $79.3-85.4$ & $82.06 \pm 1.48$ \\
\hline 4. PDL & 3.5 & 23 & $3.3-4.6$ & $4.01 \pm 0.36$ \\
\hline 5. PAL & 23.8 & 23 & $22.5-27.6$ & $24.86 \pm 1.41$ \\
\hline 6. DBL & 96.5 & 23 & $95.4-96.7$ & $96.00 \pm 0.39$ \\
\hline 7. $\mathrm{ABL}$ & 76.2 & 23 & $72.4-77.5$ & $75.16 \pm 1.41$ \\
\hline 8. PL & 9.1 & 18 & 6.9-9.7 & $8.84 \pm 0.78$ \\
\hline 9. PA & 2.5 & 22 & $1.8-5.8$ & $3.99 \pm 1.06$ \\
\hline 10. CFL & 12.1 & 16 & $11.7-14.0$ & $12.60 \pm 0.71$ \\
\hline 11. HL & 21.7 & 23 & $20.4-22.7$ & $21.51 \pm 0.71$ \\
\hline 12. HW & 25.2 & 23 & $22.7-25.6$ & $24.04 \pm 0.83$ \\
\hline 13. POL & 15.7 & 23 & $14.5-16.6$ & $15.61 \pm 0.59$ \\
\hline 14. UHL & 13.8 & 23 & $11.8-14.2$ & $13.29 \pm 0.66$ \\
\hline 15. LHL & 11.9 & 23 & $9.3-12.4$ & $10.87 \pm 0.82$ \\
\hline 16. PDL & 16.3 & 23 & $16.1-21.7$ & $18.60 \pm 1.45$ \\
\hline 17. POL & 72.3 & 23 & $71.0-74.8$ & $72.58 \pm 1.15$ \\
\hline 18. SNL & 14.8 & 23 & $11.7-15.5$ & $14.05 \pm 1.15$ \\
\hline 19. UJL & 18.6 & 23 & $17.9-20.4$ & $19.04 \pm 0.59$ \\
\hline 20. ED & 11.9 & 23 & $10.9-14.0$ & $12.31 \pm 0.87$ \\
\hline 21. CD & 18.6 & 23 & $13.9-21.0$ & $16.53 \pm 1.93$ \\
\hline 22. OPLL & 29.4 & 23 & $23.3-29.4$ & $26.39 \pm 2.03$ \\
\hline 23. OPUL & 27.7 & 23 & $19.2-27.7$ & $23.21 \pm 2.30$ \\
\hline 24. TH & 18.6 & 23 & $15.7-19.6$ & $18.12 \pm 1.13$ \\
\hline 25. HW/HL & 1.16 & 23 & $1.07-1.16$ & $1.12 \pm 0.03$ \\
\hline 26. Pupil/ED & 0.68 & 23 & $0.45-0.68$ & $0.52 \pm 0.05$ \\
\hline
\end{tabular}

Pigmentation of recently preserved specimens. Similar to that of freshly caught fishes. In specimens preserved for decades, body pigmentation usually faded, except dermal spots at bases of anterior dorsal-fin rays, spots on isthmus, some pepper-dots on body, and bluish-black peritoneum, still clearly visible.

Size and sexual maturity. Twenty-three specimens range in size from 39.4-57.0 mm SL. Females are $42.9 \mathrm{~mm}$ $\mathrm{SL}$ to $56.8 \mathrm{~mm}$ in SL. Males ( $\mathrm{n}=18,39.4-57.0 \mathrm{~mm} \mathrm{SL})$ attain similar sizes to those of females. One of five females (42.9 mm SL) is immature showing little elongation of the ovaries, while two others (45.1-50.6 mm SL) are nongravid, mature females with elongate ovaries, and two others $(51.8,56.8 \mathrm{~mm} \mathrm{SL})$ are gravid females.

Distribution. Symphurus hongae is known mostly from specimens taken from the fish landings at Da-Shi, Dong-Gang, and Nanfang-Ao, Taiwan (Fig. 3). Specimens included in the present study were found in landings also containing an assemblage of fish species that generally live at or about depths shallower than $100 \mathrm{~m}$. Based on this information, the authors suggest that $S$. hongae is a shallow-water species of tonguefish. More accurate information about localities, bathymetric distribution and substrata inhabited is needed for this species.

Etymology. The name hongae is in memory of Y.-S. Hong, mother of M.-Y. Lee, who died tragically in an automobile accident while this study was in progress, in recognition of her financial and moral support of his (M.-Y.) research.

Remarks. One additional sequence (MF415269) isolated from an ichthyoplankton assemblage and uploaded to Genbank by D. Huang and X. Zhang from China, was identified as Symphurus microrhynchus. After updating the molecular analysis into the data set of this study, that sequence grouped with those of S. hongae. This finding 
presents the possibility of extending the distribution of $S$. hongae to southern China. However, the locality information of this sequence is mentioned only as the South China Sea. Evidence to support the distribution of this species in Chinese waters still needs robust (i.e., better documented) data, and especially saving preserved specimens for confirmation of their identity.

Comparisons. Symphurus hongae is a member of the high scale count species group of the S. microrhynchus species complex. Among the five members of this group, S. hongae is most similar to $S$. robustus $\mathbf{n}$. sp. in that both have similar meristic and morphometric characters. In meristic features, $S$. hongae differs from $S$. robustus $\mathbf{n}$. sp. in having relatively lower scale counts, including counts for head scales (15-17 vs. 16-18 in S. robustus $\mathbf{n}$. sp.), transverse scales (28-31 vs. 31-34 in S. robustus n. sp.), and longitudinal scales (72-81 vs. 78-88 in S. robustus $\mathbf{n}$. sp.). Among morphometric features, generally, the sizes of several morphological features of $S$. hongae are slightly smaller than are those for corresponding features in S. robustus n. sp. (Fig. 8). Maximum size of specimens of $S$. hongae is $57.0 \mathrm{~mm}$ SL vs. $67.5 \mathrm{~mm}$ SL in S. robustus $\mathbf{n}$. sp. Besides differences in maximum size, $S$. hongae can be differentiated from $S$. robustus $\mathbf{n}$. sp. in having a thinner body (TH=15.7-19.6\% of BD vs. $22.1-30.0 \%$ of BD in $S$. robustus n. sp.), a relatively shorter upper jaw (UJL=17.9-20.4\% vs. $21.1-24.4 \%$ of HL), slightly shorter snout ( $\mathrm{SNL}=11.7-16.2 \%$ vs. $16.8-21.2 \%$ of HL in $S$. robustus $\mathbf{n}$. sp.), and relatively larger eye (ED=10.9-14.0\% of HL vs. $9.6-12.0 \%$ in $S$. robustus $\mathbf{n}$. sp.), with a larger pupil (pupil/ED=0.45-0.68 vs. $0.35-0.46$ in $S$. robustus $\mathbf{n}$. sp.). Snout length relative to eye diameter is slightly shorter in $S$. hongae compared with that of $S$. robustus $\mathbf{n}$. sp. ( $\mathrm{SNL} / \mathrm{ED}=0.86-1.39$ vs. SNL/ED $1.55-2.00$ in S. robustus n. sp.), and the head is relatively longer in S. hongae ( $\mathrm{HL}=20.4-22.7 \%$ of SL vs. $19.1-21.8 \%$ in $S$. robustus $\mathbf{n}$. sp.), as is the postorbital length (POL $=71.0-74.8 \%$ of HL in S. hongae vs. $65.8-70.2 \%$ of HL in S. robustus n. sp.), the body is relatively longer (TKL $=22.5-27.6 \%$ of SL vs. $21.6-24.7 \%$ in S. robustus $\mathbf{n}$. sp.) and deeper (BD= $27.2-30.2 \%$ of $\mathrm{SL}$ vs. $25.5-28.3 \%$ in S. robustus $\mathbf{n}$. sp.), and the head is slightly wider ( $\mathrm{HW}=22.7-25.6 \%$ of SL vs. $21.0-24.4 \%$ in S. robustus $\mathbf{n}$. $\mathbf{s p}$.) with a relatively shorter predorsal length ( $\mathrm{PDL}=16.1-21.7 \%$ of HL vs. $21.6-28.0 \% \mathrm{HL}$ in $S$. robustus $\mathbf{n} . \mathbf{s p}$.). To more clearly reveal differences between these species, various combinations of morphometric characters useful in differentiating these two species were plotted (Fig. 8).

In comparing qualitative and pigmentation features of these species, S. hongae usually features dermal spots at bases of the anteriormost ocular-side dorsal- and anal-fin rays (vs. dermal spots at ocular-side bases of the anteriormost dorsal- and anal-fin rays usually lacking in S. robustus n. sp.). In S. hongae, the upper jaw usually extends posteriorly to a point between verticals at the anterior margin of the pupil and middle of the lower eye, whereas in $S$. robustus $\mathbf{n}$. sp., the lower jaw usually extends further to the vertical at the posterior margin of the pupil of the lower eye. The eyes of $S$. hongae have a different shape (oval or slightly elongate vs. round) and are positioned differently (S. hongae with anterior margin of upper eye greatly in advance of that of lower eye vs. anterior margins of both eyes usually equal in position in S. robustus n. sp.).

Symphurus hongae is also similar to S. leptosomus n. sp., in that both species have pepper-dots on the bases of the dorsal and anal fins. In comparing meristic features between these two species, $S$. hongae has lower counts of head scales (15-17 vs. 20 in S. leptosomus $\mathbf{n}$. sp.) and fewer transverse scales (28-31 vs. 37 in S. leptosomus $\mathbf{n}$. sp.). In its morphometric features, $S$. hongae differs from $S$. leptosomus $\mathbf{n}$. sp. in having a much wider body $(\mathrm{BD}=$ $27.2-30.2 \%$ of SL vs. $24.6 \%$ of SL in S. leptosomus $\mathbf{n}$. sp.), in having the preanal length shorter than body depth (PAL/BD $=0.79-0.98$ vs. 1.08 in $S$. leptosomus $\mathbf{n}$. sp.), and by its relatively shorter head $(\mathrm{HL}=20.4-22.7 \%$ of SL vs. $23.9 \%$ of SL in S. leptosomus n. sp.). When comparing pigmentation of these two species, $S$. hongae presents a uniformly light-brown background pigmentation on the ocular side (vs. ocular side dark-brown and covered with irregular speckles and blotches in S. leptosomus n. sp.).

In most meristic and morphometric characters, counts and measurements for $S$. hongae partially or fully overlap those of S. polylepis n. sp. Despite these similarities, S. hongae is easily distinguished from S. polylepis $\mathbf{n}$. sp. in of its pigmentation. Symphurus hongae has well-developed pepper-dots and dermal melanophores on the dorsal- and anal-fin bases (vs. lacking pepper-dots and dermal melanophores lacking on the dorsal- and anal-fin bases in $S$. polylepis n. sp.). In meristic features, S. hongae also differs from S. polylepis n. sp. in having much lower counts of longitudinal scales (73-81 vs. 88-94 in S. polylepis n. sp.).

Among species of shallow-water tonguefishes from Indo-Pacific waters, S. hongae is also similar to S. brachycephalus. Differences between S. hongae and S. brachycephalus were highlighted above in the Comparisons section of the species account for $S$. brachycephalus.

Differences between $S$. hongae and members of the low scale count species group (S. holothuriae, S. longiro- 
stris, and S. microrhynchus) appear in the Comparisons sections in the species accounts for those species, respectively.

A

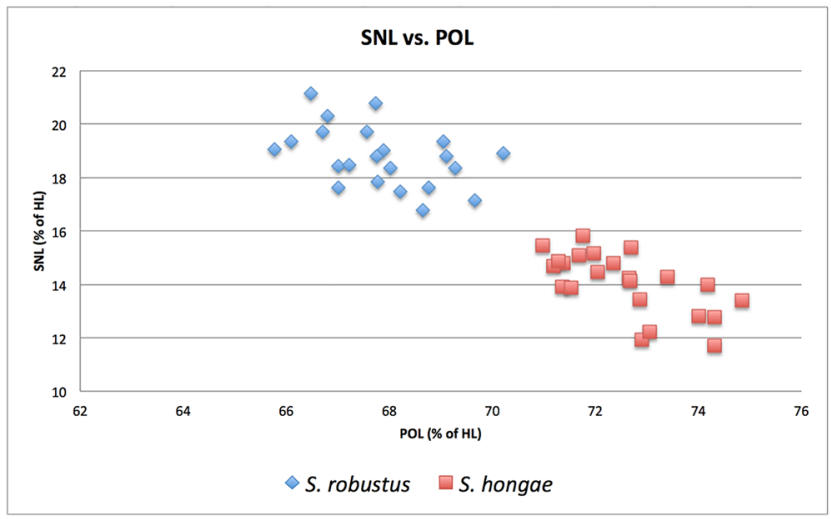

$\mathrm{C}$

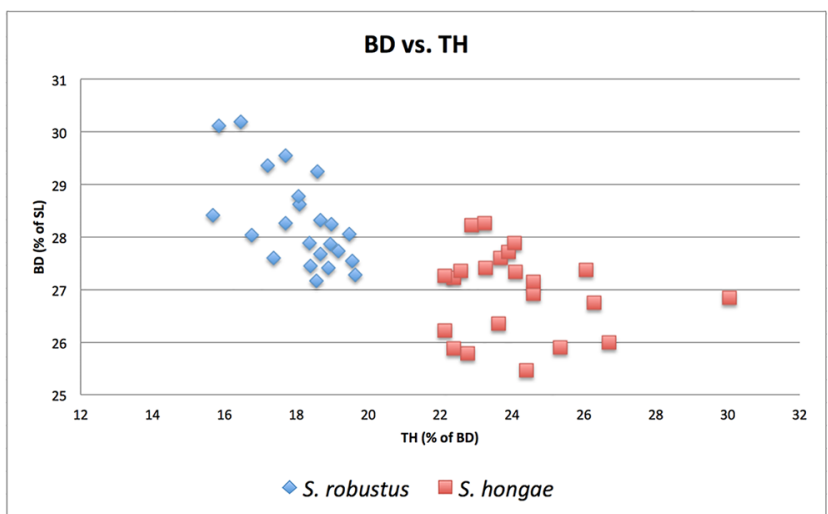

B

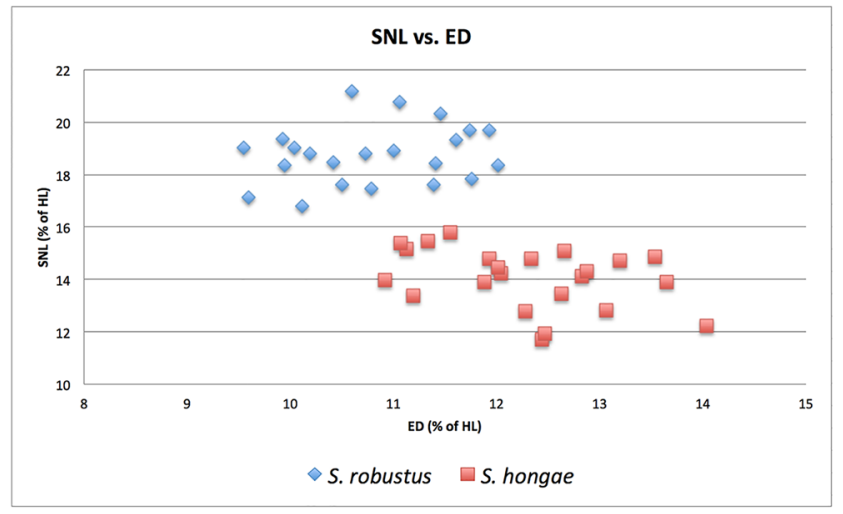

$\mathrm{D}$

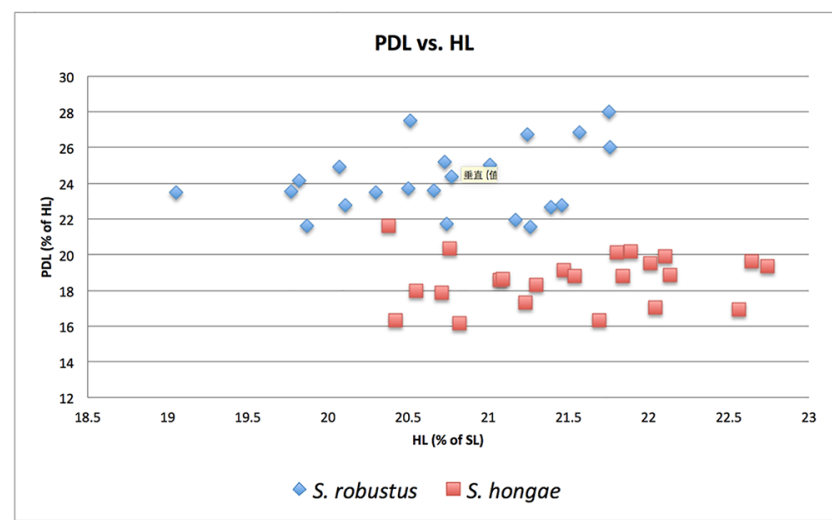

FIGURE 8. Comparison of selected diagnostic features for Symphurus hongae and S. robustus. Data for these two species are presented for individuals. A. Snout length vs. Postorbital length (both as \% of HL). B. Snout length vs. Length of eye diameter (both as \% of HL). C. Body depth (as \% of SL) vs. Body thickness (as \% of BD). D. Predorsal length (as \% of HL) vs. Head length (as \% of SL).

Symphurus hongae has the same ID pattern (1-2-2-2-2) and overlapping counts for dorsal-fin rays (85-90 vs. 86-92), anal-fin rays (71-78 vs. 73-80), and total vertebrae (48 vs. 48-51) as those found in S. monostigmus and S. leucochilus. However, S. hongae is readily differentiated from both S. monostigmus and S. leucochilus in having a membranous connection between the ocular-side anterior nostril and the lower eye, and it also has a fleshy ridge present on the ocular-side lower jaw (vs. both features absent in these other species). Additionally, $S$. hongae has fewer longitudinal scales (72-81) and fewer transverse scale rows (28-31) than is found in these other species (vs. 75-92 longitudinal and 32-38 transverse scales, respectively). Symphurus hongae differs further from S. monostigmus in having 12 (vs. 14) caudal-fin rays and 4 hypurals (vs. 5 hypurals), in lacking the pigment spot on the abdomen that features so prominently in $S$. monostigmus, and $S$. hongae has a narrower head $(\mathrm{HW} / \mathrm{HL}=1.07-1.16)$ compared with that of S. monostigmus (HW/HL=1.38-1.42).

\section{Symphurus leptosomus n. sp.}

(English name: Slender tonguefish)

(Figs. 3, 9; Tables 1-5, 9)

Symphurus microrhynchus (not Weber): Munroe \& Marsh, 1997: 191 (tentatively identified as S. microrhynchus)

Holotype: USNM 379566, male, 23.6 mm SL, rotenone, Philippines, $13^{\circ} 13.25^{`} \mathrm{~N}, 120^{\circ} 33.56^{\prime} \mathrm{E}, 15 \mathrm{~m}$, Min Team \& M. Santos, 3 Jun 2000. 


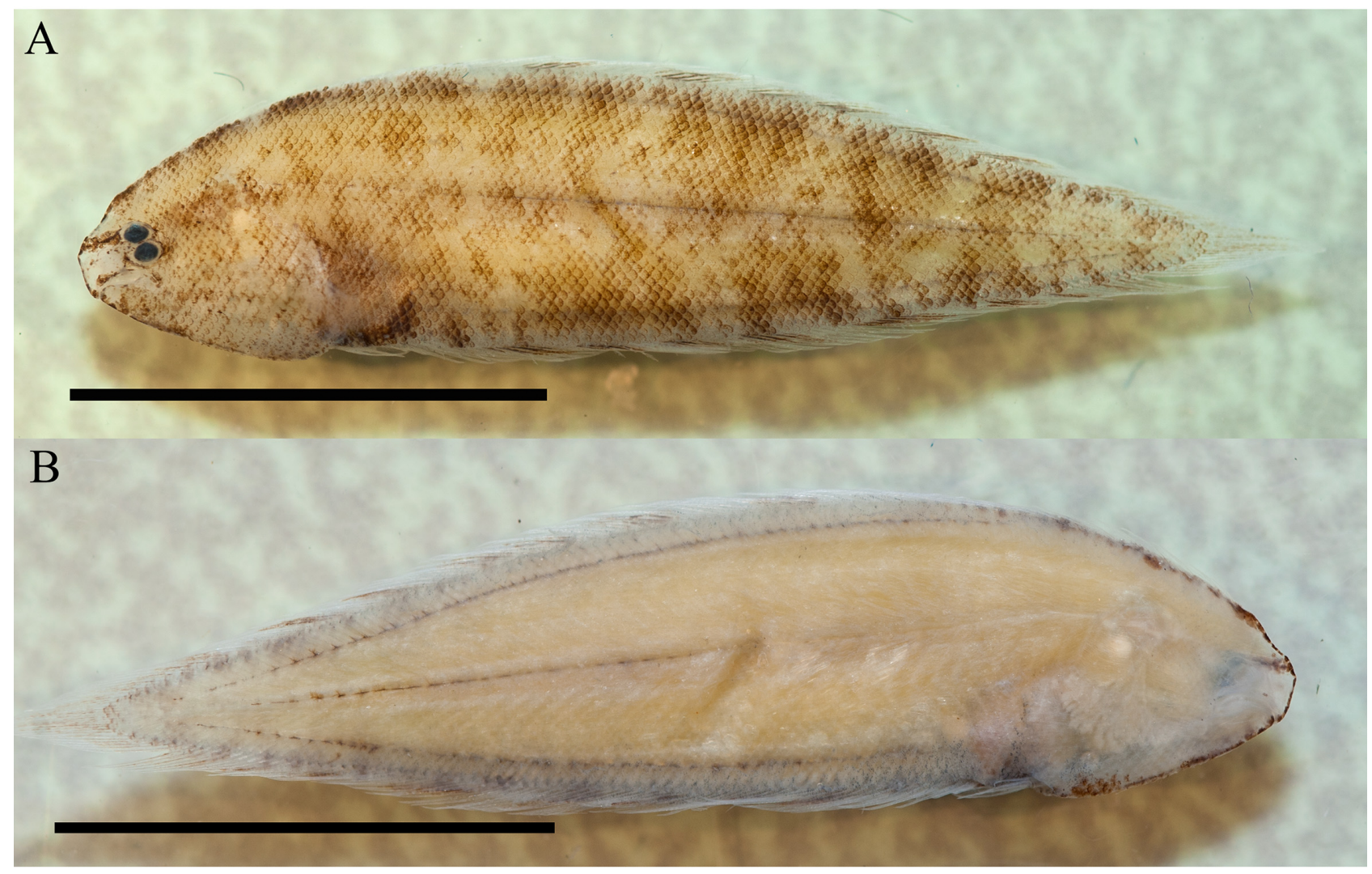

FIGURE 9. Symphurus leptosomus n. sp., holotype, USNM 379566, male, 23.6 mm SL, Off the Philippines. A. Ocular-sidepigmentation of preserved specimen. B. Blind-side pigmentation of same specimen. Scale equals $10 \mathrm{~mm}$.

Diagnosis. Symphurus leptosomus is distinguished from all congeners by the combination of: a 1-2-2-2-2 ID pattern; 12 caudal-fin rays; $9(3+6)$ abdominal vertebrae; 47 total vertebrae; 4 hypurals, 88 dorsal-fin rays, 72 analfin rays, 76 longitudinal scale rows, 37 transverse scale rows, and 20 scale rows on head posterior to lower orbit; an elongate body, with preanal length much longer than body depth $(\mathrm{PAL} / \mathrm{BD}=1.09)$; head moderately long $(\mathrm{HL}=$ $23.9 \%$ of SL), with head length slightly shorter than head width $(\mathrm{HW} / \mathrm{HL}=1.02)$; postorbital length short $(\mathrm{POL}=$ $65.5 \%$ of HL); upper head lobe larger than lower head lobe; dorsal-fin origin at vertical through midpoint of upper eye; predorsal length moderately long ( $\mathrm{PDL}=20.4 \%$ of $\mathrm{HL}$ ); snout short $(\mathrm{SNL}=16.8 \%$ of $\mathrm{HL})$, and rounded anteriorly; upper eye slightly in advance of lower eye; fleshy ridge well-developed on posterior part of ocular-side lower jaw, with fleshy membrane covering both upper and lower eyes, and membranous fleshy flap continuous between ocular-side anterior nostril and lower part of eye; with ocular-side pigmentation uniformly yellow to light-brown with dark-brown irregular speckles and blotches; blind-side pigmentation uniformly white, with well-developed pepper-dots and dermal melanophores at bases of dorsal and anal fins; bases of anteriormost dorsal- and anal-fin rays with obvious dermal spots on both sides; peritoneum bluish-black.

Description. Symphurus leptosomus is likely a dwarf species, known only from a male measuring $23.6 \mathrm{~mm} \mathrm{SL}$ (Fig. 9). Meristic characters summarized in Tables 2-5. ID pattern 1-2-2-2-2. Caudal-fin rays 12. Dorsal-fin rays 88. Anal-fin rays 72 . Pelvic-fin rays 4 . Total vertebrae 47 ; abdominal vertebrae $9(3+6)$. Hypurals 4 . Longitudinal scale rows 76 . Scale rows on head posterior to lower orbit 20. Transverse scale rows 37 .

Proportions of morphometric features presented in Table 9. Body relatively slender; maximum depth in anterior one-third of body at point equal with vertical at second anal-fin ray, body with gradual taper posterior to midpoint. Preanal length longer than body depth. Head moderately short and wide; head width longer than head length (HW/ $\mathrm{HL}=1.02)$. Upper head lobe wider than lower head lobe $(\mathrm{UHL} / \mathrm{LHL}=1.20)$; and much shorter than postorbital length. Lower lobe of ocular-side opercle wider than upper opercular lobe; posterior margin of lower lobe projecting slightly beyond posterior margin of upper opercular lobe. Snout relatively short, slightly rounded anteriorly, but its length much greater than eye diameter $(\mathrm{SNL} / \mathrm{ED}=1.72)$. Dermal papillae present, well developed, on blind side of snout and chin. Ocular-side anterior nostril tubular and short, not reaching anterior margin of lower eye when de- 
pressed posteriorly. Ocular-side posterior nostril a small, rounded tube located on snout just anterior to interorbital space. Blind-side anterior nostril tubular and moderately long, easily distinguishable from dermal papillae; blindside posterior nostril a shorter and wider, posteriorly directed tube, situated posterior to vertical at posterior margin of jaws. Jaws moderately long and slightly arched; upper jaw length much longer than snout length; posterior margin of upper jaw extending to point equal with vertical through midpoint of lower eye. Ocular-side lower jaw with well-developed fleshy ridge on its posterior half. Cheek depth narrow, slightly shorter than snout length. Eyes relatively small ( $\mathrm{ED}=9.7 \%$ of $\mathrm{HL}$ ), oval, contiguous, with membrane covering both eyes, eye membrane connected to anterior nostril by fleshy flap of skin. Upper eye slightly in advance of lower eye. Pupillary operculum absent. Dorsal-fin origin located at vertical through midpoint of upper eye; predorsal length relatively short. Anteriormost dorsal-fin rays obviously shorter than more posterior fin rays. Scales absent on both sides of dorsal- and anal-fin rays. Pelvic fin moderately long; longest pelvic-fin ray, when extended posteriorly, reaching base of fourth anal-fin ray. Posteriormost pelvic-fin ray connected to anal fin by delicate membrane. Caudal fin relatively long, with three rows of ctenoid scales on its base. Scales on both sides of body numerous, strongly ctenoid.

Teeth present and recurved slightly inwards on all jaws, but better developed on blind-side jaws. Ocular-side premaxilla and dentary with single row of sharply pointed, well-developed teeth. Blind-side premaxilla with two rows of sharp, recurved teeth. Blind-side lower jaw with four rows of well-developed teeth.

TABLE 9. Morphometrics for the holotype (USNM379566) of Symphurus leptosomus. SL in mm; characters $2-15$ in \% of SL; $16-23$ in \% of HL; 24 in \% of BD.

\begin{tabular}{ll}
\hline Character & Holotype \\
\hline 1. SL & 23.6 \\
2. BD & 24.6 \\
3. TKL & 78.8 \\
4. PDL & 4.9 \\
5. PAL & 26.7 \\
6. DBL & 95.1 \\
7. ABL & 73.3 \\
8. PL & 6.4 \\
9. PA & 3.0 \\
10. CFL & 14.0 \\
11. HL & 23.9 \\
12. HW & 24.4 \\
13. POL & 15.7 \\
14. UHL & 13.4 \\
15. LHL & 11.1 \\
16. PDL & 20.4 \\
17. POL & 65.5 \\
18. SNL & 16.8 \\
19. UJL & 24.8 \\
20. ED & 9.7 \\
21. CD & 52.7 \\
22. OPLL & 15.9 \\
23. OPUL & 27.4 \\
24. TH & 17.3 \\
25. HW/HL & 1.02 \\
26. Pupil/ED & 0.53 \\
\hline
\end{tabular}

Pigmentation. Symphurus leptosomus is only known from the preserved holotype (Fig. 9), which has lightbrown, ocular-side background pigmentation covered with irregular, dark-brown speckles and blotches. Speckles 
and blotches not continued onto dorsal and anal fins. Pigmentation overlying pterygiophore regions of dorsal and anal fins similar to that of background pigmentation elsewhere. A series of larger melanophores overlying vertebral axis. Melanophores in dermis overlying dorsal- and anal-fin pterygiophores well developed. External surface of abdominal area usually brown to bluish-black. Background pigmentation of ocular-side of head generally similar to that on body, with one darker region behind eyes formed by dense patch of dermal melanophores. Ocular side of snout light-yellow; obvious dermal spots at bases of anterior dorsal-fin rays and on the isthmus. Outer surface of ocular-side opercle yellow to light-brown, margin of opercle yellow to light-brown, with same background pigmentation as that on body and head. Inner surface of ocular-side opercle and isthmus with small blackish dots; ocularside lips and chin region uniformly yellow to brown, margins of lips pigmented with small dark chromatophores. Ocular-side anterior nostril light-yellow to brown. Upper aspects of eyes and eye sockets blackish; pupils bluishblack, lighter in pigmentation than sockets. Blind side generally white to light-yellow with pepper-dots present on pterygiophore regions overlying dorsal- and anal-fins. Peritoneum bluish-black. Median longitudinal row of darkly pigmented melanophores clearly visible along vertebral axis. Outer surface of blind-side opercle white to lightyellow similar to background pigmentation on blind side of body. Inner surface of blind-side opercle more darkly pigmented than outer surface. Fin rays of dorsal, anal, and pelvic fins uniformly light-brown; basal regions of fin rays and membranes covering fin rays yellow, with diffuse scattering of yellow to brown chromatophores covering entire fin membranes on both sides of fins. Entire dorsal and anal fins with pattern of darker streaks separated by lighter areas. Basal margins of fin rays on blind side, and associated fin membranes, light-yellow to light-brown.

Size and Sexual maturity. Symphurus leptosomus is only known from the holotype, a male measuring 23.6 $\mathrm{mm}$ SL. Additional specimens are needed to further investigate and determine maximum size and size at maturity for this species.

Distribution. Symphurus leptosomus is only known from a specimen collected at an offshore site off western Mindoro, Philippines (Fig. 3). Based on information associated with this specimen, S. leptosomus is a shallow-water species of tonguefish, occurring at depths of ca. $15 \mathrm{~m}$. Further investigations are needed to better understand intraspecific variation, ecology, abundance and life history of this species.

Etymology. The name leptosomus is derived from the Greek, lepto meaning slender, and somus, meaning body, in reference to its relatively slender, elongate body compared with that of other similar species of shallow-water tonguefishes.

Comparisons. Symphurus leptosomus is a member of the high scale count species group of the S. microrhynchus species complex. Among the five members of this group, $S$. leptosomus is most similar to $S$. hongae and $S$. robustus $\mathbf{n}$. sp. in that these three species have pepper-dots and dermal melanophores at the bases of the dorsal and anal fins. Other differences between S. leptosomus and S. hongae were highlighted in the Comparisons section of the species account for $S$. hongae above.

Compared with S. robustus n. sp., S. leptosomus has higher counts for head scales (20 vs. 16-18 in S. robustus n. sp.) and transverse scales (37 vs. 31-34 in S. robustus n. sp.). In its morphometric features, S. leptosomus differs from $S$. robustus $\mathbf{n}$. sp. in having a relatively narrower body (BD $=24.6 \%$ of SL vs. $25.5-28.3 \%$ of SL in $S$. robustus n. sp.), a preanal length longer than body depth ( $\mathrm{PAL} / \mathrm{BD}=1.08$ vs. $0.77-0.96$ in $S$. robustus $\mathbf{n} . \mathbf{s p}$.), and S. leptosomus has a relatively longer head ( $\mathrm{HL}=23.9 \%$ of SL vs. $19.1-21.8 \%$ of SL in $S$. robustus $\mathbf{n}$. sp.). These species also differ in some aspects of their pigmentation. For example, S. leptosomus features irregular dark-brown speckles and blotches covering its ocular side (vs. ocular side uniformly light-brown, usually with 5-7 crossbands, in S. robustus n. sp.).

Comparisons between S. leptosomus and S. brachycephalus were highlighted in the Comparisons section of the species account above for S. brachycephalus. Symphurus leptosomus is easily distinguished from S. polylepis $\mathbf{n}$. sp. in having well-developed pepper-dots and dermal melanophores at the bases of the dorsal and anal fins (vs. no pepper-dots or dermal melanophores at bases of the dorsal and anal fins in S. polylepis n. sp.). In meristic features, S. leptosomus differs from S. polylepis n. sp. in having more transverse scales (37 vs. 32-34 in S. polylepis n. sp.), and fewer longitudinal scales (76 vs. 88-94 in S. polylepis n. sp.).

Differences between $S$. leptosomus and members of the species group of the $S$. microrhynchus species complex characterized by having lower scale counts (S. holothuriae, S. longirostris, and S. microrhynchus) were discussed and highlighted above in the Comparisons section in each of the accounts for these species.

Symphurus leptosomus has the same ID pattern (1-2-2-2-2) and has similar or overlapping counts for dorsal-fin rays ( 88 vs. $86-92$ ), anal-fin rays ( 72 vs. $73-80)$, and total vertebrae (47 vs. $48-51)$ as those found in $S$. 
monostigmus and S. leucochilus. However, S. leptosomus is readily differentiated from both S. monostigmus and $S$. leucochilus in having a membranous connection between the ocular-side anterior nostril and lower eye and also in having a fleshy ridge on the ocular-side lower jaw; both features that are absent in these other species. Symphurus leptosomus also has its head length nearly equal to its width $(\mathrm{HW} / \mathrm{HL}=1.02)$ versus head width greater than head length $(\mathrm{HW} / \mathrm{HL}=1.07-1.42)$ in these other two species,.

Symphurus leptosomus differs further from S. monostigmus in having 12 (vs. 14) caudal-fin rays and 4 hypurals (vs. 5 hypurals), and in lacking the pigment spot on the abdomen that features so prominently in S. monostigmus.

\section{Symphurus polylepis n. sp.}

(English name: Small-scale tonguefish)

(Figs. 3, 10; Tables 1-5, 10)

Symphurus microrhynchus (not Weber 1913). (?) Kailola, 1971: 118 (specimen from Papua New Guinea, not examined in present study; compared with $S$. holothuriae and S. trifasciatus).

New Guinea species. Munroe 1992: 362, 374, 401 (ID patterns of five specimens; unidentified species, likely undescribed, distinct from $S$. microrhynchus and $S$. holothuriae).

Symphurus microrhynchus (not Weber): Munroe \& Marsh, 1997: 191 (misidentified as S. microrhynchus).

Holotype: USNM 245733, male, $49.5 \mathrm{~mm}$ SL, North of Tovel, Papua New Guinea, bottom trawl, $23 \mathrm{~m}, 10^{\circ} 10.22$ 'S, 14806' E, “Alpha Helix” CR. Moro, 13 Jun 1979.

Paratypes: Four specimens (26.7-34.8 mm SL): USNM 236607, 2 specimens, immature female and male, 31.0-34.8 mm SL, Creek Mouth, West side of Daru, Papua New Guinea, 0-10 m, 10 Oct 1975. USNM 265183, 2 males, 26.7-32.8 mm SL, Daru Wharf, East side of Daru, Papua New Guinea, 0-10 m, T. Roberts, 10 Oct 1975.

Diagnosis. Symphurus polylepis is distinguished from all congeners by the combination of: a 1-2-2-2-2 ID pattern; 12 caudal-fin rays; $9(3+6)$ abdominal vertebrae; 46-48 total vertebrae; 4 hypurals; 84-87 dorsal-fin rays; 68-74 anal-fin rays; 88-94 longitudinal scale rows; 32-34 transverse scale rows; and 17-19 scale rows on head posterior to lower orbit. Fleshy ridge well developed on posterior part of ocular-side lower jaw; and with fleshy membrane covering both eyes; anterior margin of upper eye usually slightly in advance of anterior margin of lower eye; with fleshy flap continuous between ocular-side anterior nostril and anterior region of lower eye; upper head lobe usually wider than lower head lobe; head length moderately long $(\mathrm{HL}=21.9-23.8 \%$ of SL) with relatively large postorbital length $(\mathrm{POL}=15.7-16.6 \%$ of $\mathrm{SL}, 69.3-73.3 \%$ of $\mathrm{HL})$; preanal length relatively short $(\mathrm{PAL}=23.5-24.6 \%$ of SL); snout short ( $\mathrm{SNL}=16.0-18.3 \%$ of $\mathrm{HL}, \mathrm{SNL} / \mathrm{ED}=1.44-1.86)$, rounded to obliquely blunt anteriorly; head length usually shorter than head width $(\mathrm{HW} / \mathrm{HL}=1.02-1.14)$; dorsal-fin origin in posterior position at, or slightly posterior to, vertical through posterior margin of upper eye; moderately long predorsal length (PDL $=5.7-7.1 \%$ of SL; $24.4-31.4 \%$ of HL); ocular side uniformly yellow to light-brown; blind side uniformly white; both sides with obvious dermal spots on bases of anteriormost dorsal- and anal-fin rays; peritoneum bluish-black.

Description. Symphurus polylepis (Fig. 10) is a tonguefish species, known only from five specimens, the largest of which is $49.5 \mathrm{~mm}$ SL. Meristic characters summarized in Tables 2-5. Predominant ID pattern 1-2-2-2-2 (5/5 specimens). Caudal-fin rays 12 . Dorsal-fin rays 84-87. Anal-fin rays 68-74. Pelvic-fin rays 4 . Total vertebrae 46-48; abdominal vertebrae $9(3+6)$. Hypurals 4 . Longitudinal scale rows $88-94$. Scale rows on head posterior to lower orbit $17-19$. Transverse scale rows $32-34$.

Proportions of morphometric features presented in Table 10. Body moderately deep; maximum depth in anterior one-third of body usually at point between anus and third anal-fin ray; body with gradual taper posterior to midpoint. Preanal length slightly shorter than body depth. Head moderately short and wide; head width longer than head length $(\mathrm{HW} / \mathrm{HL}=1.02-1.14$, Mean=1.09). Upper head lobe wider than lower head lobe $(\mathrm{UHL} / \mathrm{LHL}=1.04-1.24$, Mean=1.15); much shorter than postorbital length. Lower lobe of ocular-side opercle wider than upper opercular lobe; posterior margin of lower lobe projecting slightly beyond posterior margin of upper opercular lobe. Snout relatively short, slightly rounded to obliquely blunt anteriorly, its length slightly greater than eye diameter (SNL/ED= 1.44-1.86, Mean=1.59). Dermal papillae present and well developed on blind side of snout and chin. Ocular-side anterior nostril tubular and short, usually when depressed posteriorly not reaching anterior margin of lower eye. Ocular-side posterior nostril a small, rounded tube located on snout just anterior to interorbital space. Blind-side anterior nostril tubular, moderately long, easily distinguishable from dermal papillae; blind-side posterior nostril 
a shorter and wider, posteriorly directed tube situated posterior to vertical at rear margin of jaws. Jaws short and slightly arched; upper jaw length much longer than snout length; posterior margin of upper jaw usually extending to point between verticals through anterior margin of lower eye and midpoint of lower eye. Ocular-side lower jaw with well-developed fleshy ridge on its posterior half. Cheek depth narrow, slightly shorter than snout length. Eyes moderate in size ( $\mathrm{ED}=9.9-11.3 \%$ of $\mathrm{HL}$ ), oval, contiguous, with membrane covering both eyes; fleshy membrane of skin connecting lower eye to anterior nostril. Eyes usually unequal in position with anterior margin of upper eye usually in advance of anterior margin of lower eye. Pupillary operculum absent. Dorsal-fin origin located between verticals at posterior margin of pupil and posterior margin of upper eye; predorsal length moderately long. Anteriormost dorsal-fin rays obviously shorter than more posterior fin rays. Scales absent on both sides of dorsal- and anal-fin rays. Pelvic fin moderately long; longest pelvic-fin ray, when extended posteriorly, usually reaching base of third to fifth anal-fin ray. Posteriormost pelvic-fin ray connected to anal fin by delicate membrane. Caudal fin relatively long, with several (usually less than four) rows of ctenoid scales on its base. Scales on both sides of body numerous, strongly ctenoid.

Teeth present and recurved slightly inwards on all jaws, but better developed on blind-side jaws. Ocular-side premaxilla and dentary with single row of sharply pointed, well-developed teeth. Blind-side premaxilla with two to three rows of sharp, recurved teeth. Blind-side lower jaw with three to seven rows of well-developed teeth.

TABLE 10. Morphometrics for the holotype (USNM245733) and examined specimens of Symphurus polylepis. SL in $\mathrm{mm}$; characters $2-15$ in $\%$ of SL; $16-23$ in \% of HL; 24 in \% of BD.

\begin{tabular}{lllll}
\hline Character & Holotype & \multicolumn{3}{l}{ Examined Specimens } \\
\cline { 3 - 5 } & & $\mathrm{n}$ & Range & Mean \pm SD \\
\hline 1. SL & 49.5 & 5 & $25.1-49.5$ & $34.66 \pm 9.06$ \\
2. BD & 28.1 & 5 & $26.0-29.2$ & $27.84 \pm 1.37$ \\
3. TKL & 79.4 & 5 & $78.3-80.1$ & $79.33 \pm 0.73$ \\
4. PDL & 5.7 & 5 & $5.7-7.1$ & $6.20 \pm 0.59$ \\
5. PAL & 24.4 & 5 & $23.5-24.6$ & $24.06 \pm 0.46$ \\
6. DBL & 94.3 & 5 & $92.9-94.3$ & $93.80 \pm 0.59$ \\
7. ABL & 75.6 & 5 & $75.4-76.5$ & $75.94 \pm 0.46$ \\
8. PL & 7.3 & 3 & $6.8-8.9$ & $7.67 \pm 1.10$ \\
9. PA & 2.6 & 4 & $2.6-3.9$ & $3.29 \pm 0.55$ \\
10. CFL & 14.1 & 3 & $12.9-14.1$ & $13.69 \pm 0.69$ \\
11. HL & 21.9 & 5 & $21.9-23.8$ & $22.68 \pm 0.72$ \\
12. HW & 24.7 & 5 & $23.1-25.8$ & $24.77 \pm 1.06$ \\
13. POL & 16.1 & 5 & $15.7-16.6$ & $16.10 \pm 0.33$ \\
14. UHL & 13.6 & 5 & $12.3-14.1$ & $13.16 \pm 0.72$ \\
15. LHL & 11.0 & 5 & $10.7-12.2$ & $11.43 \pm 0.59$ \\
16. PDL & 26.2 & 5 & $24.4-31.4$ & $27.36 \pm 2.71$ \\
17. POL & 73.6 & 5 & $69.3-73.6$ & $71.03 \pm 1.72$ \\
18. SNL & 16.0 & 5 & $16.0-18.3$ & $16.76 \pm 0.91$ \\
19. UJL & 21.2 & 5 & $21.2-23.3$ & $22.05 \pm 0.80$ \\
20. ED & 10.9 & 5 & $9.9-11.3$ & $10.59 \pm 0.56$ \\
21. CD & 18.7 & 5 & $17.1-19.1$ & $18.27 \pm 0.88$ \\
22. OPLL & 30.2 & 5 & $27.9-35.2$ & $30.76 \pm 2.78$ \\
23. OPUL & 21.2 & 5 & $18.1-23.3$ & $20.26 \pm 2.01$ \\
24. TH & 20.2 & $20.2-23.8$ & $21.93 \pm 1.40$ \\
25. HW/HL & 1.13 & $1.02-1.14$ & $1.09 \pm 0.05$ \\
26. Pupil/ED & 0.47 & $0.44-0.47$ & $0.46 \pm 0.01$ \\
\hline & & 5 & & \\
\hline
\end{tabular}




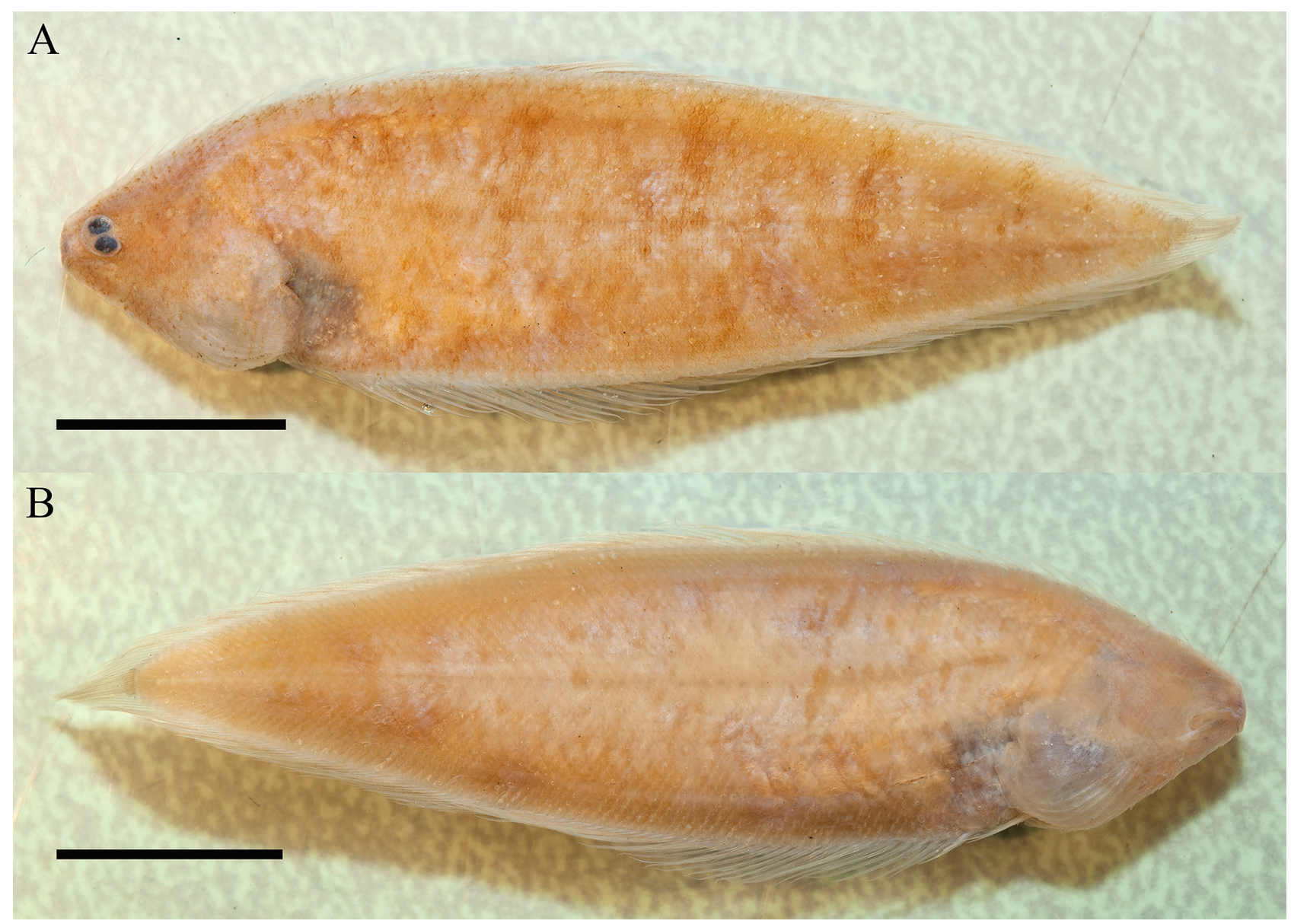

FIGURE 10. Symphurus polylepis n. sp., holotype, USNM 245733, male, $49.5 \mathrm{~mm}$ SL, Off North of Tovel, Papua New Guinea. A. Ocular-side pigmentation of preserved specimen. B. Blind-side pigmentation of same specimen. Scale equals $10 \mathrm{~mm}$.

Pigmentation. Only known from preserved and faded specimens examined in this study (Fig. 10). Pattern of body pigmentation generally similar for both sexes and for all sizes. Background body pigmentation of ocular side generally light-yellow to light-brown, usually with 4-9 distinct, narrow (covering about 2-4 scales), complete or incomplete, brown, crossbands; crossbands not continued onto dorsal and anal fins; some specimens with crossbands faded and indistinct, or with uniformly brown pigmentation without crossbands; pigmentation of body region overlying pterygiophores of dorsal and anal fins usually the same as background pigmentation. Dark pigment along vertebral axis absent on all specimens. No melanophores in dermis on body region overlying pterygiophores. External surface of abdominal area usually brown to bluish-black. Background pigmentation of ocular side of head generally similar to that on body, except for dark region of dermal melanophores concentrated behind eyes. Ocular side of snout light-yellow, obvious dermal spots at bases of anterior dorsal-fin rays and also on the isthmus. Outer surface of ocular-side opercle yellow to light-brown, margin of opercle yellow to light-brown, with same background pigmentation as that on body and head. Inner surface of ocular-side opercle and isthmus with small light reddish dots; ocular-side lips and chin region uniformly yellow to brown; margins of lips with small, dark chromatophores. Ocular-side anterior nostril light-yellow to brown. Upper aspects of eyes and eye sockets blackish; pupils bluish-black, usually lighter in pigmentation than sockets. Blind side generally white to light-yellow with bluish-black peritoneum. No median longitudinal row of darkly pigmented melanophores along vertebral axis at all sizes. Outer surface of blind-side opercle white to light-yellow similar to background pigmentation on body. Inner surface of blind-side opercle unpigmented. Fin rays of dorsal, anal, and pelvic fins uniformly yellow to brown; basal regions of fin rays and membranes covering fin rays light-yellow, with diffuse scattering of yellow to brown chromatophores covering entire fin membrane on both sides of fins. Entire dorsal and anal fins with regularly scattered streaks separating darker and lighter areas of fins. Basal margins of fin rays on blind side and associated fin membranes, light-yellow to light-brown.

Size and Sexual maturity. Five specimens range in size from 25.1-49.5 mm SL. Four are males (25.1-49.5 
$\mathrm{mm} \mathrm{SL})$, while the fifth specimen is an immature female $(34.8 \mathrm{~mm} \mathrm{SL})$ with little elongation of the ovaries. Since none of the five specimens are adult females, i.e., either gravid or with elongate ovaries, we are unable to determine size or size at maturity offor adult females s, or size at maturity of females, forof this species.

Distribution. Symphurus polylepis is only known from specimens collected at two inshore sites offshore at Daru, and one offshore site north of Tovel, Papua New Guinea (Fig. 3). Based on information associated with these limited specimens, S. polylepis is a shallow-water species of tonguefish, occurring at depths ranging from 0-23 m, with most captures usually occurring between 0 and $10 \mathrm{~m}$. More accurate information about geographic distribution, bathymetric distribution and substrata inhabited is needed to better understand the ecology, distribution and life history of this species.

Etymology. The name polylepis is derived from the Greek, poly meaning many, and lepis, meaning scale, in reference to the greater number of longitudinal scale rows compared with that of similar species of shallow-water tonguefishes.

Remarks. Kailola (1971) tentatively identified a specimen taken off Papua, New Guinea, as S. microrhynchus based on its meristic features ( 87 dorsal-fin rays; 76 anal-fin rays; 86 longitudinal scales), and by its distinct pigmentation. This specimen was not examined in the present study. However, meristic values for this specimen are identical, or nearly so, to those of S. polylepis (dorsal-fin rays 84-87; anal-fin rays 68-74; and longitudinal scales 88-94). Based on similarities in meristic characters and capture location, we tentatively identify this specimen as $S$. polylepis.

In his survey of ID patterns of species of Symphurus, Munroe (1992) examined five specimens of an unidentified species of Symphurus from New Guinea. He considered this unidentified species distinct from S. microrhynchus and S. holothuriae and treated this as probably an undescribed species. Later, Munroe \& Marsh (1997) re-examined these specimens and incorrectly re-identified them as S. microrhynchus based on their similarities in meristic features to that species.

Comparisons. Of IWP shallow-water tonguefishes, S. polylepis is most similar to four other nominal species (S. brachycephalus, S. robustus n. sp., S. hongae, and S. leptosomus) that together with S. polylepis belong to the high scale count group of species of the $S$. microrhynchus species complex. Except for S. robustus $\mathbf{n}$. sp., differences between S. polylepis and these other species were highlighted in the Comparisons sections appearing in the accounts above for each of these species.

Symphurus polylepis is easily distinguished from S. robustus n. sp. by differences in their pigmentation. Symphurus polylepis lacks pepper-dots and dermal melanophores at bases of the dorsal- and anal-fin rays (vs. well-developed pepper-dots and dermal melanophores at bases of dorsal- and anal-fin rays present in S. robustus $\mathbf{n}$. sp.). In its meristic features, S. polylepis differs from S. robustus $\mathbf{n}$. sp. in having more longitudinal scales (88-94 vs. 78-88 in S. robustus $\mathbf{n}$. sp.).

Differences between $S$. polylepis and members of the $S$. microrhynchus species complex with lower scale counts (S. holothuriae, S. longirostris, and S. microrhynchus) were discussed in the Comparisons sections above for each of these species, respectively.

Symphurus polylepis has the same ID pattern (1-2-2-2-2) and counts for some meristic features that overlap those found in the South African species, S. monostigmus, and in the northwestern Pacific Ocean shallow-water species, S. leucochilus. Symphurus polylepis differs from both in possessing a fleshy membranous connection between the ocular-side anterior nostril and the eye (vs. absent in these others), and S. polylepis has a fleshy ridge on the ocular-side lower jaw, which is also absent in both S. monostigmus and S. leucochilus.

Symphurus polylepis is readily differentiated from S. monostigmus in having 12 caudal-fin rays and 4 hypurals (vs. 14 caudal-fin rays and 5 hypurals in S. monostigmus). Symphurus polylepis also has a narrower head (HW/HL= $1.02-1.14)$ compared with that $(\mathrm{HW} / \mathrm{HL}=1.38-1.42)$ found in $S$. monostigmus. Symphurus polylepis is further differentiated from $S$. monostigmus by differences in their ocular-side pigmentation (ocular-side background pigmentation generally light-yellow to light-brown, usually with 4-9 distinct, narrow (covering about 2-4 scales), complete or incomplete, brown, crossbands and no freckles or conspicuous spot on the abdomen in S. polylepis vs. whitish background overlain with freckles and with conspicuous pigmented spot on the abdomen in S. monostigmus).

Symphurus polylepis differs further from S. leucochilus in numbers of dorsal-fin rays (84-87 in S. polylepis vs. $89-92$ in S. leucochilus), anal-fin rays (68-74 vs. 76-80), total vertebrae (46-48 vs. 49-51), longitudinal scales (88-94 vs. 75-83), and S. polylepis also has more head scales (17-19 vs. 15-17) than does S. leucochilus. 
Symphurus robustus $\mathrm{n}$. sp.

(English name: Robust tonguefish)

(Figs. 3, 11; Tables 1-5, 11)

Holotype: BSKU 45132, male, 60.0 mm SL, Off Kochi, Tosa Bay, Japan, bottom trawl, 90 m, 33⒛33'-33⒛76'N, 133³6.40'-133³4.97’E, R/V Toyohata-maru, 22 Oct 1987.

Paratypes. 21 specimens (35.3-67.5 mm SL); off Kochi, Tosa Bay, Japan, collected by R/V Toyohata-maru using bottom trawl: ASIZP0072351, immature female, $35.3 \mathrm{~mm} \mathrm{SL}, 45 \mathrm{~m}, 33^{\circ} 16.12^{\prime}-33^{\circ} 26.31^{\prime} \mathrm{N}, 133^{\circ} 33.12^{\prime}-$ 133²0.60'E, 9 May 1994. ASIZP0072353, 8 specimens, 51.3-61.8 mm SL, $46 \mathrm{~m}, 33^{\circ} 25.74^{\prime}-33^{\circ} 25.86^{\prime} \mathrm{N}$, $133^{\circ} 32.88^{\prime}-133^{\circ} 33.22^{\prime} \mathrm{E}, 9$ May 1994. ASIZP0072354, 5 specimens, 47.9-67.5 mm SL, 64 m, 33⒉ $23.86^{\prime}-33^{\circ} 24.04^{\prime} \mathrm{N}$,

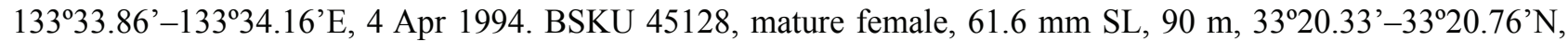
$133^{\circ} 36.40^{\prime}-133^{\circ} 34.97^{\prime} \mathrm{E}, 22$ Oct 1987. BSKU 45129, male, $60.5 \mathrm{~mm}$ SL, $90 \mathrm{~m}, 33^{\circ} 20.33^{\prime}-33^{\circ} 20.76^{\prime} \mathrm{N}, 133^{\circ} 36.40^{\prime}-$ $133^{\circ} 34.97^{\prime} \mathrm{E}, 22$ Oct 1987. BSKU 45131, male, $64.9 \mathrm{~mm} \mathrm{SL}, 90 \mathrm{~m}, 33^{\circ} 20.33^{\prime}-33^{\circ} 20.76^{\prime} \mathrm{N}, 133^{\circ} 36.40^{\prime}-133^{\circ} 34.97^{\prime} \mathrm{E}$, 22 Oct 1987. BSKU 45133, male, $61.5 \mathrm{~mm} \mathrm{SL}, 90 \mathrm{~m}, 33^{\circ} 20.33^{\prime}-33^{\circ} 20.76^{\prime} \mathrm{N}, 133^{\circ} 36.40^{\prime}-133^{\circ} 34.97^{\prime} \mathrm{E}, 22$ Oct 1987. BSKU 45448, mature female, $63.2 \mathrm{~mm}$ SL, $60 \mathrm{~m}, 33^{\circ} 23.73^{\prime}-33^{\circ} 24.98^{\prime} \mathrm{N}, 133^{\circ} 31.81^{\prime}-133^{\circ} 35.40^{\prime} \mathrm{E}, 21 \mathrm{Apr}$ 1986. BSKU 45459, mature female, $54.0 \mathrm{~mm}$ SL, $45 \mathrm{~m}, 33^{\circ} 25.29^{\prime}-33^{\circ} 25.97^{\prime} \mathrm{N}, 133^{\circ} 32.40^{\prime}-133^{\circ} 33.58^{\prime} \mathrm{E}, 9$ Jun 1988. BSKU 45464, mature female, $65.5 \mathrm{~mm} \mathrm{SL}, 60 \mathrm{~m}, 33^{\circ} 23.99^{\prime}-33^{\circ} 24.46^{\prime} \mathrm{N}, 133^{\circ} 32.43^{\prime}-133^{\circ} 34.47^{\prime} \mathrm{E}, 22$ Jun 1988.

Diagnosis. Symphurus robustus is distinguished from all congeners by the combination of: a 1-2-2-2-2 ID pattern; 12 caudal-fin rays; $9(3+6)$ abdominal vertebrae; $47-49$ total vertebrae; 4 hypurals; $85-88$ dorsal-fin rays; 72-76 anal-fin rays; 78-88 longitudinal scale rows; 31-34 transverse scale rows; and 16-18 scale rows on head posterior to lower orbit; moderately wide body $(\mathrm{BD}=25.5-28.3 \%$ of $\mathrm{SL})$; short preanal length $(\mathrm{PAL}=22.2-24.7 \%$ of SL); relatively short head $(\mathrm{HL}=19.1-21.8 \%$ of SL), with its length much shorter than its width $(\mathrm{HW} / \mathrm{HL}=1.06-$ $1.20)$; postorbital length moderately short $(\mathrm{POL}=65.8-70.2 \%$ of $\mathrm{HL})$; upper head lobe usually larger than lower head lobe; dorsal-fin origin at vertical through posterior margin of upper eye; predorsal length moderately long $(\mathrm{PDL}=21.6-28.0 \%$ of $\mathrm{HL})$; snout moderately long $(\mathrm{SNL}=16.8-21.2 \%$ of $\mathrm{HL}$; $\mathrm{SNL} / \mathrm{ED}=1.55-2.00)$, and round to obliquely blunt anteriorly; anterior margin of upper eye usually equal to, or slightly in advance of, anterior margin of lower eye; fleshy ridge well developed on posterior part of ocular-side lower jaw; membrane covering both eyes; a membranous flap continuous between ocular-side anterior nostril and lower part of eye; ocular-side pigmentation uniformly yellow to light-brown, usually with 5-7 complete or incomplete crossbands; blind-side pigmentation uniformly white, usually with pepper-dots and relatively few dermal melanophores at bases of dorsal and anal fins; obvious dermal spots on bases of the anteriormost dorsal- and anal-fin rays on both sides; peritoneum bluish-black.

Description. Symphurus robustus (Fig. 11) is a dwarf species known from 22 specimens, the largest of which measures $67.5 \mathrm{~mm}$ SL. Meristic characters are summarized in Tables 2-5. Predominant ID pattern 1-2-2-2-2 (20/22 specimens). Caudal-fin rays 12 . Dorsal-fin rays $85-88$. Anal-fin rays $72-76$. Pelvic-fin rays 4 . Total vertebrae 47-49; abdominal vertebrae $9(3+6)$. Hypurals 4 . Longitudinal scale rows $78-88$. Scale rows on head posterior to lower orbit 16-18. Transverse scale rows 31-34.

Proportions of morphometric features presented in Table 11. Body moderately deep; maximum depth in anterior one-third of body usually at point between anus and third anal-fin ray; body with gradual taper posterior to midpoint. Preanal length much shorter than body depth. Head moderately short and wide; head width longer than head length $(\mathrm{HW} / \mathrm{HL}=1.06-1.20$, Mean= 1.09). Upper head lobe wider than lower head lobe $(\mathrm{UHL} / \mathrm{LHL}=1.05-1.34$, Mean=1.18); shorter than postorbital length. Lower lobe of ocular-side opercle wider than upper opercular lobe; posterior margin of lower lobe projecting slightly beyond posterior margin of upper opercular lobe. Snout moderately long, slightly round to obliquely blunt anteriorly, its length usually much greater than eye diameter (SNL/ED= 1.52-1.99, Mean=1.73). Dermal papillae present and well developed on blind side of snout and chin. Ocular-side anterior nostril tubular and short, when depressed posteriorly usually not reaching anterior margin of lower eye. Ocular-side posterior nostril a small, rounded tube located on snout just anterior to interorbital space. Blind-side anterior nostril tubular and relatively long, easily distinguishable from dermal papillae; blind-side posterior nostril a shorter and wider, posteriorly directed tube situated posterior to vertical at rear margin of jaws. Jaws short and slightly arched; upper jaw length slightly longer than snout length; posterior margin of upper jaw usually extending to point between verticals through anterior margin of pupil and anterior margin of lower eye. Ocular-side lower jaw with well-developed fleshy ridge on its posterior portion. Cheek depth narrow, slightly shorter than, or equal to, 
snout length. Eyes moderately large $(E D=9.6-12.0 \%$ of $\mathrm{HL})$ and oval, contiguous, with membrane covering both eyes; fleshy membranous skin flap connecting eye with ocular-side anterior nostril. Eyes usually equal in position, or with anterior margin of upper eye slightly in advance of anterior margin of lower eye. Pupillary operculum absent. Dorsal-fin origin located at point between verticals through posterior margin of upper eye and point posterior to eye; predorsal length moderately long. Anteriormost dorsal-fin rays obviously shorter than more posterior fin rays. Scales absent on both sides of dorsal- and anal-fin rays. Pelvic fin moderately long; longest pelvic-fin ray, when extended posteriorly, reaching base of fifth anal-fin ray. Posteriormost pelvic-fin ray connected to anal fin by delicate membrane. Caudal fin relatively long, with three rows of ctenoid scales on its base. Scales on both sides of body numerous, strongly ctenoid.

Teeth present and recurved slightly inwards on all jaws, but better developed on blind-side jaws. Ocular-side premaxilla and dentary with single row of sharply pointed, well-developed teeth. Blind-side premaxilla with two to three rows of sharp, recurved teeth. Blind-side lower jaw with three to five rows of well-developed teeth.

Pigmentation of freshly caught specimens. Pattern of body pigmentation generally similar for both sexes at all sizes (Fig. 11). Ocular-side background pigmentation generally light-yellow to light-brown; usually with 5-7 complete or incomplete crossbands. External surface of abdominal area usually bluish-black. Background pigmentation of ocular side of head generally similar to that on body, with dark region behind eyes formed by concentration of dermal melanophores. Ocular side of snout light yellow. Obvious dermal spots at bases of anterior dorsal-fin rays and on the isthmus. Outer surface of ocular-side opercle yellow to brown, with same background pigmentation as that on body and head; margin of opercle darker brown and easily distinguishable from bluish regions of opercle; inner surface of ocular-side opercle and isthmus with small dark-brownish or blackish dots. Ocular-side lips and chin region uniformly yellow to brown, margins of lips pigmented with small melanophores. Ocular-side anterior nostril light-yellow to brown. Upper aspects of eyes and eye sockets light blue with darker spots; pupils bluish-black. Blind side generally white to light-yellow with bluish-black peritoneum; pepper-dots present on body regions overlying pterygiophores of dorsal and anal fins, some specimens also with median longitudinal row of darkly-pigmented melanophores along vertebral axis. Well-developed dermal melanophores also forming single longitudinal row along bases of dorsal and anal fins. Outer surface of blind-side opercle white to light-yellow similar to background pigmentation of blind side. Inner surface of blind-side opercle unpigmented. Fin rays of dorsal, anal, and pelvic fins uniformly yellow to brown; basal regions of fin rays and membranes covering fin rays light yellow, with diffuse scattering of yellow to brown chromatophores covering entire fin membranes on both sides of fins. Entire dorsal and anal fins with scattered streaks separating fins into darker and lighter areas. Basal margins on blind sides of these fin rays and associated fin membranes light-yellow to light-brown.

Pigmentation of recently preserved specimens. Similar to that of freshly caught fishes; pigmentation of specimens preserved for decades usually faded, except dermal spots at bases of anterior dorsal-fin rays, pepper-dots on the isthmus, and the bluish-black peritoneum still clearly visible.

Size and sexual maturity. A total of 22 specimens, ranging in size from $35.3-67.5 \mathrm{~mm}$ SL, included $12 \mathrm{fe}-$ males, 35.3-67.5 mm SL. Males ( $\mathrm{n}=10,47.9-65.5 \mathrm{~mm} \mathrm{SL})$ attain similar sizes to those of females. Of the $12 \mathrm{fe}-$ males, three (35.3-53.4 mm SL) are immature showing little elongation of the ovaries, while eight others (54.0-63.0 $\mathrm{mm} \mathrm{SL})$ are non-gravid, mature females with elongate ovaries, only one female $(67.5 \mathrm{~mm} \mathrm{SL})$ was gravid.

Distribution. Symphurus robustus is known from voucher specimens taken on the continental shelf in Tosa Bay, the Pacific side of Japan. (Fig. 3). Based on these specimens, S. robustus is a shallow-water tonguefish, occurring at depths ranging from $45 \mathrm{~m}$ to $90 \mathrm{~m}$, with most captures usually occurring between 45 and $64 \mathrm{~m}$. Symphurus robustus is frequently collected on muddy substrata, or on substrata consisting of a mixture of mud and sand.

Etymology. The name robustus is derived from the Latin, in reference to the relatively massive, and much thicker body of this species compared with that of other similar shallow-water tonguefishes.

Comparisons. Of species of shallow-water tonguefishes from the Indo-West Pacific, S. robustus is most similar to the other four nominal species belonging to the high scale count group of the S. microrhynchus species complex, i.e., S. brachycephalus, S. hongae, S. leptosomus, and S. polylepis. Differences between S. robustus and these other species were highlighted above in the Comparisons sections in the species accounts for each of these species, respectively.

Differences between $S$. robustus and members of the low scale count species group of the S. microrhynchus complex (S. holothuriae, S. longirostris, and S. microrhynchus) were discussed above in the Comparisons section in the species accounts for each of these species, respectively. 


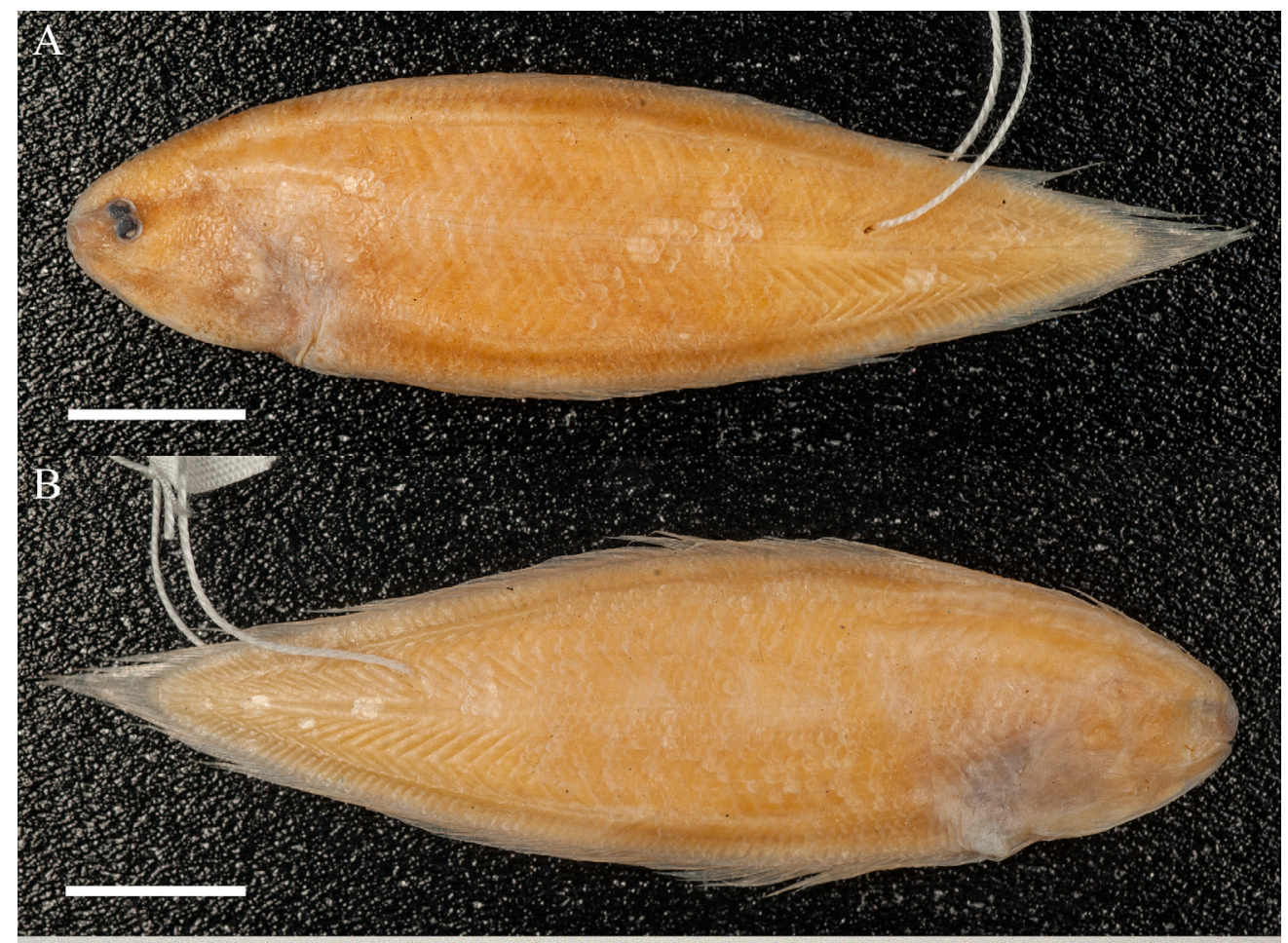

C
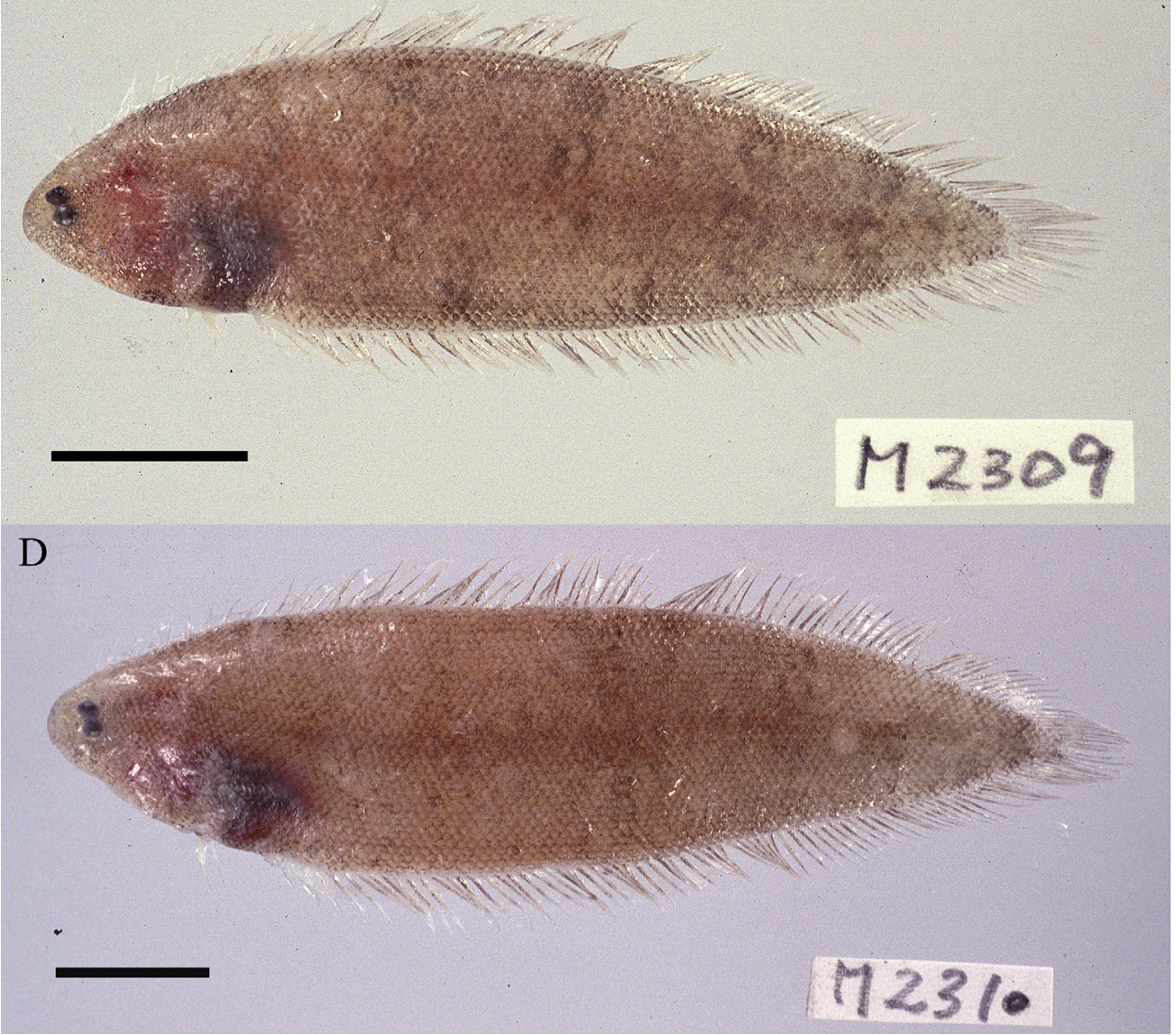

FIGURE 11. Symphurus robustus n. sp., holotype, BSKU 45132, male, 60.0 mm SL, Off Kochi, Japan. A. Ocular side pigmentation of preserved specimen. B. Blind-side pigmentation of holotype. C. Symphurus robustus n. sp., paratype, BSKU 44097 , male, $50.0 \mathrm{~mm} \mathrm{SL}$, Off Kochi, Japan, Ocular-side pigmentation of fresh specimen (Provided by Dr. H. Endo). D. Symphurus robustus n. sp., paratype, BSKU 44098, male, $63.7 \mathrm{~mm}$ SL, Off Kochi, Japan, Ocular-side pigmentation of fresh specimen (Provided by Dr. H. Endo). Scale equals $10 \mathrm{~mm}$. 
TABLE 11. Morphometrics for the holotype (BSKU45132) and examined specimens of Symphurus robustus. SL in mm; characters $2-15$ in $\%$ of SL; $16-23$ in $\%$ of HL; 24 in $\%$ of BD.

\begin{tabular}{|c|c|c|c|c|}
\hline \multirow[t]{2}{*}{ Character } & \multirow[t]{2}{*}{ Holotype } & \multicolumn{3}{|c|}{ Examined Specimens } \\
\hline & & $\mathrm{n}$ & Range & Mean \pm SD \\
\hline 1. SL & 60.0 & 22 & $35.3-67.5$ & $59.60 \pm 7.02$ \\
\hline 2. $\mathrm{BD}$ & 27.9 & 22 & $25.5-28.3$ & $26.95 \pm 0.79$ \\
\hline 3. TKL & 80.8 & 22 & $80.2-85.0$ & $81.85 \pm 1.17$ \\
\hline 4. PDL & 5.1 & 22 & $4.3-6.1$ & $5.01 \pm 0.48$ \\
\hline 5. PAL & 22.2 & 22 & $21.6-24.7$ & $23.62 \pm 0.86$ \\
\hline 6. DBL & 94.9 & 22 & $93.9-95.7$ & $95.18 \pm 0.50$ \\
\hline 7. $\mathrm{ABL}$ & 77.8 & 22 & $75.3-78.4$ & $76.40 \pm 0.87$ \\
\hline 8. PL & 9.3 & 21 & $7.3-10.4$ & $9.17 \pm 0.82$ \\
\hline 9. PA & 3.4 & 22 & $2.7-5.2$ & $3.98 \pm 0.65$ \\
\hline 10. CFL & 11.9 & 21 & $10.4-13.0$ & $11.53 \pm 0.64$ \\
\hline 11. HL & 20.8 & 22 & $19.1-21.8$ & $20.71 \pm 0.71$ \\
\hline 12. HW & 23.3 & 22 & $21.0-24.4$ & $22.59 \pm 0.86$ \\
\hline 13. POL & 13.8 & 22 & $13.0-15.0$ & $14.05 \pm 0.57$ \\
\hline 14. UHL & 12.8 & 22 & $11.9-14.1$ & $12.69 \pm 0.46$ \\
\hline 15. LHL & 10.8 & 22 & $8.9-11.9$ & $10.79 \pm 0.66$ \\
\hline 16. PDL & 24.4 & 22 & $21.6-28.0$ & $24.17 \pm 1.88$ \\
\hline 17. POL & 66.5 & 22 & $65.8-70.2$ & $67.85 \pm 1.15$ \\
\hline 18. SNL & 21.2 & 22 & $16.8-21.2$ & $18.77 \pm 1.11$ \\
\hline 19. UJL & 23.6 & 22 & $21.1-24.4$ & $22.70 \pm 1.03$ \\
\hline 20. ED & 10.6 & 22 & $9.6-12.0$ & $10.81 \pm 0.76$ \\
\hline 21. $\mathrm{CD}$ & 19.1 & 22 & $15.0-22.4$ & $18.69 \pm 1.73$ \\
\hline 22. OPLL & 27.8 & 22 & $24.9-31.1$ & $28.04 \pm 1.81$ \\
\hline 23. OPUL & 23.7 & 22 & $21.7-27.2$ & $24.52 \pm 1.53$ \\
\hline 24. TH & 24.1 & 22 & $22.1-30.0$ & $24.14 \pm 1.83$ \\
\hline 25. HW/HL & 1.12 & 22 & $1.06-1.20$ & $1.09 \pm 0.03$ \\
\hline 26. Pupil/ED & 0.42 & 22 & $0.35-0.46$ & $0.42 \pm 0.03$ \\
\hline
\end{tabular}

Symphurus robustus also shares some similarities with $S$. monostigmus and S. leucochilus, including the same ID pattern (1-2-2-2-2) and overlapping counts for dorsal-fin rays (85-88 vs. 86-92), anal-fin rays (72-76 vs. $73-$ 80 ), total vertebrae (46-48 vs. 48-51), and several scale counts. However, S. robustus is readily differentiated from both S. monostigmus and S. leucochilus in having a membranous connection between the ocular-side anterior nostril and lower eye, and S. robustus also possesses a fleshy ridge on the ocular-side lower jaw; both features absent in these other species.

Symphurus robustus differs further from S. monostigmus in having 12 caudal-fin rays and 4 hypurals (vs. 14 caudal-fin rays and 5 hypurals), and in lacking the pigment spot on the abdomen that features so prominently in $S$. monostigmus. Symphurus robustus also has fewer scales in longitudinal series (72-78) and fewer transverse scales (32-34) compared with that (vs. 92 and 36-38, respectively) found in S. monostigmus. The head of S. robustus is much narrower $(\mathrm{HW} / \mathrm{HL}=1.06-1.20)$ compared with that $(\mathrm{HW} / \mathrm{HL}=1.38-1.42)$ of $S$. monostigmus.

A further difference between $S$. robustus and $S$. leucochilus is the number of longitudinal scales, which are more numerous in S. robustus (78-88) compared with values (75-83) for this feature found in S. leucochilus. 


\section{Species accounts for shallow-water species not members of Symphurus microrhynchus species complex}

\section{Symphurus monostigmus Munroe, 2006}

(English name: Spotbelly tonguefish)

(Figs. 12; Tables 1-5, 12)

Symphurus monostigmus Munroe, 2006: 230, Fig. 1(South Africa, KwaZulu-Natal, off Gypsy Hill, 65-110 m. Holotype: SAIAB 39811). Munroe \& Hashimoto, 2008: 53 (compared with S. thermophilus). Lee et al. 2009: 347 (compared with $S$. megasomus). Munroe et al. 2011: 64 (compared with S. maculopinnis). Lee et al. 2014: 580 (listed in comparisons). Lee et al. 2017: 72 (listed in introduction).

Holotype: SAIAB 39811, male, 48.8 mm SL, off Gypsy Hill, KwaZulu-Natal, South Africa, Western Indian Ocean, 110 m, 2745.20’ S, 32³9.80’ E, R. N. Kilburn, aboard the R/V Meiring Naude, 8 Jun 1988.

Paratype: USNM 383435), male, 54.6 mm SL, off Gypsy Hill, KwaZulu-Natal, South Africa, Western Indian Ocean, 65-70 m, 27²7.40’ S, 32³8.90’ E, R. N. Kilburn, aboard the R/V Meiring Naude, 8 Jun 1988.

Diagnosis. Symphurus monostigmus is distinguished from all congeners by the combination of: a 1-2-2-2-2 ID pattern; 14 caudal-fin rays; $9(3+6)$ abdominal vertebrae; 48 total vertebrae; 5 hypurals; 86 dorsal-fin rays; 73-74 anal-fin rays; 92 longitudinal scale rows; 36-38 transverse scale rows; and 18-19 scale rows on the head posterior to lower orbit; body deep $(\mathrm{BD}=28.8-32.4 \%$ of $\mathrm{HL}$ ); preanal length short ( $\mathrm{PAL}=21.3-25.5 \%$ of $\mathrm{SL}$ ); upper head lobe much wider than lower head lobe; head moderately short $(\mathrm{HL}=18.0-20.2 \%$ of SL), with head length much shorter than head width $(\mathrm{HW} / \mathrm{HL}=1.38-1.42)$; postorbital length long $(\mathrm{POL}=75.8-79.4 \%$ of $\mathrm{HL})$; snout short $(\mathrm{SNL}=13.6-14.8 \%$ of $\mathrm{HL}$; SNL/ED $=1.08-1.25)$, rounded to obliquely blunt anteriorly; dorsal-fin origin at vertical at anterior margin of upper eye; predorsal length short ( $\mathrm{PDL}=16.4-19.3 \%$ of $\mathrm{HL}$ ); eyes equal in position (anterior margin of upper eye equal with anterior margin of lower eye), or slightly subequal (with anterior margin of upper eye anterior to that of lower eye); without fleshy ridge on ocular-side lower jaw; ocular-side pigmentation yellowish-white with numerous freckles along bases of dorsal- and anal-fin rays; blind-side pigmentation uniformly white; peritoneum bluish-black.

Description (from Munroe 2006). Known from two specimens, the holotype (Fig. 12a) measuring $48.8 \mathrm{~mm}$ SL, and a paratype (Fig. 12b) of $54.6 \mathrm{~mm} \mathrm{SL}$. Meristic data for paratype in parentheses when different from that of holotype. Meristic information summarized in Tables 2-5. ID pattern 1-2-2-2-2. Caudal-fin rays 14. Dorsal-fin rays 86 . Anal-fin rays 74 (73). Pelvic-fin rays 4 . Total vertebrae 48 ; abdominal vertebrae $9(3+6)$. Hypurals 5 . Longitudinal scale rows about 92 (many scales missing, count made from blind side; paratype missing too many scales to estimate). Scale rows on head posterior to lower orbit 18 (19).

Proportions of morphometric features for holotype and paratype are presented in Table 12. Body moderately elongate, tapering gradually anteriorly and posteriorly; greatest body depth in anterior one-third of body, slightly posterior to anus. Preanal length less than or slightly greater than body depth. Head width greater than head length $(\mathrm{HW} / \mathrm{HL}=1.39$ for holotype, 1.42 for paratype). Postorbital head length shorter than width of upper head lobe. Snout short, bluntly rounded to squarish, its length noticeably longer than eye diameter. Dermal papillae present on blind side of snout and chin. Ocular-side anterior nostril tubular, elongate, when depressed posteriorly reaching, or nearly reaching, anterior margin of lower eye. Ocular-side posterior nostril a small round opening situated in anterior interorbital space. Blind-side anterior nostril a short, round tube, readily distinguishable from dermal papillae. Blind-side posterior nostril a small round opening. Eyes moderate in size (ED $=10.9-13.6 \%$ of $\mathrm{HL})$, round; equal or slightly subequal in position, with anterior margin of lower eye slightly posterior to that of upper eye. Eyes nearly contiguous for most of their lengths, without ctenoid scales in extremely narrow interorbital space, and without small scales on upper aspects of eyes. Pupillary operculum absent. Pupil small, pupil diameter/eye diameter 32\% (28\% in paratype). Upper-jaw length greater than snout length, posterior margin reaching point between verticals through anterior margin of pupil and midpoint of lower eye. Upper head lobe noticeably wider than lower head lobe. Posterior margin of opercle with obvious indentation. Upper opercular lobe much wider than lower opercular lobe, which extends more posteriorly than upper opercular lobe. Dorsal-fin origin located at point between verticals through anterior margin of pupil and midpoint of upper eye. Both sides of dorsal- and anal-fin rays without scales. Caudal fin elongate, with several rows of small ctenoid scales on basal one-third to one-half of blind and ocular sides of fin. 


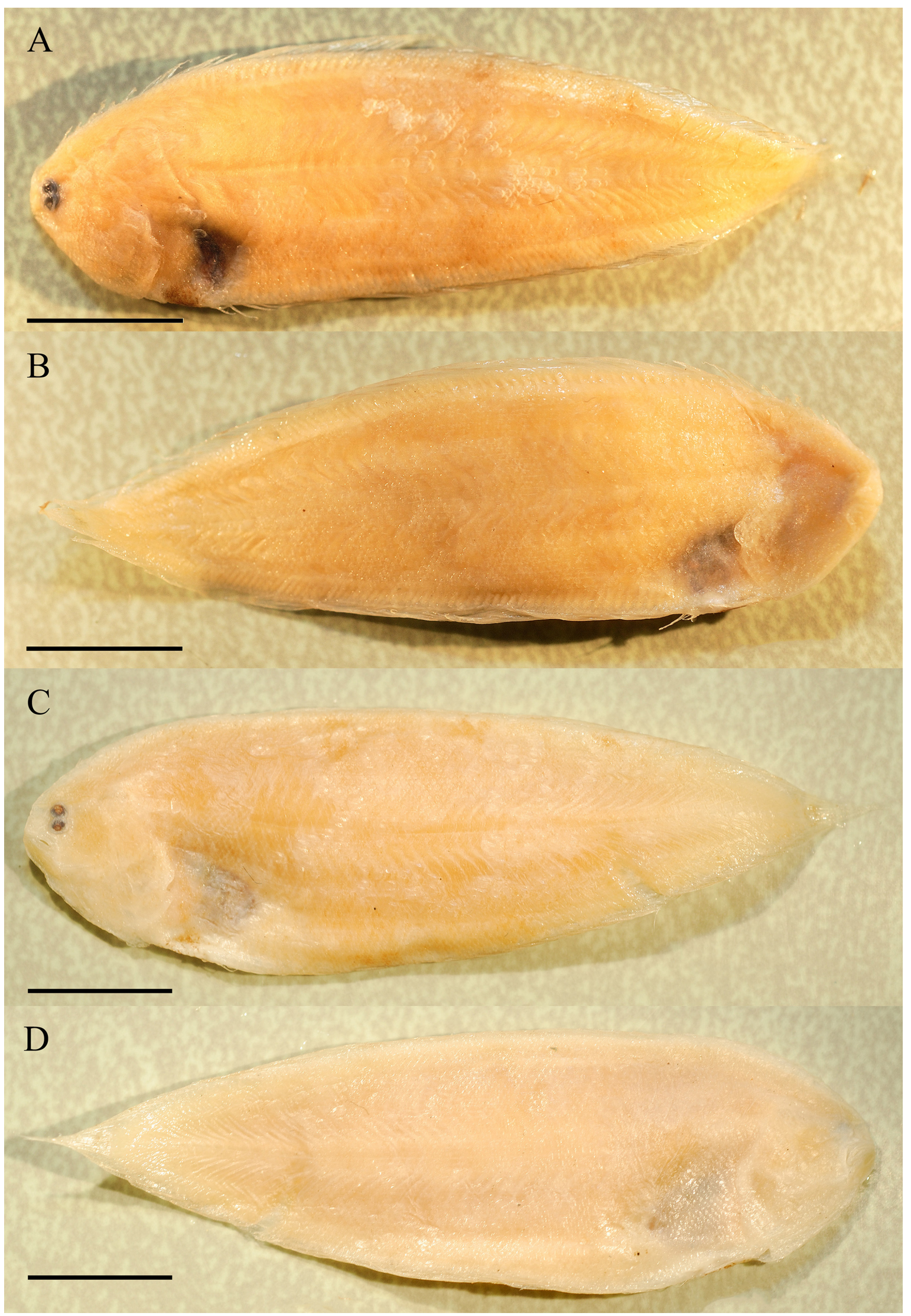

FIGURE 12. Symphurus monostigmus, holotype, SAIAB 39811, male, 48.8 mm SL, Off Gypsy Hill, KwaZulu-Natal, South Africa, Western Indian Ocean. A. Ocular-side pigmentation of holotype. B. Blind-side pigmentation of holotype. C. Symphurus monostigmus, paratype USNM 383435, male, 54.6 mm SL, Off Gypsy Hill, KwaZulu-Natal, South Africa, Western Indian Ocean, Ocular-side pigmentation. D. Blind-side pigmentation of paratype. Scale equals $10 \mathrm{~mm}$. 
Teeth well developed on all jaws; blind-side dentary with three to four rows of teeth, blind-side premaxilla with two to three rows; ocular-side dentary with two rows of teeth anteriorly and one row posteriorly, ocular-side premaxilla with single row covering about one-half of anterior jaw.

TABLE 12. Morphometrics for the examined specimens from Symphurus monostigmus (holotype: SAIAB 39811, paratype: USNM 383435) and S. leucochilus (holotype in the parentheses). SL in mm; characters 2-15 in \% of SL; 16-23 in $\%$ of HL; 24 in $\%$ of BD.

\begin{tabular}{|c|c|c|c|}
\hline \multirow[t]{2}{*}{ Character } & \multicolumn{2}{|c|}{ S. monostigmus } & \multirow{2}{*}{$\begin{array}{l}\text { S. leucochilus } \\
\text { Range }\end{array}$} \\
\hline & SAIAB39811 & USNM383435 & \\
\hline 1. SL & 48.8 & $54.6-$ & $31.0-66.9(58.7)$ \\
\hline 2. $\mathrm{BD}$ & 28.8 & 32.4 & $26.3-32.3(32.3)$ \\
\hline 3. TKL & 82.1 & 80.8 & $79.4-83.0(82.2)$ \\
\hline 4. PDL & 3.3 & 3.3 & $3.4-4.6(4.6)$ \\
\hline 5. PAL & 21.3 & 25.5 & $24.3-26.0(24.4)$ \\
\hline 6. DBL & 96.7 & 96.7 & $95.5-96.6(95.5)$ \\
\hline 7. $\mathrm{ABL}$ & 78.7 & 77.7 & $74.0-75.7(75.6)$ \\
\hline 8. PL & 9.6 & 10.1 & $5.1-7.9(6.8)$ \\
\hline 9. PA & 5.5 & 5.3 & $2.7-4.6(4.6)$ \\
\hline 10. CFL & NA & NA & $10.2-11.6(11.4)$ \\
\hline 11. HL & 18.0 & 20.2 & $18.7-21.8(20.4)$ \\
\hline 12. HW & 24.8 & 28.6 & $22.4-26.0(26.0)$ \\
\hline 13. POL & 14.1 & 15.2 & $12.6-14.7(13.4)$ \\
\hline 14. UHL & 14.8 & 17.0 & $12.8-14.6(14.6)$ \\
\hline 15. LHL & 10.9 & 13.6 & $9.9-12.3(10.9)$ \\
\hline 16. PDL & 19.3 & 16.4 & $17.6-22.3(22.3)$ \\
\hline 17. POL & 78.4 & 75.5 & $65.6-69.5(65.6)$ \\
\hline 18. SNL & 14.8 & 1.4 & $18.4-23.4(23.4)$ \\
\hline 19. UJL & 19.3 & 23.6 & $19.6-23.6(23.6)$ \\
\hline 20. ED & 13.6 & 10.9 & $10.4-12.5(11.7)$ \\
\hline 21. CD & 14.8 & 17.3 & $15.5-20.9(20.9)$ \\
\hline 22. OPLL & 39.8 & 38.2 & $26.8-34.4(27.4)$ \\
\hline 23. OPUL & 25.0 & 24.6 & $23.2-27.2(26.4)$ \\
\hline 24. TH & 17.8 & 19.5 & $21.3-25.5(24.9)$ \\
\hline 25. HW/HL & 1.38 & 1.42 & $1.07-1.29(1.27)$ \\
\hline 26. Pupil/ED & 0.32 & 0.28 & $41.9-55.9(44.6)$ \\
\hline
\end{tabular}

Pigmentation in alcohol. Ocular side generally yellowish-white and freckled with numerous, darker, reddishbrown markings especially well developed on posterior halves of scales (best viewed under magnification), with traces of two or three dorsal and two ventral, darker, reddish-brown blotches along dorsal and ventral margins on posterior half of body (blotches extending slightly medially), and with a prominent, irregular, conspicuous brown spot (about seven scales long and six scales wide) on anteroventral portion of abdominal cavity just behind gill opening. Abdominal spot extending slightly beyond ventral midline onto blind side of paratype. Head pigmentation generally similar to that of body, but lighter overall. Outer and inner surfaces of opercles on both sides without conspicuous pigmentation. Isthmus unpigmented. Lips without dark pigmentation. Anterior nostril yellowish-white. Blind side of body uniformly yellowish-white. Peritoneum unpigmented anteriorly, spotted in mid-region, black posteriorly; darker posterior region visible externally through body wall on both sides of body. Middle and posterior dorsal and anal fins with faint traces of series of pigmented rays (two to three successive fin rays) alternating with larger series of unpigmented fin rays. Pelvic fin unpigmented. Distal two-thirds of caudal fin unpigmented, proximal one-third with faint, light-brown pigment on bases of fin rays. 
Remarks. Symphurus monostigmus is a poorly known species, with only two specimens, collected on the inner continental shelf at 65-110 m, off KwaZulu-Natal, South Africa, known for the species (Munroe 2006). Further investigation is needed to gain better understanding of intraspecific variation, genetic information, ecology, abundance and life history of this species.

Comparisons. Symphurus monostigmus has some meristic features that overlap those of members of the $S$. microrhynchus species complex and also overlap with those of S. leucochilus. Symphurus monostigmus differs from all members of the S. microrhynchus species complex and also from S. leucochilus because it is the only known IWP shallow-water tonguefish with five hypurals and 14 caudal-fin rays. All other IWP shallow-water congeners feature four hypurals and 12 caudal-fin rays. Symphurus monostigmus also differs from these others in its unique ocularside pigmentation, which consists of a uniformly yellowish-white background overlain by freckles (Munroe 2006), and with a prominent spot on the anterior abdomen. This pigmentation pattern easily separates this species from all other IWP shallow-water tonguefishes.

\section{Symphurus leucochilus Lee, Munroe \& Shao. 2014}

(Figs. 13, 14; Tables 1-5, 12-13)

Symphurus leucochilus Lee et al. 2014: 563, Fig. 1 (Off Japan and Taiwan, 150 m. Holotype: USNM 408271; sister group of S. orientalis; S. microrhynchus sensu Munroe \& Marsh 1997 represents composite mix of several species; meristic data overlaps that of several species in the $S$. microrhynchus species complex). Lee et al. 2017: 78 (compared with S. longirostris; S. microrhynchus sensu Munroe \& Marsh 1997 represents a composite mix of several species; recognized two species groups among the nominal species included in the $S$. microrhynchus complex).

Holotype: USNM 408271, mature female, $58.7 \mathrm{~mm}$ SL, Da-Shi fish market, northeastern Taiwan, 24 August 2011. Detailed information on material examined can be found in Lee et al. (2014).

Paratypes: Seven specimens. Two non-type specimens also included in the original description. Paratypes and non-type specimens $21.7-66.9 \mathrm{~mm}$ SL.

Diagnosis. Symphurus leucochilus is distinguished from all congeners by the combination of: a 1-2-2-2-2 ID pattern; 12 caudal-fin rays; $9(3+6)$ abdominal vertebrae; 49-51 total vertebrae; 4 hypurals; 89-92 dorsal-fin rays; 76-80 anal-fin rays; 75-83 longitudinal scale rows; $32-35$ transverse scale rows; $15-17$ scale rows on head posterior to lower orbit; relatively deep body $(\mathrm{BD}=26.3-32.3 \%$ of $\mathrm{HL})$; moderately long preanal length $(\mathrm{PAL}=$ $24.3-26.0 \%$ of SL); upper head lobe much larger than lower head lobe; moderately short head (HL $=18.7-21.8 \%$ of $\mathrm{SL})$, shorter than head width $(\mathrm{HW} / \mathrm{HL}=1.07-1.29)$; short postorbital length $(\mathrm{POL}=65.6-69.5 \%$ of $\mathrm{HL})$; long snout $(\mathrm{SNL}=18.4-23.4 \%$ of $\mathrm{HL} ; \mathrm{SNL} / \mathrm{ED}=1.47-2.09)$, round to obliquely blunt anteriorly; dorsal-fin origin at point between verticals at anterior margin of upper eye and anterior margin of pupil of upper eye; relatively long predorsal length ( $\mathrm{PDL}=17.6-22.3 \%$ of $\mathrm{HL}$ ); no fleshy ridge on ocular-side lower jaw; eyes separate, with anterior margin of upper usually equal to, or slightly in advance of, anterior margin of lower eye; anterior ocular-side nostril not connected to eyes; ocular-side pigmentation light-yellow to light-brown without melanophores; blind-side pigmentation uniformly white to light yellow; peritoneum bluish-black.

Description (from Lee et al. 2016). Symphurus leucochilus (Fig. 13) is a diminutive species, known from 10 specimens, the largest reaching a maximum size of $66.9 \mathrm{~mm}$ SL. Meristic characters are summarized in Tables 2-5. Predominant ID pattern 1-2-2-2-2 (eight of nine specimens). Caudal-fin rays 12. Dorsal-fin rays 89-92. Anal-fin rays 76-80. Pelvic-fin rays four. Total vertebrae 49-51; abdominal vertebrae, nine $(3+6)$. Hypurals four. Longitudinal scale rows 75-83. Scale rows on head posterior to lower orbit 15-17. Transverse scale rows 32-35.

Proportions of morphometric features are presented in Table 12. Body relatively deep; maximum depth in anterior one-third of body usually at point between anus and eighth anal-fin ray, body depth tapering rapidly posterior to midpoint. Preanal length usually smaller than body depth. Head moderately long and wide; head width (HW) slightly shorter than body depth, and much greater than head length $(\mathrm{HW} / \mathrm{HL}=1.07-1.29, \mathrm{Mean}=1.20)$. Upper head lobe wider than lower head lobe (UHL/LHL=1.05-1.37, Mean=1.22); slightly shorter than postorbital length. Upper lobe of ocular-side opercle wider than lower opercular lobe; posterior margin of lower lobe projecting slightly beyond posterior margin of upper opercular lobe, or both lobes equal with their posterior margins reaching similar points along same vertical plane. Snout moderately long, slightly round to obliquely blunt anteriorly; snout length much greater than eye diameter $(\mathrm{SNL} / \mathrm{ED}=1.47-2.09$, Mean=1.83). Dermal papillae present, but not well devel- 
oped, on blind side of snout. Ocular-side anterior nostril tubular and short, usually not reaching anterior margin of lower eye when depressed posteriorly. Ocular-side posterior nostril a small, rounded tube located on snout just anterior to interorbital space. Blind-side anterior nostril tubular and short, easily distinguishable from dermal papillae; blind-side posterior nostril a shorter, and wider, posteriorly directed tube situated posterior to vertical at rear margin of jaws. Jaws long and slightly arched; upper jaw length equal to, or slightly longer than, snout length; posterior margin of upper jaw usually extending to point between verticals through anterior margin of eye and anterior margin of pupil of lower eye. Ocular-side lower jaw without fleshy ridge. Cheek depth shorter than snout length. Eyes moderately large $(E D=10.4-12.5 \%$ of $\mathrm{HL})$, oval, separated by two to three rows of small ctenoid scales in narrow interorbital space. Eyes usually equal in position, or with anterior margin of upper eye slightly in advance of that of lower eye. Pupillary operculum absent. Dorsal-fin origin located at point between verticals through anterior margin of upper eye and anterior margin of pupil of upper eye; predorsal length moderately short. Anteriormost dorsal-fin rays slightly shorter than more posterior fin rays. Scales absent on both sides of dorsal- and anal-fin rays. Pelvic fin moderately long; longest pelvic-fin ray, when extended posteriorly, usually reaching base of first to fourth anal-fin ray. Posteriormost pelvic-fin ray connected to anal fin by delicate membrane. Caudal fin relatively long, with several rows of ctenoid scales on its base. Both sides of body with numerous, strongly ctenoid scales.

Teeth present and recurved slightly inwards on all jaws; better developed on blind-side jaws. Ocular-side premaxilla and dentary with single row of sharply pointed, well-developed teeth. Blind-side premaxilla with three to four rows of sharp, recurved teeth. Blind-side lower jaw with four to six rows of well-developed teeth.

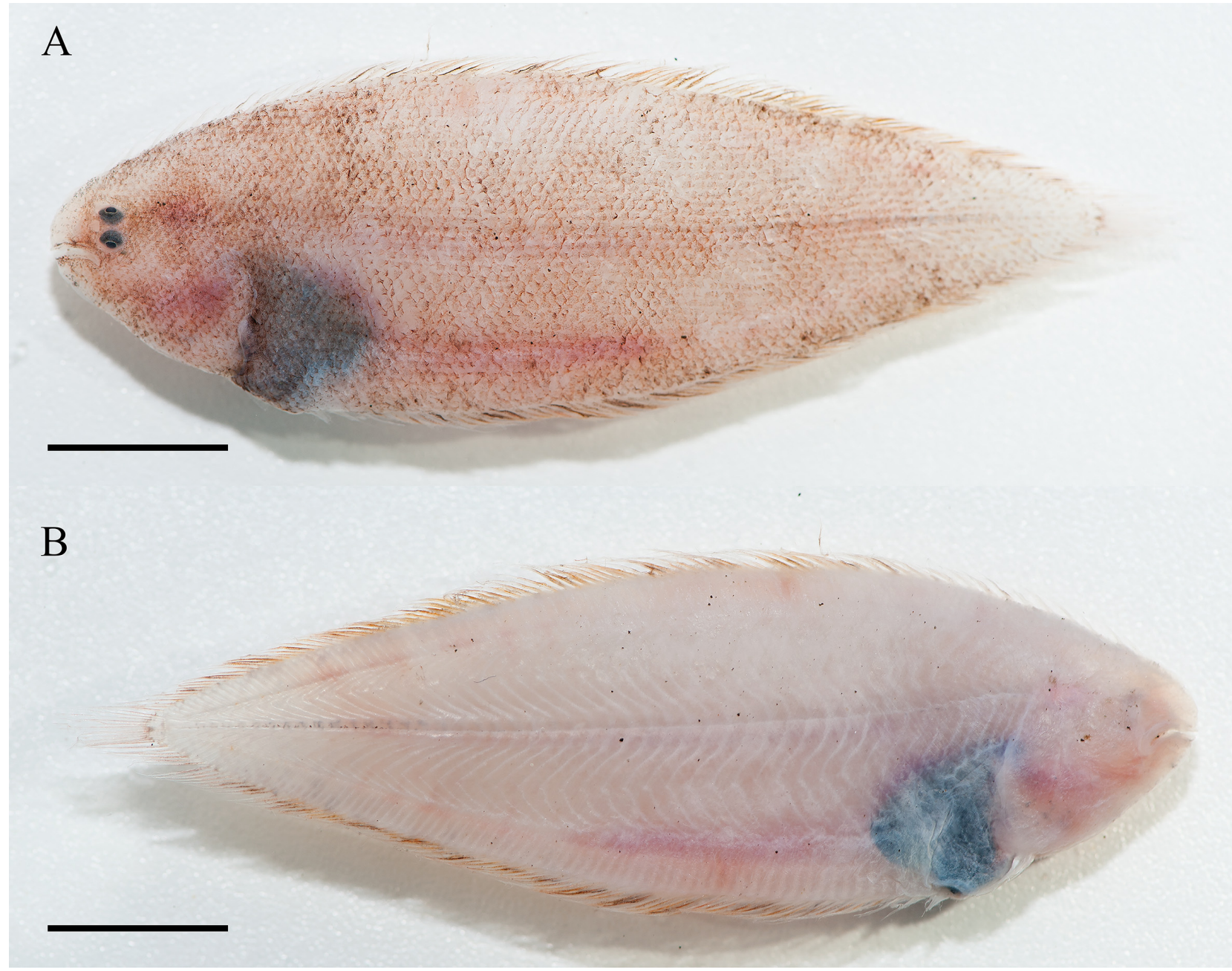

FIGURE 13. Symphurus leucochilus, holotype, USNM 408271, mature female, 58.7 mm SL, Da-Shi Fish Market, northeastern Taiwan. A. Ocular-side pigmentation. B. Blind-side pigmentation.

Pigmentation of freshly caught specimens (Fig. 13). Ocular-side background coloration of body, head and most of external surface of opercle generally light-yellow to light-brown, sometimes also with irregular, darkly shaded areas. External surface overlying abdominal area usually darker bluish-black due to dark peritoneal pigment 
visible through abdominal wall. Posterior margin of opercle darker brown than more lightly pigmented anterior regions. Outer surface of ocular side of isthmus without conspicuous melanophores. Inner surface of ocular-side opercle and isthmus unpigmented. Ocular-side lips and chin region light-yellow to light-brown; margins of lips with numerous small black dots. Ocular-side anterior nostril light-yellow to brown. Upper aspects of eyes and eye sockets light blue to bluish-green; pupils bluish-black. No conspicuous melanophores on head region posterior to eyes. No conspicuous dermal spots or melanophores at bases of anterior dorsal-fin rays. Blind side generally white to light yellow with darkly pigmented bluish-black region overlying peritoneum. Background of outer surface of blind-side opercle white to light yellowish; inner surface unpigmented. Small specimens with streak of black on vertebrae distinctly visible externally through body musculature.

TABLE 13. Matrix of genetic divergences (K2P distance) from partial COI gene between Symphurus species of this study.

\begin{tabular}{lllllllllll}
\hline No. & Species & 1 & 2 & 3 & 4 & 5 & 6 & 7 & 8 & 9 \\
\hline 1 & S. brachycephalus & & & & & & & & & \\
2 & S. hongae & 0.0903 & & & & & & & & \\
3 & S. leucochilus & 0.2616 & 0.2626 & & & & & & & \\
4 & S. longirostris & 0.2286 & 0.2234 & 0.2626 & & & & & & \\
5 & S. orientalis & 0.2449 & 0.2602 & 0.1889 & 0.2483 & & & & & \\
6 & S. hondoensis & 0.2276 & 0.2503 & 0.2441 & 0.2695 & 0.2275 & & & & \\
7 & S. megasomus & 0.2330 & 0.2665 & 0.2162 & 0.2820 & 0.2315 & 0.1423 & & & \\
8 & S. strictus & 0.2346 & 0.2328 & 0.2379 & 0.2473 & 0.2458 & 0.1410 & 0.1556 & & \\
9 & S. thermophilus & 0.2875 & 0.2980 & 0.1906 & 0.2870 & 0.2217 & 0.2514 & 0.2385 & 0.2525 & \\
\hline
\end{tabular}

Pigmentation of alcohol-preserved specimens. Similar to that of freshly caught fish, except bluish-black coloration of pupil of freshly caught specimens blending more gradually and eventually fading into white background coloration. Fin rays of dorsal, anal and pelvic fins uniformly yellow to brown; basal regions of fin rays and membranes covering fin rays light-yellow, with diffuse scattering of yellow to brown chromatophores covering entire fin membranes on both sides of fins. Entire dorsal and anal fin with a series of dark streaks alternating with lighter areas on fins. Basal margins of blind sides of dorsal- and anal-fin rays and associated fin membranes light-yellow to light-brown.

Remarks. Information about $S$. leucochilus, including color photos were detailed in the description of this species by Lee et al. (2014). One additional specimen (NMMB-P21879) of S. leucochilus, discovered after the description by Lee et al. (2014), was collected in the bycatch landed at Dong-Gang fish market, Taiwan. Information regarding date of capture, depth of capture, and other ecological data are unknown for this specimen. This is a very common situation encountered when using specimens from bycatch. To collect reliable environmental data necessary for understanding the ecology (e.g. bathymetric distribution, substrata, etc.) of S. leucochilus we still need to rely on further investigations conducted by research vessels.

Comparisons. Symphurus leucochilus has the same ID pattern (1-2-2-2-2) and the same number of caudalfin rays (12), and has counts for dorsal- (89-92) and anal-fin rays (76-80), total vertebrae (49-51) and longitudinal scales (75-83) that overlap those found in members of the $S$. microrhynchus species complex. Some features also overlap those of S. monostigmus. Differences between S. leucochilus and members of the S. microrhynchus species complex were discussed in the Comparisons sections under the individual species accounts above.

Symphurus leucochilus is similar to S. monostigmus in that these are the only two shallow-water IWP species that lack a membranous connection between the ocular-side anterior nostril and lower eye, and these two species also lack a fleshy ridge on the ocular-side lower jaw that is found in members of the S. microrhynchus species complex. Symphurus leucochilus differs distinctly from S. monostigmus in having 12 caudal-fin rays and 4 hypurals (vs. 14 caudal-fin rays and 5 hypurals), and $S$. leucochilus has different pigmentation including lacking freckles on the ocular side and lacking the pigment spot on the abdomen that feature so prominently in S. monostigmus. Symphurus leucochilus also has fewer longitudinal (75-83 vs. 92) and transverse scales (32-35 vs. 36-38) than is found in $S$. monostigmus. Other differences between these species were discussed in the Comparisons section of the species account for S. monostigmus above. 


\section{Molecular and species delimitation analyses results}

Genetic divergence (K2P distance) was established from analysis of the partial COI gene. Results are presented in Table 13. Maximum likelihood trees (Fig. 14) calculated on analyses of COI genes also reveal clearly separated clades with high bootstrap probabilities for these species of Symphurus. Results of ABGD and bPTP analyses were combined with Maximum likelihood trees. The ABGD analysis was conducted by partitioning of all individuals with prior maximal distance $(\mathrm{P})=0.00464$, which resulting in 9 OTUs, excluding the outgroup. Results of the bPTP analysis also had 9 OTUs, excluding the outgroup. Results from ABGD and bPTP are congruent in that all 9 OTUs support the hypothesis that these OTUs are well-defined species.

Among Indo-Pacific Symphurus, 14 nominal species, including the nominal species described in this study, have 12 caudal-fin rays (Alcock 1891; Chabanaud 1948; 1955b; 1957; Munroe \& Marsh 1997; Munroe 2001; Lee et al. 2013; 2014). Of these 14 species, only five: S. brachycephalus, S. robustus, S. leptosomus, S. polylepis, and S. hongae, have similar meristic features, including numbers of dorsal-fin rays (81-88), anal-fin rays (68-74), total vertebrae (45-48), transverse scale rows (26-37), and longitudinal scale rows (72-94). Also, these five species among those within the S. microrhynchus complex (Lee et al. 2014; 2017) are hypothesized to belong to the same species group because they all have high scale counts relative to the other species.

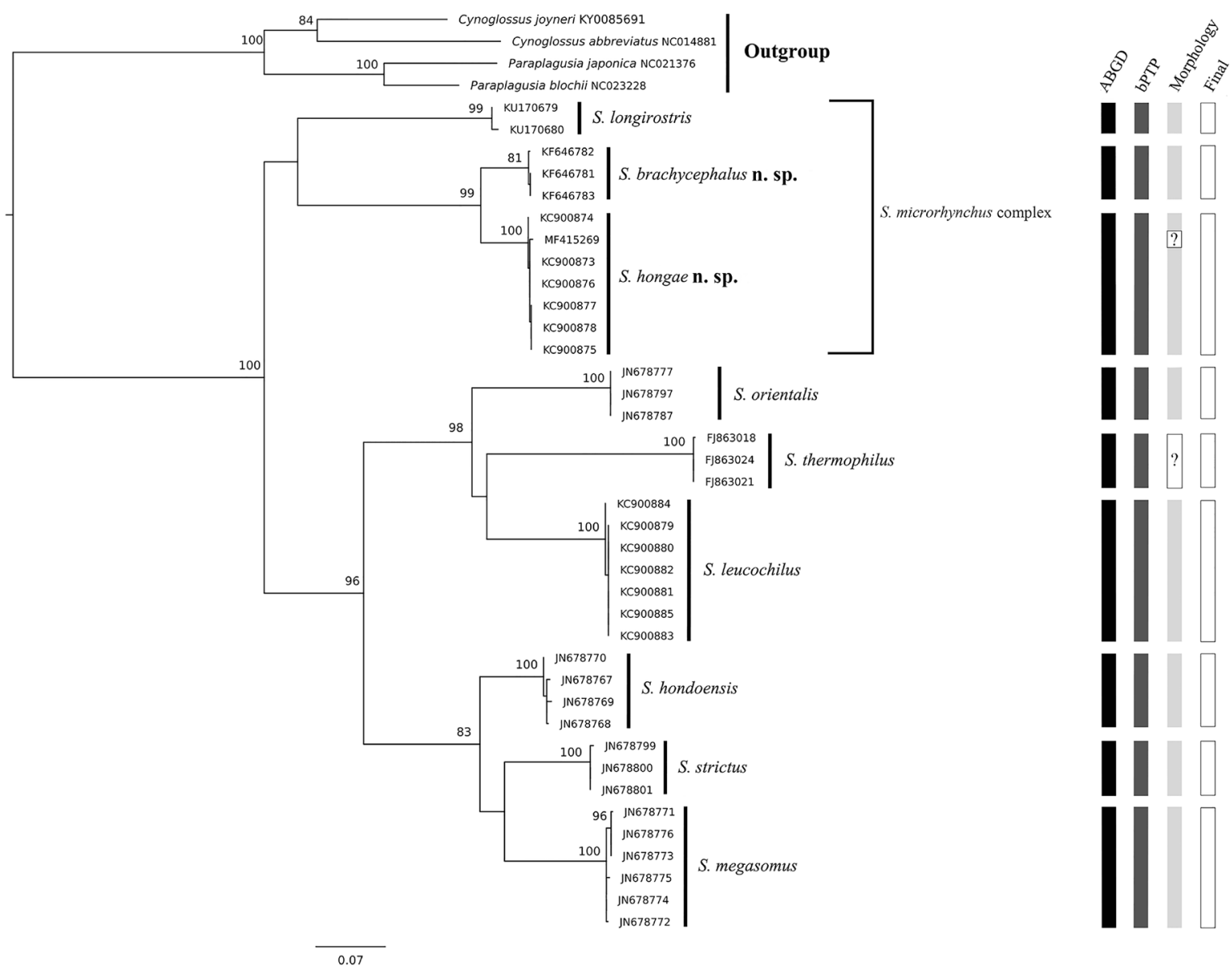

FIGURE 14. Summarized maximum-likelihood (ML) tree of selected species of the genus Symphurus from the Indo-West Pacific Ocean based on partial COI gene dataset and results from the species delimitation analyses and other considerations (see materials \& methods). Numbers above nodes indicate bootstrap values in percentage. Values below $70 \%$ not shown. Information of samples indicated in Table 1. 


\section{Discussion}

The most recent systematic treatment of $S$. microrhynchus and morphologically similar specimens identified as that taxon, collected from several Indo-West Pacific localities, is that of the morphological study conducted by Munroe \& Marsh (1997). Based on shared similarities in morphological features, Munroe \& Marsh (1997) concluded that specimens they examined represented one species, $S$. microrhynchus (Weber). Consequently, they considered $S$. microrhynchus to be a widespread, shallow-water species found throughout the Indo-West Pacific. Munroe \& Marsh (1997) also considered S. holothuriae, a nominal species known only from the holotype collected off northwest Australia, to be a junior subjective synonym of $S$. microrhynchus. Recent studies (Lee et al. 2013; 2014; 2017), together with results of the present study, incorporate results of both morphological and molecular approaches in evaluating the taxonomic status of $S$. microrhynchus, S. holothuriae, and morphologically similar forms. Data from these combined approaches provide a different concept for the nominal species, S. microrhynchus, than that hypothesized by Munroe \& Marsh (1997). These studies find that tonguefishes identified as S. microrhynchus sensu Munroe \& Marsh (1997) represent a composite series of specimens that, in addition to S. microrhynchus (Weber) and $S$. holothuriae Chabanaud, also includes at least five undescribed nominal species, each with a restricted allopatric distribution. Five of these nominal species, not previously described, were identified and formally named in the present revision.

An important finding of the present study is that differences in morphological features between these species, though subtle, nevertheless, represent significant species-specific differences. Subtle morphological differences between each nominal species described in the present study are now recognized as species diagnostic features, and those features are also supported by the results obtained from molecular analyses.

Lee et al. (2017) identified several morphological differences between the holotypes of S. microrhynchus and S. holothuriae, considered the junior subjective synonym of S. microrhynchus by Munroe \& Marsh (1997), which indicate $S$. holothuriae should be recognized as a valid species. No new specimens of this nominal species have been collected since collection of the holotype, so this species remains poorly known.

Recent studies (Tunnicliffe et al. 2010; Lee et al. 2014; 2017) have used molecular evidence for resolving taxonomic questions within symphurine tonguefishes, especially in identifying cryptic species with similar morphological features, and in resolving historical taxonomic issues of synonymy (Lee et al. 2013). Molecular evidence available to the present taxonomic revision, although limited by tissue availability, was nevertheless informative. Five of the nominal species recognized in this study as members of the S. microrhynchus species complex, S. microrhynchus, S. holothuriae, S. leptosomus, S. polylepis, and S. robustus, are known only from preserved specimens without any tissue samples for genetic examination. Examination of genetic distance was restricted between S. longirostris, a species having lower scale counts, and two species, $S$. brachycephalus and $S$. hongae, with higher scale counts. Even though taxon sampling was limited, examination of sequence divergence in these individuals still assisted in the identification of specimens belonging to these morphologically similar species. Lee et al. $(2014 ; 2017)$ already discussed the genetic distances among these three lineages, previously identified as S. microrhynchus (Munroe \& Marsh 1997) based on their morphology. Based on the algorithm (Fig. 14) and results of the species delimitation analyses, Lee et al. $(2014 ; 2017)$ concluded that the genetic distances between $S$. longirostris, S. brachycephalus and $S$. hongae were sufficient to recognize these three different lineages as distinct species.

Allopatric populations of specimens previously identified as $S$. microrhynchus differ in their pigmentation, including such external features as presence/absence of pepper-dots, dermal spots, and crossbands, and differences in coloration of the peritoneum. Munroe \& Marsh (1997) observed some of this pigmentation variation among specimens they examined from different geographical locations, but they considered these differences as population level variation within a single widespread species, and not as differences reflecting a complex of cryptic species. Their decision was restricted partly by the limited number of specimens (11) available to their study and also by the more limited evidence they extracted from these specimens. Molecular evidence obtained in the present study confirms that subtle pigmentation and morphological differences observed among specimens from different geographical locations actually represent variation between different nominal species and not just variation among allopatric populations of a single, widespread species. Results of this study also highlight that pigmentation features are important identification characters for distinguishing cryptic species of IWP tonguefishes having similar, even overlapping, meristic and morphometric features.

Although pigmentation can be a useful character, caution must be used when considering pigmentation charac- 
ters to diagnose species within this genus. Also, the condition of the specimens needs to be considered. For example, Munroe \& Marsh (1997) mentioned that pigmentation of two specimens (ANSP 122498) from Zanzibar differed from that of other specimens they tentatively identified as S. microrhynchus. However, whether these differences in their pigmentation was important or not could not be evaluated because Munroe \& Marsh (1997) were unable to determine whether pigmentation of these specimens resulted from an artefact of their preservation, or if the pigmentation of these specimens reflected their actual pigmentation. Based on this situation, without other specimens from Zanzibar to compare, these authors could not make any definitive conclusions regarding the taxonomic status of these two specimens. Given that these specimens derive from an allopatric location different from that of all other populations of small, shallow-water tonguefishes included in the present study, it is suspected that they likely represent yet another undescribed species in the S. microrhynchus species complex. However, resolution of this question will have to await capture of additional specimens.

Likewise, specimens of shallow-water tonguefishes collected from French Polynesia (USNM 342266-342269) present another taxonomic issue that we decided to exclude from consideration in this study. These specimens are newly settled juveniles much smaller (17.8-18.8 mm SL) compared with other specimens we examined in the $S$. microrhynchus species complex. At time of capture these specimens had just recently completed metamorphosis from the larval stage (Dufour et al. 1996). These specimens have an elongate peritoneum whose posterior end is usually posterior to the vertical at the anal-fin origin. This morphological feature is attributed to the fact that these specimens represent transitional stage early juveniles (Lee et al. 2014). Therefore, morphometric and pigmentation characters present in these specimens could vary significantly from those of sub-adult or adult specimens of the species. Thus, we don't consider it suitable to base a species description on these transitional (juvenile) specimens, nor did we include this nominal species when constructing the identification key to the other shallow-water species. Again, as with the specimens from Zanzibar, these specimens derive from a population allopatric from all other populations and likely represent yet another undescribed species. Formal description of this putative nominal species will have to await the capture of adult specimens in order to diagnose them properly.

This revision actually reveals that previous studies dealing with species of shallow-water tonguefishes underestimated the biodiversity within the genus Symphurus, especially for diversity estimates of small-sized species inhabiting shallow-waters of the Indo-West Pacific Ocean. To date, 10 small-sized, shallow-water species have been described from geographically widely separated areas: S. microrhynchus from Indonesia; S. holothuriae from off northwest Australia; S. monostigmus from off east Africa; S. brachycephalus from Vietnam; S. hongae from Taiwan; S. leptosomus from the Philippines; S. leucochilus from Japan and Taiwan; and two species, S. longirostris and S. robustus, from Japanese waters. This study also recognized several additional possible cryptic species that were excluded from this revision due to the lack of appropriate specimens on which to base a formal species description.

Evidence gained in the present study indicates that different species inhabit allopatric locations. Based on the diversity of species from allopatric locations that we found among the specimens examined, we suggest the possibility that more, undescribed cryptic species of Symphurus will likely be found in other shallow-water habitats of this region. Further investigations and expeditions to these habitats are needed to collect additional specimens to test this hypothesis. As new shallow-water locations are explored, and if specimens of small-sized flatfishes and suitable habitat are found there, it is not unreasonable to expect a high probability these new areas will yield new species.

The group of tonguefishes of the $S$. microrhynchus species complex are interesting from the standpoint that morphological characters compared among species varied by only a few percent, which in most cases dealing with species of Symphurus has been considered reflective of population-level differences. In contrast, when molecular differences were examined between these same individuals, substantial differences as high as 9.0 to $26.3 \%$ were observed. Although these cryptic species displayed "minor" variation in pigmentation and morphology, these differences actually represent species-level diagnostic features as supported by the large amount of genetic variation between these cryptic taxa. How many other "widespread" species of small-sized IWP flatfishes, especially species of Cynoglossidae and Soleidae, might be in the same situation is unknown. Several nominal species of small-sized cynoglossid and soleid flatfishes are presently considered to have widespread distribution in the Indo-West Pacific. Many of these species have several junior synonyms described from allopatric sites within their geographic ranges. How many of these nominal species now residing in synonymy and thought to be populations of a widespread species will be resurrected from synonymy once additional specimens and their genetic information become available remains an interesting question for future study. 


\section{Key to the shallow-water species of Symphurus from the Indo-Pacific region}

1a. Conspicuous pigmented spot on anterior ocular-side abdomen; ocular-side with conspicuous freckled color pattern; 14 caudalfin rays; five hypurals. . . . . . . . . . . . . . . . . . . . . . . . . . . . . . S. monostigmus Munroe 2006

1b. No pigment spot on anterior ocular-side abdomen; ocular-side without conspicuous freckled pattern; 12 caudal-fin rays; four

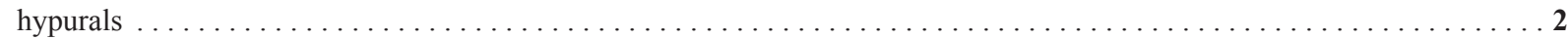

2a. Fleshy ridge present on ocular-side lower jaw; black dermal spots present at bases of anterior dorsal-fin rays and on the isthmus; anterior margin of upper eye in advance, or equal with, anterior margin of lower eye; eyes contiguous; a membrane covering both eyes usually present; anterior nostril connected to eyes by fleshy membrane $\ldots \ldots \ldots \ldots \ldots \ldots \ldots \ldots$

2b. No fleshy ridge on ocular-side lower jaw; no dermal spots at bases of anterior dorsal-fin rays or on the isthmus; anterior margins of eyes usually equal in position; eyes separated from each other by narrow interorbital space; no membrane covering eyes; anterior ocular-side nostril not connected to eyes by fleshy membrane . . . . . . . . . . . . . . . S. leucochilus Lee et al. 2014

3a. Transverse scale rows 21-26; longitudinal scale rows 56-66; head width usually equal to, or shorter than, head length (HW/HL

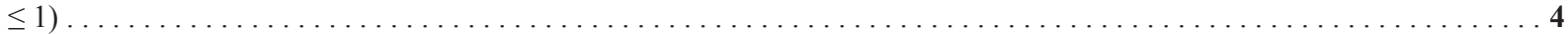

3b. Transverse scale rows 26-37; longitudinal scale rows $72-94$; head width greater than head length $(\mathrm{HW} / \mathrm{HL}>1) \ldots \ldots .66$

4a. Scale rows on head posterior to lower orbit 15-16; postorbital length $75.9-76.4 \%$ of HL; predorsal length $18.1-19.7 \%$ of HL; snout length $10.4-14.3 \%$ of $\mathrm{HL}$; $\mathrm{SNL} / \mathrm{ED}=1.25-1.45$; head length $24.0-24.2 \%$ of $\mathrm{SL} \ldots \ldots \ldots \ldots \ldots \ldots$

4b. Scale rows on head posterior to lower orbit 11-14; postorbital length $62.8-67.5 \%$ of SL; predorsal length $23.1-30.4 \%$ of HL; snout length 18.5-23.4\% of HL; SNL/ED=1.66-2.24; head length 20.5-22.6\% of SL . . . . S. longirostris Lee et al. 2016

5a. Lower head lobe much larger than upper head lobe (UHL/LHL=0.78); ID pattern 1-2-2-2-2; total vertebrae $48 \ldots \ldots . .$.

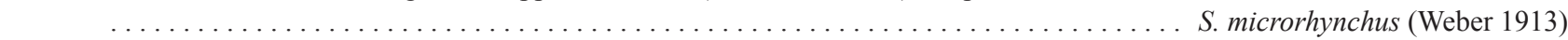

5b. Lower head lobe smaller than upper head lobe (UHL/LHL=1.01); ID pattern 1-2-3-2-2 total vertebrae $46 \ldots \ldots \ldots \ldots$ S. holothuriae Chabanaud 1948

6a. Blind-side uniformly white; no pepper-dots; dermal melanophores only present at bases of anterior dorsal-fin rays . . . . . 7

6b. Blind side with well-developed pepper-dots and with dermal melanophores along the bases of dorsal-and anal-fin rays ....8

7a. Transverse scale rows 26-30; longitudinal scale rows 72-82; head length $17.3-20.8 \%$ of SL; postorbital length $12.6-15.2 \%$ of SL; peritoneum reddish or bluish-black only on dorsalmost surface . . . . . . . . . . . . S. brachycephalus Lee \& Munroe

7b. Transverse scale rows 32-34; longitudinal scale rows 88-94; head length $21.9-23.8 \%$ of SL; postorbital length $15.6-16.6 \%$ of

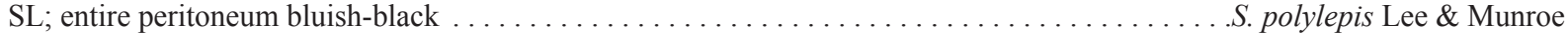

8a. Transverse scale rows 37; PAL longer than BD; body depth $24.6 \%$ of SL; HW/HL $=1.02$; ocular side speckled, with irregular

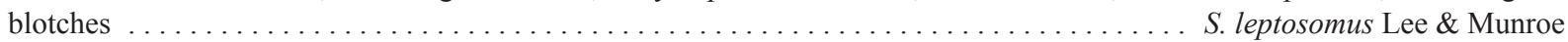

8b. Transverse scale rows 28-34; PAL shorter than BD; body depth 25.5-30.3\% of SL; HW/HL=1.06-1.19; ocular side uniformly

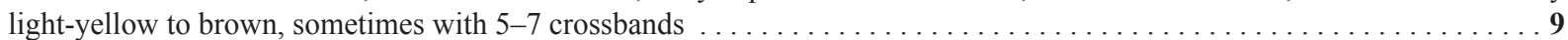
Transverse scale rows 28-31; longitudinal scale rows 72-81; body thin, TH $15.7-19.6 \%$ of BD; upper jaw length $17.9-20.4 \%$ of HL; snout length $11.7-16.2 \%$ of HL; SNL/ED= 0.86-1.45; postorbital length $14.5-16.6 \%$ of SL, $71.0-74.6 \%$ of HL; ocular side uniformly light yellow to brown, with well-developed dermal spots at bases of dorsal- and anal-fin rays; eyes oval; anterior margin of upper eye greatly in advance of anterior margin of lower eye, usually extending anteriorly by about $50 \%$ of ED of

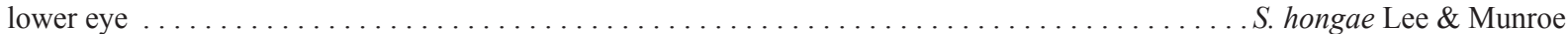

9b. Transverse scale rows 31-34; longitudinal scale rows 78-88; body thick, TH $22.1-30.0 \%$ of BD; upper jaw length $21.1-24.4 \%$ of HL; snout length $16.8-21.2 \%$ of HL; SNL/ED= 1.52-2.00; postorbital length $13.0-15.0 \%$ of SL, $65.8-70.2 \%$ of HL; ocular side with 5-7 crossbands and scattered dermal spots; eyes slightly round, usually equal in position, or with anterior margin of upper eye slightly in advance of that of lower eye (usually extending beyond lower eye by less than $25 \%$ of ED) ........

S. robustus Lee \& Munroe

\section{Acknowledgements}

The authors express their appreciation to K.-T. Shao (BRCAS) for funding to support molecular analyses, for support to M.-Y. Lee for museum visits conducted during this study, and for travel support to T.A. Munroe to work in fish collections in Taiwan. L.-P. Lin and S.-P. Huang (ASIZP), J. Clayton (USNM), and L. Willis (NSL) assisted with loan, cataloguing, and shipment of specimens; H. Endo, N. Nakayama, R. Asaoka, and T. Naito (BSKU) provided assistance and support during M.-Y. Lee's visit to their institution. The authors also thank H. Endo, N. Nakayama, R. Asaoka, and T. Naito (BSKU) for providing many preserved specimens from Japanese waters, which provided us with better understanding of the intraspecific morphological variation in these fishes. The authors also thank H.-C. Ho (NMMBA) for helping with specimens and tissue samples collected in Vietnam for inclusion in the morphological examinations, comparisons with other species, and for tissue samples included in molecular analysis. M.-Y. Lee extends his appreciation to W.-J. Chen (NTU) for providing useful comments about molecular aspects of this study. J. Maclaine (BMNH) and R. de Ruiter (RMNH) provided great assistance and hospitality during M.-Y. Lee's visits to their institutions to re-examine type specimens. Also, M.-Y. Lee extends his appreciation and gratitude to members of the Laboratory of Fish Ecology and Evolution for their support and assistance during this study. 
M.-Y. Lee wishes, especially, to express his gratitude to his mother, Y.-S. Hong, who provided continued assistance and encouragement to him during the course of this study until her untimely death. Finishing this study would not have been possible without her support. M.-Y. Lee expresses the deep loss of his mother and laments the fact that he no longer can convey his sentiments to her.

\section{References}

Alcock, A.W. (1891) Class Pisces. In: II.-Natural history notes from H. M. Indian marine survey steamer 'Investigator,' Commander R. F. Hoskyn, R. N., commanding. Series II., No. 1. On the results of deep-sea dredging during the season $1890-91$. The Annals and Magazine of Natural History, Series 6, 8, 125-126. https://doi.org/10.1080/00222939109460385

Chabanaud, P. (1939) Catalogue systématique et chorologique des Téléostéens dyssymétriques du globe. Bulletin de L'Institut Océanograp hique (Foundation AlbertIer, Prince de Monaco), No. 763, 1-31.

Chabanaud, P. (1948) Description de quatre espe`ces ine`dites du genre Symphurus. Bulletin du Muséum National d'Histoire Naturelle, Série 2, 20 (1), 508-511.

Chabanaud, P. (1955a) Flatfishes of the genus Symphurus from the U.S.S. “Albatross” Expedition to the Philippines, 1907-1910. Journal of the Washington Academy of Sciences, 45 (1), 30-32.

Chabanaud, P. (1955b) Revision des Symphurus du Siboga. Beaufortia, 5 (No. 46), 43-45.

Chabanaud, P. (1957) Description d'un Symphurus inédit, fruit de la croisière 1899-1900 du Siboga. Beaufortia, 5 (62), $183-$ 185.

Dufour, V., Riclet, R. \& Lo-Yat, A. (1996) Colonization of reef fishes at Moorea Island, French Polynesia: temporal and spatial variation of the larval flux. Marine and Freshwater Research, 47, 413-422. https://doi.org/10.1071/MF9960413

Edgar, R.C. (2004) MUSCLE: a multiple sequence alignment method with reduced time and space complexity. BMC Evolutionary Biology, 10, 50-68. https://doi.org/10.1186/1471-2105-5-113

Felsenstein, J. (1985) Confidence limits on phylogenies: an approach using bootstrap. Evolution, 39, $783-791$. https://doi.org/10.1111/j.1558-5646.1985.tb00420.x

Fricke, R. \& Eschmeyer, W.N. (2021) A Guide to Fish Collections in the Catalog of Fishes. Available from: http://researcharchive.calacademy.org/research/ichthyology/catalog/collections.asp (accessed 7 Jul 2021)

Hung, K.-W., Russell, B.C. \& Chen, W.-J. (2017) Molecular systematics of threadfin breams and relatives (Teleostei, Nemipteridae). Zoologica Scripta, 46 (5), 536-551. https://doi.org/10.1111/zsc. 12237

Kailola, R. (1971) New records of fish from Papua. Papua N. Guinea Agriculture Journal, 22, 116-133.

Kekkonen, M. \& Hebert, P.D. (2014) DNA barcode-based delineation of putative species: efficient start for taxonomic workflows. Molecular Ecology Resources, 14 (4), 706-715. https://doi.org/10.1111/1755-0998.12233

Koumans, E.R. (1953) Biological results of the Snellius expedition. XVI. The Pisces and Leptocardii of the Snellius Expedition. Temminckia, 9, 12-275.

Krabbenhoft, T.J. \& Munroe, T.A. (2003) Symphurus bathyspilus: a new cynoglossid flatfish (Pleuronectiformes: Cynoglossidae) from deepwaters of the Indo-West Pacific. Copeia, 2003 (4), 810-817. https://doi.org/10.1643/IA02-189.1

Kumar, S., Stecher, G. \& Tamura, K. (2016) MEGA7: Molecular Evolutionary Genetics Analysis Version 7.0 for Bigger Datasets. Molecular Biology and Evolution, 33 (7), 1870-1874. https://doi.org/10.1093/molbev/msw054

Lee, M.-Y., Shao, K.-T. \& Chen, H.-M. (2009a) A new species of deep-water tonguefish Genus Symphurus (Pleuronectiformes: Cynoglossidae) from Taiwan. Copeia, 2009 (2), 342-347. https://doi.org/10.1643/CI-08-080

Lee, M.-Y., Munroe, T.A. \& Chen, H.-M. (2009b) A new species of tonguefish (Pleuronectiformes: Cynoglossidae) from Taiwanese waters. Zootaxa, 2203 (1), 49-58. https://doi.org/10.11646/zootaxa.2203.1.4

Lee, M.-Y., Munroe, T.A. \& Shao, K.-T. (2013) Symphurus orientalis (Bleeker) redefined based on morphological and molecular characters (Pleuronectiformes; Cynoglossidae). Zootaxa, 3620 (3), 379-403.

https://doi.org/10.11646/zootaxa.3620.3.3

Lee, M.-Y., Munroe, T.A. \& Shao, K.-T. (2014) Description of a new cryptic, shallow-water tonguefish (Pleuronectiformes: Cynoglossidae: Symphurus) from the western North Pacific Ocean. Journal of Fish Biology, 85 (3), 563-585. https://doi.org/10.1111/jfb.12440

Lee, M.-Y., Munroe. T.A. \& Kai, Y. (2017) Description of a new cryptic species of tonguefish (Pleuronectiformes: Cynoglossidae: Symphurus) from shallow waters off Japan. Ichthyological Research, 64 (1), 71-83. [article and species online at 
2016]

https://doi.org/10.1007/s10228-016-0541-8

Lo, P.-C., Liu, S.-H., Nor S.A.M. \& Chen W.-J. (2017) Molecular exploration of hidden diversity in the Indo-West Pacific sciaenid clade. PLoS ONE, 12 (4), e0176623.

https://doi.org/10.1371/journal.pone.0176623

Munroe, T.A. (1992) Interdigitation pattern of dorsal-fin pterygiophores and neural spines, an important diagnostic character for symphurine tonguefishes (Symphurus: Cynoglossidae: Pleuronectiformes). Bulletin of Marine Science, 50 (3), 357-403.

Munroe, T.A. (1998) Systematics and ecology of tonguefishes of the genus Symphurus (Cynoglossidae: Pleuronectiformes) from the western Atlantic Ocean. Fishery Bulletin, 96 (1), 1-182.

Munroe, T.A. (2006) New western Indian Ocean tonguefish (Pleuronectiformes: Cynoglossidae, Symphurus). Copeia, 2006 (2), $230-234$. https://doi.org/10.1643/0045-8511(2006)6[230:NWIOTP]2.0.CO;2

Munroe, T.A. \& Marsh, B.N. (1997) Taxonomic status of three nominal species of Indo-Pacific symphurine tonguefishes (Symphurus: Cynoglossidae: Pleuronectiformes). Ichthyological Research, 44 (2), 189-200. https://doi.org/10.1007/BF02678697

Munroe, T.A. \& Amaoka, K. (1998) Symphurus hondoensis Hubbs 1915 (Cynoglossidae, Pleuronectiformes), a valid species of western Pacific tonguefish. Ichthyological Research, 45 (2), 385-391. https://doi.org/10.1007/BF02725191

Munroe, T.A. \& Hashimoto, J. (2008) A new Western Pacific Tonguefish (Pleuronectiformes: Cynoglossidae): The first pleuronectiform discovered at active hydrothermal vents. Zootaxa, 1839 (1), 43-59. https://doi.org/10.11646/zootaxa.1839.1.2

Munroe, T.A., Tyler, J. \& Tunnicliffe, V. (2011) Description and biological observations on a new species of deepwater symphurine tonguefish (Pleuronectiformes: Cynoglossidae: Symphurus) collected at Volcano-19, Tonga Arc, West Pacific Ocean. Zootaxa, 3061 (1), 53-66. https://doi.org/10.11646/zootaxa.3061.1.3

Puillandre, N., Lambert, A., Brouillet, S. \& Achaz, G. (2012) ABGD, Automatic Barcode Gap Discovery for primary species delimitation. Molecular Ecology, 21, 1864-1877. https://doi.org/10.1111/j.1365-294X.2011.05239.x

Norman, J.R. (1939) Fishes. The John Murray Expedition 1933-34. Scientific Reports, John Murray Expedition, 7 (1), 1-116.

Shen, S.-C. (1993) Pleuronectiformes. In: Shen, S.-C., Lee, S.-C., Shao, K.-T., Mok, H.-C., Chen, C.-H., Chen, C.-C., \& Tzeng, C.-S. (Eds.), Fishes of Taiwan. National Taiwan University, Taipei, pp. 565-585.

Stamatakis, A. (2014) RAxML version 8: a tool for phylogenetic analysis and post-analysis of large phylogenies. Bioinformatics, 30 (9), 1312-1313. https://doi.org/10.1093/bioinformatics/btu033

Thompson, J.D., Gibson, T.J., Plewniak, F., Jeanmougin, F. \& Higgins, D.G. (1997) The CLUSTAL_X windows interface: flexible strategies for multiple sequence alignment aided by quality analysis tools. Nucleic Acids Research, 25 (24), 48764882. https://doi.org/10.1093/nar/25.24.4876

Tunnicliffe, V., Koop, B.F., Tyler, J. \& So, S. (2010) Flatfish at seamount hydrothermal vents show strong genetic divergence between volcanic arcs. Marine Ecology, 31 (Supplement 1), 158-167. https://doi.org/10.1111/j.1439-0485.2010.00370.x

Voronina, E.P., Prokofiev, A.M. \& Prirodina, V.P. (2016) Review of the flatfishes of Vietnam in the collection of Zoolgical Institute, Saint Petersburg. Proceedings of the Zoological Institute RAS, 320 (4), 381-430. https://doi.org/10.31610/trudyzin/2016.320.4.381

Weber, M. (1913) Die Fische der Siboga-Expedition. E.J. Brill, Leiden, 710 pp.

Weber, M. \& de Beaufort, L.F. (1929) The fishes of the Indo-Australian Archipelago. V. Anacanthini, Allotriognathi, Heterostomata, Berycomorphi, Percomorphi: families Kuhliidae, Apogonidae, Plesiopidae, Pseudoplesiopidae, Priacanthidae, Centropomidae. The Fishes of the Indo-Australian Archipelago. Vol. 5. E.J. Brill Ltd, Leiden, 458 pp.

Zhang, J.J., Kapli, P., Pavlidis, P. \& Stamatakis, A. (2013) A general species delimitation method with applications to phylogenetic placements. Bioinformatics, 29, 2869-2876.

https://doi.org/10.1093/bioinformatics/btt499 